Aus der Abteilung Gastroenteropathologie

(Prof. Dr. med. L. Füzesi)

im Zentrum Pathologie

der Medizinischen Fakultät der Universität Göttingen

\title{
Prognostischer Zusammenhang zwischen \\ Mutationen des KIT- und PDGFRA-Gens und molekularzytogenetischen Veränderungen gastrointestinaler Stromatumoren
}

\author{
INAUGURAL-DISSERTATION \\ zur Erlangung des Doktorgrades \\ der Medizinischen Fakultät der \\ Georg-August-Universität zu Göttingen
}

vorgelegt von

Oliver Haupt

aus

Salzgitter

Göttingen 2010 


\section{Dekan:}

I. Berichterstatter:

II. Berichterstatter/in: Prof. Dr. rer. nat. P. Burfeind

III. Berichterstatter/in:
Prof. Dr. med. C. Frömmel

Prof. Dr. med. L. Füzesi

Tag der mündlichen Prüfung: 18.10 .2010 


\section{Inhaltsverzeichnis}

1. Einleitung 6

1.1. Definition und Klassifikation 6

1.2. Immunhistochemie $\quad 7$

1.3. Pathogenese 8

1.4. Lokalisation 13

1.5. Klinik 15

1.6. Dignität und Rezidive 16

1.7. Therapie und Prognose 19

1.8. Zielstellung 23

2. Material und Methoden $\quad 24$

2.1. Kollektiv 24

2.2. Methoden $\quad 24$

2.2.1. Immunhistochemie 24

2.2.2. DNA-Isolierung 27

2.2.3. Komparative genomische Hybridisierung 29

2.2.4. Mutationsanalyse 36

$\begin{array}{ll}\text { 2.2.5. Statistische Auswertung } & 40\end{array}$

3. Ergebnisse $\quad 41$

3.1. Kollektiv 41

3.1.1. Lokalisation 41

3.1.2. Tumorgröße 41

3.1.3. Immunhistochemie 42

3.1.4. Histomorphologische Dignitätsmerkmale 43

3.1.5. Therapie 44

3.1.6. Follow-Up 45

3.2. Ergebnisse der CGH 48

3.2.1. Chromosomale Imbalanzen 48

3.2.2. Lokalisation 48

3.2.3. Tumorgröße und Mitosen 50

3.2.4. Dignität und Prognose 51

3.2.5. Metastasen 56 
3.2.6. Imatinib-Therapie 57

3.3. Ergebnisse der Mutationsanalyse 57

3.3.1. Lokalisation 58

3.3.2. Tumorgröße und Mitosen $\quad 59$

3.3.3. Dignität und Prognose 60

3.3.4. Metastasen 62

3.3.5. Imatinib-Therapie 63

3.4. CGH und Mutationsanalyse 64

3.4.1. Mutation vs. Anzahl der chromosomalen Imbalanzen 64

3.4.2. Chromosomale Imbalanzen an $1 p \quad 65$

3.4.3. Chromosomale Imbalanzen an 9p und 9q 65

3.4.4. Chromosomale Imbalanzen an $14 q$

3.4.5. Chromosomale Imbalanzen an $15 q$

3.4.6. Chromosomale Imbalanzen an 22q 66

4. Diskussion 68

4.1. Kollektiv 68

4.1.1. Klassifikation und Prognose 69

4.2. $\mathrm{CGH} \quad 69$

4.2.1. Chromosomale Imbalanzen $\quad 70$

4.2.2. Tumorlokalisation 71

4.2.3. Klassifikation und Prognose 72

4.3. Mutationsanalyse 74

4.3.1. Mutationen 75

4.3.2. Tumorlokalisation 76

4.3.3. Klassifikation und Prognose 77

4.3.4. Imatinib-Therapie $\quad 80$

4.4. CGH und Mutationsanalyse $\quad 81$

4.4.1. Chromosomale Imbalanzen an $1 p$ und $15 q$

4.4.2. Chromosomale Imbalanzen an 9p und 9q 84

4.4.3. Chromosomale Imbalanzen an $14 q$

4.4.4. Chromosomale Imbalanzen an 22q 86

4.4.5. Imatinib-Therapie 88

$\begin{array}{lr}\text { 5. Zusammenfassung } & 90\end{array}$ 
$\begin{array}{ll}\text { 6. Anhang } & 91\end{array}$

6.1. Klinisch-pathologische Parameter - Kollektivübersicht 91

6.2. Risikoklassifikation und Follow-Up - Kollektivübersicht 93

6.3. Ergebnisse der CGH - Kollektivübersicht 95

6.4. Ergebnisse der Mutationsanalyse - Kollektivübersicht 97

6.5. Tabellenverzeichnis 99

6.6. Abbildungsverzeichnis 101

6.7. Abkürzungsverzeichnis 102

6.8. Aminosäuren - 1-Buchstaben-/ 3-Buchstaben-Code 103

$\begin{array}{ll}\text { 7. Literaturverzeichnis } & 104\end{array}$ 


\section{Einleitung}

\subsection{Definition und Klassifikation}

Gastrointestinale Stromatumoren (GIST) sind fast immer CD117-positive mesenchymale Tumoren mit spindeliger oder epitheloider Zellmorphologie (Miettinen et al. 2002).

Sie gehören zu den häufigsten mesenchymalen Tumoren des Gastrointestinaltrakts (< $1 \%$ aller Primärtumoren des Gastrointestinaltrakts), die vorher den myogenen Tumoren zugeordnet worden waren (Golden und Stout 1941). Der Begriff des "gastrointestinalen Stromatumors" selbst geht auf Appelman (1986) zurück. Bezüglich ihrer Herkunft und inres klinischen Verhaltens unterscheiden sich GIST jedoch deutlich von anderen mesenchymalen Tumoren wie Leiomyomen, Schwannomen und Lipomen (DeMatteo 2002, Miettinen und Lasota 2001), obwohl man sie aufgrund ihrer histomorphologischen Erscheinung (neurogene und myogene Differenzierungsmerkmale) lange Zeit zu diesen Tumoren gezählt hat.

GIST treten am häufigsten zwischen dem 40. und 80. Lebensjahr mit einem Gipfel um das 60. Lebensjahr auf. Die Geschlechterverteilung ist annährend ausgewogen, mit einem leichten Trend (55\%) zum männlichen Geschlecht (Antonescu et al. 2003, Miettinen et al. 2005, Wong et al. 2003). Die Inzidenz in einer schwedischen Studie lag bei 14,5 pro 1 Mio. Einwohner, die Prävalenz bei 129 pro 1 Mio. Einwohner (Nilsson et al. 2005). Tran et al. (2005) zeigten für die USA eine Inzidenz von 6,8 pro 1 Mio. Einwohner mit einer leicht erhöhten Inzidenz in der männlichen gegenüber der weiblichen Bevölkerung.

Familiäre (Chompret et al. 2004, Hartmann et al. 2005), sowie im Rahmen von Syndromen, z.B. im Zusammenhang mit Neurofibromatosis Typ 1 (Andersson et al. 2005) oder der Carney-Trias (gastrale GIST, pulmonale Chondrohamartome und extraadrenale Paragangliome; Carney 1999) auftretende GIST machen nur einen geringen Anteil unter den GIST aus (Miettinen et al. 2005).

Als Abkömmlinge von den interstitiellen Cajal- bzw. deren Vorläuferzellen (Kindblom et al. 1998, Sircar et al. 1999), können sie sowohl eine leiomyogene, neurogene oder 
weder leiomyogene noch neurogene Differenzierung aufweisen. Die Cajal-Zellen fungieren normalerweise als Schrittmacher ("Pacemaker")-Zellen im Plexus myentericus und benachbarten Muskelschichten. Sie sind u.a. für Darmmotorik und Peristaltik zuständig (Sircar et al. 1999).

Makroskopisch wächst der Tumor intramural, hat runde Form und imponiert bei der Endoskopie ab einer gewissen Größe als halbkugelige Vorwölbung, teilweise ulzeriert, bei erhaltener Schleimhaut und verstrichenem Faltenrelief. Gegenüber dem umgebenden Gewebe sind GIST ohne bindegewebige Kapsel scharf abgegrenzt. Zum Peritoneum hin werden sie oft nur von der Serosa und einer dünnen Bindegewebsschicht bedeckt. Das oftmals weiche Gewebe offenbart auf der Schnittfläche bei größeren Tumoren oft regressive Veränderungen in Form von Ödem, Nekrosen und selten auch Verkalkungen (Erlandson et al. 1996, Füzesi 2003).

Bei GIST handelt es sich um histomorphologisch zellreiche Tumoren, die in spindelzellige (70\%), epitheloide (20\%) oder gemischt epitheloid-/spindelzellige Formen in storiformer oder faszikulärer Anordnung unterteilt werden können (Fletcher et al. 2002, Miettinen et al. 1999 a), wobei epitheloide öfter im Magen und die spindelzelligen Varianten eher im Dünndarm anzutreffen sind (Appelman 1986).

\subsection{Immunhistochemie}

Immunhistochemisch zeigen GIST ein charakteristisches Muster, was bei der uneinheitlichen und unspezifischen Zellmorphologie differentialdiagnostisch hilfreich sein kann.

Antikörper gegen c-kit (CD117) sind in 91\% der Fälle positiv (Miettinen et al. 2005, Sarlomo-Rikala et al. 1998 a, Wong et al. 2003). Dies macht deutlich, dass es CD117negative Zellen gibt, die, trotz der in o.g. Definition geforderten CD117-Positivität, den GIST zuzurechnen sind (Debiec-Rychter et al. 2004 a). Auf der anderen Seite kann CD117 auch in kleinzelligen Bronchialkarzinomen, sowie Melanomen, Angiosarkomen, Mastozytomen und Seminomen in unterschiedlichem Ausmaß nachgewiesen werden (Miettinen et al. 2000 c, Montone et al. 1997, Tsuura et al. 1994). 
In der immunhistochemischen Färbung exprimieren GIST mit Mutationen im PDGFRAGen oft nur fokal CD117, bis hin zur kompletten Negativität gegenüber dem Antikörper. Obwohl einige Studien bei Mutationen in PDGFRA eine nur geringe Expression von CD117 nachgewiesen haben (Debiec-Rychter et al. 2004 a, Wasag et al. 2004), zeigten Lasota et al. (2004) bei 139 GIST mit Mutationen in PDGFRA in 87\% eine Expression dieses Oberflächenproteins.

In bis zu 82\% kann CD34, in 19\% SMA (Smooth muscle antigen) nachgewiesen werden. S100 $(<1 \%)$ und Desmin (5\%) werden nur in seltenen Fällen von den Zellen exprimiert, die so immunhistochemisch negativ sind (Miettinen et al. 2005, SarlomoRikala et al. 1998 a, Wong et al. 2003). Die Verteilung der Antikörper variiert je nach Tumorlokalisation. So zeigen nach Miettinen et al. (2000 d) ösophageale und rektale GIST die stärkste Expression von CD34 (> 90\%).

\subsection{Pathogenese}

Nur durch die Immunhistochemie kann keine definitive Diagnose eines GIST gestellt werden. Es gibt eine gewisse Anzahl an CD117-negativen GIST (siehe 1.2). Hier kann eine Mutationsanalyse des KIT- und PDGFRA-Gens für Klarheit sorgen. Sihto et al. (2005) fanden bei einer Analyse von 334 soliden Tumoren aus 32 verschiedenen histologischen Geweben Mutationen im KIT- und PDGFRA-Gen nur in GIST. Keine anderen untersuchten Tumoren zeigten Mutationen in diesen Genen.

\section{KIT- und PDGFRA-Gen}

Eine postulierte und mittlerweile allgemein anerkannte Theorie der Tumorgenese von GIST geht von aktivierenden Mutationen des KIT- und PDGFRA-Gens aus, die zu einer dauerhaften Aktivierung der von diesen Genen kodierten RezeptorTyrosinkinasen führen (Miettinen und Lasota 2001).

Der normale Ligand dieser Tyrosinkinasen ist der Stammzellfaktor (SCF), der nach Bindung eine Konformationsänderung der juxtamembranären Domäne des Rezeptors bewirkt und so zu einer Homodimerisation des Rezeptors führt. Durch eine Aktivierung von Tyrosinkinasen werden so verschiedene Substrate phosphoryliert, die die 
intrazelluläre Signaltransduktion einleiten (Blume-Jensen et al. 1991).

GIST, als Abkömmlinge der Cajal-Zellen (siehe 1.1), exprimieren auf ihrer Zelloberfläche typischerweise als Produkt des Protoonkogens KIT (lokalisiert auf Chromosom 4q11-12) eine transmembranäre Typ-III-Rezeptor-Tyrosinkinase (ein 145kDa-Glykoprotein) (Hornick und Fletcher 2002, Sarlomo-Rikala et al. 1998 a). Die Tyrosinkinase, CD117 nach aktueller CD-Nomenklatur, findet sich neben den CajalZellen u.a. auf Knochenmarksstammzellen, Mastzellen, Melanozyten und Keimzellen, wobei der Stammzellfaktor (SCF) als natürlicher Ligand dient (Zsebo et al. 1990).

Furitsu et al. (1993) wiesen nach, dass Punktmutationen im KIT-Gen zu einer dauerhaften Aktivierung des Genprodukts führen können. Bei GIST wurden erstmalig durch Hirota et al. (1998) "gain-of-function"-Mutationen auf Exon 11 des KIT-Gens beschrieben, die durch eine dauerhafte Aktivierung der Tyrosinkinase die Tumorgenese einleiten können.

Im KIT-Gen zeigen sich bei GIST in 90\% Aktivierungsmutationen, überwiegend in Exon 11 und Exon 9 (Heinrich et al. 2002, Lux et al. 2000, Rubin et al. 2001, Singer et al. 2002). Untersucht man die nicht in KIT-mutierten GIST weiterhin auf Mutationen im Platelet derived growth factor receptor alpha-Gen (PDGFRA), einer der c-kit verwandten, ebenfalls auf Chromosom 4 lokalisierten Typ-III-Tyrosinkinase (Qiu et al. 1988), so zeigen sich auch hier, vor allem in Exon 18 und Exon 12, aktivierende Mutationen entsprechend denen im KIT-Gen. Die Angaben über die Häufigkeit von Mutationen schwanken dabei zwischen 7 - 30\% der bzgl. einer KIT-Mutation negativen GIST (Corless et al. 2005, Debiec-Rychter et al. 2004 b, Lasota et al. 2004), wobei KIT- und PDGFRA-Mutationen sich gegenseitig auszuschließen scheinen (Heinrich et al. 2003 a, Lasota et al. 2004, Miettinen et al. 2005). Vor allem GIST ohne Aktivierungsmutation in KIT zeigten in 35\% Mutationen im PDGFRA-Gen. Die meisten GIST mit Mutationen im letztgenannten Gen zeigen histomorphologisch eine epitheloide oder gemischt epitheloid-/spindelzellige Form, einen geringen Mitoseindex ( $<=5$ Mitosen/50 High Power Fields (HPF)) und kommen fast ausschließlich im Magen vor. Die meisten GIST mit Mutationen im KIT-Gen sind dagegen eher vom spindelzelligen Phänotyp (Corless et al. 2005, Lasota et al. 2004, Pauls et al. 2005, Wardelmann et al. 2002, 2004). 


\section{KIT - Exon 11}

Durch Mutationen vor allem im Exon 11 (58 - 70\%) des KIT-Gens (DeMatteo et al. 2008, Keun Park et al. 2008, Wozniak et al. 2007), welches für den juxtamembranösen Bereich des Rezeptors kodiert, wird dieser strukturell so verändert, dass es zu einer ligandenunabhänigen Homodimerisation und so zu einer dauerhaften Aktivierung des Rezeptors kommen kann. Die Tumoren sind dabei überwiegend im Magen (78,6\% nach Wardelmann et al. 2004) lokalisiert. Die Aktivierung führt durch eine nachgeschaltete intrazelluläre Signalkaskade u.a. zu einem proliferativen Stimulus und einer Hemmung der Apoptose, was zu ungebremster Zellvermehrung führt. Die meisten KIT-Exon-11-Mutationen liegen am 5' Ende (84\%), die meisten Internal Tandem Duplications (ITD) von 5 - 14 Aminosäuren (AS) am 3' Ende. Am häufigsten waren einfache Deletionen (23 - 50\%) und Punktmutationen (13 - 18\%) zwischen Codon 550 - 560. In absoluten Zahlen kam die Substitution W557R gefolgt von Deletion W557-K558 und Substitution V560D am häufigsten vor. Codon 557 und 558 waren in 29\% aller Mutationen betroffen (Andersson et al. 2006, Antonescu et al. 2003, Corless et al. 2004, Heinrich et al. 2003 b, Keun Park et al. 2008, KontogianniKatsarou et al. 2008).

\section{KIT - Exon 9}

Am zweithäufigsten bei GIST ist Exon 9, mit 5 - 13\% aller Tumoren, mutiert. Die Lokalisation des Tumors liegt dabei fast ausschließlich im Dünndarm (Antonescu et al. 2003, Koay et al. 2005, Penzel et al. 2005, Wardelmann et al. 2004). Es handelt sich vor allem um eine 6-Basenpaar(bp)-Insertion (4,5 - 7,6\%), die zu einer ITD AY502-503 führt (Antonescu et al. 2005, Lasota et al. 2000, Pauls et al. 2005, Penzel et al. 2005, Willmore et al. 2004).

\section{KIT - Exon 13}

Mutation in Exon 13 betreffen vor allem die Substitution K642E, die in $2-5 \%$ aller GIST auftritt (Lasota et al. 2000, Willmore et al. 2004). Von Relevanz ist noch die Mutation V654A (Antonescu et al. 2005, Chen L et al. 2004), die zu einer Resistenz gegenüber einer Therapie mit Imatinib führt. 


\section{KIT - Exon 14}

Bisher sind nur vereinzelte Fälle einer KIT-Exon-14-Mutation bekannt, die alle zu einer sekundären Resistenz gegenüber Imatinib führten (Antonescu et al. 2005, Hirota et al. 2001, Tamborini et al. 2004).

\section{KIT - Exon 17}

Exon 17 ist nur in seltenen Fällen (0,6 - 1\%) von einer Mutation betroffen, z.B. N822K (Corless et al. 2004, Penzel et al. 2005). Bei ca. 85\% der Patienten mit nachweisbarer sekundärer Mutation während der Imatinib-Therapie fand sich diese Mutation in Exon 17 (Antonescu et al. 2005), überwiegend N822K und D820Y.

\section{PDGFRA - Exon 18}

Mutationen im PDGFRA-Gen betreffen in 82,5\% das Exon 18 (Corless et al. 2005). Ingesamt zeigen 6 - 23\% aller GIST eine Mutation im PDGFRA Exon 18 (Corless et al. 2005, Wozniak et al. 2007), wobei als häufigste Mutation die Substituion D842V vorkommt, die durch ihre Resistenz gegenüber einer Therapie mit Imatinib (siehe Kapitel 1.7 Therapie und Prognose) besondere klinische Bedeutung hat. Weitere Mutationen des Exon 18 sind v.a. Deletionen zwischen den Codons 842 - 846 (DIMH842 - 845, IMHD843 - 846).

\section{PDGFRA - Exon 12}

2 - 4\% aller Mutationen betreffen das PDGFRA Exon 12 (Corless et al. 2005, Penzel et al. 2005, Pauls et al. 2005). Die häufigste Mutation betrifft auch hier, wie in Exon 18, die Substitution einer Aminosäure (V561D).

\section{PDGFRA - Exon 14}

Nur in seltenen Fällen (3,7\%) ist Exon 14 von Mutationen des PDGFRA-Gens betroffen (Corless et al. 2005). 


\section{Tumorprogression und chromosomale Imbalanzen}

Presti et al. (1991) sprechen im Rahmen der Tumorprogression von primären, sekundären und tertiären chromosomalen Imbalanzen $(\mathrm{Cl})$. Primäre $\mathrm{Cl}$, als häufigste genetische Veränderung eines Tumortyps, führen zur Tumorentstehung (z.B. Punktmutationen eines Gens). Sekundäre führen im weiteren Verlauf der Tumorentwicklung zu tumorspezifischen Veränderungen an bestimmten Chromosomen (z.B. Deletionen und Amplifikationen) und tertiäre $\mathrm{Cl}$, auftretend aufgrund der genetischen Instabilität, führen zu individuell verschiedenen und zufällig auftretenden Veränderungen.

\section{Chromosomale Imbalanzen}

Nach Heinrich et al. (2002) führt die (dauerhafte) Aktivierung der Tyrosinkinase zu einer Hyperplasie der interstitiellen Cajal-Zellen. Für die weitere Entwicklung von der Hyperplasie hin zu einer Neoplasie sind dabei weiterführende genetische Veränderungen notwendig. In mehr als $90 \%$ der GIST treten multiple chromosomale Veränderungen im Sinne von Translokationen, Amplifikationen und Deletionen auf, wobei Verluste wesentlich häufiger als Zugewinne beobachtet werden (EI-Rifai et al. 2000). Da bereits benigne GIST in der komparativen genomischen Hybridisierung (CGH) einen Verlust an Chromosom 14q, 22q und $1 p$ zeigen, scheinen diese bereits frühzeitig in der KIT- oder PDGFRA-Mutation 14q Deletion

22q Deletion $1 p$ Deletion 8p Zugewinn $11 p$ Deletion 9p Deletion

17q Zugewinn

Tumorgenese auftretende Imbalanzen zu sein Abbildung 1.3/1 Darstellung der Tumor(Debiec-Rychter et al. 2001, El-Rifai et al. 2002) 2000). Im Gegensatz zu diesen Verlusten kommen andere Imbalanzen, wie z.B. Zugewinne und Amplifikationen, z.B. an Chromosom 5p, 8q, 17q und 20q oder Verluste an 9p, 13q, 15q und 19q, vor allem in malignen Tumoren vor (El-Rifai et al. 1996, Sarlomo-Rikala et al. 1998 b). Sie sind dabei als sekundäre Imbalanzen im o.g. Sinne zu verstehen und könnten Sitz von Tumorsuppressorgenen, Proto-Onkogenen oder Proteinen der Signaltransduktion sein 
(Bergmann et al. 1998, Corless et al. 2004, El-Rifai et al. 2000), die während der Tumorprogression u.a. von Bedeutung für das klinische Verhalten und die Dignität sein könnten. Die Abbildung 1.3/1 zeigt eine daraus abgeleitete und vereinfachte Darstellung der Tumorgenese und -progression (Heinrich et al. 2002).

El-Rifai et al. (2000) fanden bei benignen GIST durchschnittlich 2,6, bei primär malignen durchschnittlich 7,5 und bei metastasierten GIST 9,0 chromosomale Imbalanzen. Das vermehrte Auftreten von sekundären und tertiären Imbalanzen bei malignen und metastasierten GIST betrifft dann nicht mehr nur GIST-spezifische Veränderungen, sondern zeigt vermehrt ein inhomogenes Muster an chromosomalen Verlusten und Zugewinnen. Als GIST-charakteristische chromosomale Imbalanzen gelten vor allem Verluste an 14q, 22q und an 1p (Derré et al. 2001, El-Rifai et al. 2000), wobei die Veränderungen lokalisationsabhängig in unterschiedlicher Häufigkeit anzutreffen sind (Gunawan et al. 2004; siehe Tabelle 1.3/1 und Tabelle 1.3/2). Bestimmte Veränderungen oder eine Kombination von Veränderungen zeigten dabei gehäuft eine Assoziation zu malignen Verläufen, z.B. zeigen Verluste an 1p zusammen mit Verlusten an 15q eine Assoziation mit kleinen intestinalen GIST (Magen 0\%, Darm 75\%) und die Kombination von Verlusten an 1p und 9q mit kolorektalen GIST (siehe auch 1.7 Therapie und Prognose, S. 19).

\subsection{Lokalisation}

GIST können überall im Gastrointestinaltrakt zwischen Ösophagus und Rektum auftreten, sowie in seltenen Fällen auch primär im Mesenterium, Omentum und Retroperitoneum (Miettinen et al. 1999 b, Tworek et al. 1999 a).

70\% der GIST manifestieren sich im Magen, 20 - 30\% im Dünndarm, 5\% in Dickdarm / Rektum und weniger als 5\% im Ösophagus (Emory et al. 1999, Miettinen et al. 1999 a, 2000 a). GIST mit Mutationen im Exon 18 des PDGFRA-Gens scheinen fast ausschließlich im Magen vorzukommen und solche mit Mutationen in Exon 9 von KIT überwiegend im Dünndarm (Antonescu et al. 2003, Corless et al. 2005). 
Tabelle 1.3/1

Literaturübersicht über die Häufigkeit chromosomaler Imbalanzen bei GIST

\begin{tabular}{|c|c|c|}
\hline CGH & Häufigkeit & Literatur \\
\hline $1 p /$ Loss & $\begin{array}{l}40-51 \% \\
81,8 \% \text { high-risk, } 47,1 \% \text { low-risk }\end{array}$ & $\begin{array}{l}\text { Gunawan et al. 2004, } \\
\text { El-Rifai et al. 2000, Bergmann et al. } \\
1998 \\
\text { Chen } Y \text { et al. } 2004\end{array}$ \\
\hline $4 q$ / Gain & $21 \%$ & Gunawan et al. 2004 \\
\hline $5 p /$ Gain & $\begin{array}{l}25 \% \\
5,9 \% \text { low-risk, } 27,2 \% \text { high-risk } \\
31 \% \text { maligne, } 29 \% \text { metastasiert }\end{array}$ & $\begin{array}{l}\text { Gunawan et al. } 2004 \\
\text { Chen Y et al. } 2004 \\
\text { El-Rifai et al. } 2000\end{array}$ \\
\hline $5 q$ / Gain & $31 \%$ & Gunawan et al. 2004 \\
\hline $7 q$ / Gain & $13 \%$ & Gunawan et al. 2004 \\
\hline $8 p$ / Gain & $15 \%$ & Gunawan et al. 2004 \\
\hline $8 q$ / Gain & $\begin{array}{l}25 \% \\
8 \% \text { benigne, } 33 \% \text { maligne, } 57 \% \text { metastasiert }\end{array}$ & $\begin{array}{l}\text { Gunawan et al. } 2004 \\
\text { El-Rifai et al. } 2000\end{array}$ \\
\hline 9 / Loss & $40 \%$ & Bergmann et al. 1998 \\
\hline 9p / Loss & $\begin{array}{l}12-14,3 \% \\
36 \% \text { maligne, } 63 \% \text { metastasiert }\end{array}$ & $\begin{array}{l}\text { Gunawan et al. 2004, Kim NG et al. } \\
\text { 2000, El-Rifai et al. } 2000\end{array}$ \\
\hline 9q / Loss & $14,3-29 \%$ & $\begin{array}{l}\text { Gunawan et al. 2004, Kim NG et al. } \\
2000\end{array}$ \\
\hline $10 q /$ Loss & $\begin{array}{l}17 \% \\
27,2 \% \text { high-risk }\end{array}$ & $\begin{array}{l}\text { Gunawan et al. } 2004 \\
\text { Chen Y et al. } 2004\end{array}$ \\
\hline $11 p /$ Loss & $11,8 \%$ low-risk, $27,2 \%$ high-risk & Chen Y et al. 2004 \\
\hline $12 q$ / Gain & $\begin{array}{l}12 \% \\
5,9 \% \text { low-risk, } 27,2 \% \text { high-risk }\end{array}$ & $\begin{array}{l}\text { Gunawan et al. } 2004 \\
\text { Chen Y et al. } 2004\end{array}$ \\
\hline $13 q$ / Loss & $\begin{array}{l}17 \% \\
5,9 \% \text { low-risk, } 45,5 \% \text { high-risk }\end{array}$ & $\begin{array}{l}\text { Gunawan et al. } 2004 \\
\text { Chen Y et al. } 2004\end{array}$ \\
\hline 14 / Loss & $60-78 \%$ & Derre et al. 2001, Bergmann et al. 1998 \\
\hline $14 q /$ Loss & $\begin{array}{l}64-77 \% \\
70,6 \% \text { low-risk, 54,5\% high-risk }\end{array}$ & $\begin{array}{l}\text { Gunawan et al. 2004; } \\
\text { El-Rifai et al. 2000, } \\
\text { Sarlomo-Rikala et al. 1998, } \\
\text { Marci et al. 1998, Chen Y et al. } 2004\end{array}$ \\
\hline 15 / Loss & $57 \%$ & Derre et al. 2001 \\
\hline $15 q /$ Loss & $\begin{array}{l}29 \% \\
29,4 \% \text { low-risk, } 54,5 \% \text { high-risk }\end{array}$ & $\begin{array}{l}\text { Gunawan et al. } 2004 \\
\text { Chen Y et al. } 2004\end{array}$ \\
\hline 17q / Gain & $\begin{array}{l}5,9 \% \text { low-risk, } 36,4 \% \text { high-risk } \\
25 \% \text { maligne, } 43 \% \text { metastasiert }\end{array}$ & $\begin{array}{l}\text { Chen Y et al. } 2004 \\
\text { El-Rifai et al. } 2000\end{array}$ \\
\hline $18 q$ / Loss & $27,2 \%$ high-risk & Chen Y et al. 2004 \\
\hline 20q / Gain & $\begin{array}{l}26 \% \text { metastasiert } \\
36,4 \% \text { high-risk }\end{array}$ & $\begin{array}{l}\text { El-Rifai et al. } 2000 \\
\text { Chen Y et al. } 2004\end{array}$ \\
\hline $22 q$ / Loss & $\begin{array}{l}53-58 \% \\
17,6 \% \text { low-risk, } 63,6 \% \text { high-risk }\end{array}$ & $\begin{array}{l}\text { Gunawan et al. } 2004, \\
\text { El-Rifai et al. } 2000 \\
\text { Chen Y et al. } 2004\end{array}$ \\
\hline
\end{tabular}


Tabelle 1.3/2

Lokalisationsabhängige chromosomale Imbalanzen bei GIST (nach Gunawan et al. 2004)

\begin{tabular}{|c|c|c|c|}
\hline Chromosom & Lokalisation & Veränderung(en) & \\
\hline \multirow[t]{2}{*}{$14 q$} & Magen & Verluste in $83 \%$ & \multirow{2}{*}{$\begin{array}{l}\text { lokalisationsunabhängig } \\
\text { Verluste in } 67 \%\end{array}$} \\
\hline & Darm & Verluste in $35 \%$ & \\
\hline \multirow[t]{2}{*}{$22 q$} & Magen & Verluste in $46 \%$ & \multirow{2}{*}{$\begin{array}{l}\text { lokalisationsunabhängig } \\
\text { Verluste in } 58 \%\end{array}$} \\
\hline & Darm & Verluste in $82 \%$ & \\
\hline \multirow[t]{2}{*}{$1 p$} & Magen & Verluste in $23 \%$ & \multirow{2}{*}{$\begin{array}{l}\text { lokalisationsunabhängig } \\
\text { Verluste in } 44 \%\end{array}$} \\
\hline & Darm & Verluste in $88 \%$ & \\
\hline \multirow[t]{2}{*}{$15 q$} & Magen & Verluste in $14 \%$ & \multirow{2}{*}{$\begin{array}{l}\text { lokalisationsunabhängig } \\
\text { Verluste in } 29 \%\end{array}$} \\
\hline & Darm & Verluste in $59 \%$ & \\
\hline \multirow[t]{2}{*}{$9 q$} & Magen & Verluste in $14 \%$ & \multirow{2}{*}{$\begin{array}{l}\text { lokalisationsunabhängig } \\
\text { Verluste in } 27 \%\end{array}$} \\
\hline & Darm & Verluste in $53 \%$ & \\
\hline \multirow[t]{2}{*}{$5 p$} & Magen & Zugewinn in $11 \%$ & \multirow{2}{*}{$\begin{array}{l}\text { lokalisationsunabhängig } \\
\text { Verluste in } 25 \%\end{array}$} \\
\hline & Darm & Zugewinn in $53 \%$ & \\
\hline
\end{tabular}

\subsection{Klinik}

Das klinische Verhalten von GIST weicht vom Verhalten anderer mesenchymaler Tumoren des Gastrointestinaltrakts (z.B. leiomyogene und neurogene Neoplasien) ab. Unter anderem im Hinblick auf Therapie, Tumornachsorge und Prognose ist die Unterscheidung zwischen GIST und anderen mesenchymalen Tumorentitäten sehr wichtig, da z.B. Leiomyome meist gutartig sind und oft keiner intensiveren Nachsorge bedürfen.

Viele kleinere und asymptomatische GIST werden zufällig (10 - 20\%) bei Routineuntersuchen, z.B. einer Endoskopie oder Sonographie, entdeckt, andere wiederum als Zufallsbefund bei operativen Eingriffen im Abdomen (Nilsson et al. 2005).

Es gibt keine typischen oder pathognomischen Symptome. GIST wachsen, nach überwiegender Meinung ausgehend von den Cajal-Zellen, submukös in der Muscularis propria, verursachen mit zunehmender Größe oft erst spät Probleme und führen je 
nach Lokalisation im Verlauf des Gastrointestinaltrakts zu unterschiedlichen Symptomen. Häufig sind mit $40 \%$ vor allem obere und untere gastrointestinale Blutungen mit Anämie und allgemeiner Leistungsabnahme das erste Symptom, mit 10 - 20\% folgen Schmerzen als zweithäufigstes Symptom (v.a. bei Tumoren im Magen und Duodenum; Miettinen et al. 2005). Daneben kann es zu Dysphagie, Übelkeit und Erbrechen, sowie Meteorismus, Diarrhoen und Tenesmen kommen. Dies kann zu den verschiedensten Komplikationen führen, beginnend bei leichten Obstruktionserscheinungen bis hin zum lleus mit Perforation und akutem Abdomen (Lam et al. 1996, Miettinen et al. 2005).

\subsection{Dignität und Rezidive}

Den größten Anteil an den GIST bilden mit ca. $70-80 \%$ die benignen Tumoren (Miettinen et al. 2005).

Eine Prognose über das klinische Verhalten eines GIST ist schwer zu treffen, da selbst primär als benigne eingestufte Tumoren metastasieren können. Aufgrund der Schwierigkeiten, die sich bei der Beurteilung von GIST sowohl im Hinblick auf die Dignität als auch Prognose ergeben haben, wurde, anstatt benigne und maligne Tumoren strikt voneinander zu trennen, in mehreren Studien versucht, mittels verschiedener Parameter eine Risikoklassifizierung bzw. Dignitätsbeurteilung vorzunehmen (Franquemont 1995).

\section{Histomorphologische Dignitätsmerkmale}

Die klassischen histomorphologischen Dignitätskriterien wie Kernpolymorphie und hyperchromasie im Rahmen des Tumorgradings sind bei GIST nur bedingt anwendbar (Rossi et al. 2003). Mitoserate, bzw. die immunhistochemische Färbung mit dem Proliferationsmarker Ki-67, sind allerdings mittlerweile als Prognosefaktor anerkannt. Vor allem die gemeinsame Bewertung der Mitoserate zusammen mit der Tumorgröße lassen einen Rückschluss auf die Dignität und damit auch auf die Prognose zu (Carillo et al. 1997, Miettinen et al. 2002, 2005, Wong et al. 2003),

Allgemein anerkannt sind die Risikoklassifizierungen nach Franquemont und nach 
Fletcher (siehe Tabelle 1.6/1 und 1.6/2) sowie die Dignitätsbeurteilung nach Miettinen (siehe Tabelle 1.6/3).

Tabelle 1.6/1

GIST - Risikoklassifizierung nach Franquemont (1995)

\begin{tabular}{|c|c|c|}
\hline & Tumorgröße und Mitosezahl & PCNA Index \\
\hline Low-risk & $<5 \mathrm{~cm}$ und $<2 / 10 \mathrm{HPF}$ & \\
\hline & $>=5 \mathrm{~cm}$ oder $>=2 / 10 \mathrm{HPF}$ & $<=10 \%$ \\
\hline High-risk & $>=5 \mathrm{~cm}$ und $>=2 / 10 \mathrm{HPF}$ & $>10 \%$ \\
\hline & $>=5 \mathrm{~cm}$ oder $>=2 / 10 \mathrm{HPF}$ & \\
\hline
\end{tabular}

PCNA index, Proliferating cell nuclear antigen index

Tabelle 1.6/2

GIST - Risikoklassifizierung nach Fletcher et al. (2002)

\begin{tabular}{|c|c|c|}
\hline & Tumorgröße & Mitosezahl / 50 HPF \\
\hline Very low-risk & $<2 \mathrm{~cm}$ & $<5$ \\
\hline Low-risk & $2-5 \mathrm{~cm}$ & $<-10$ \\
\hline Intermediate-risk & $<5 \mathrm{~cm}$ & $<5$ \\
\hline High-risk & $5-10 \mathrm{~cm}$ & $>5$ \\
\hline & $5-10 \mathrm{~cm}$ & unabhängig \\
\hline & $>10 \mathrm{~cm}$ & $>10$ \\
\hline
\end{tabular}

${ }^{*} \mathrm{HPF}$, High Power Fields

\section{Lokalisation}

Ein weiterer Faktor bei der Dignitätsbeurteilung ist die Lokalisation des Tumors. GIST im Dünndarm sind häufiger maligne als solche im Magen (Chen Y et al. 2004, Emory et al. 1999, Gunawan et al. 2004). Intestinale Tumoren haben meist einen größeren Tumordurchmesser und höhere Mitoseraten (Gunawan et al. 2004) und werden häufiger als (wahrscheinlich) maligne eingestuft. Von den meisten in der Literatur 
beschriebenen ösophagealen und rektalen Tumoren ist der überwiegende Anteil maligne (Miettinen et al. 1999 a), wobei ösophageale GIST eine wesentlich bessere Prognose als GIST im Dünndarm aufweisen (Emory et al. 1999).

Tabelle 1.6/3

GIST - Dignität nach Miettinen et al. (2002)

\begin{tabular}{|c|ll|}
\hline Wahrscheinlich benigne & Magen: & $\begin{array}{l}\text { Größe }<=5 \mathrm{~cm} \\
\text { Mitoserate }<=5 / 50 \mathrm{HPF} \text { (High Power Fields) }\end{array}$ \\
\hline Wahrscheinlich maligne & Mäße $<=2 \mathrm{~cm}$ \\
Mitoserate $<=5 / 50 \mathrm{HPF}$
\end{tabular}

\section{Metastasierungsverhalten}

Bereits kleine und als benigne eingestufte GIST können in 2 - 3\% aller Fälle metastasieren. Bei den als maligne eingestuften Tumoren liegt die Metastasierungsrate bereits bei $86 \%$ (Miettinen et al. 2005).

$50 \%$ der Primärtumore zeigen nach 5 Jahren ein Rezidiv (DeMatteo et al. 2000). Rezidive, auch nach R0-Resektion, treten meist in Form intraabdomineller, peritonealer und / oder hepatischer Metastasen auf (DeMatteo et al. 2000, Miettinen et al. 2005), wobei GIST bevorzugt hämatogen in die Leber metastasieren oder disseminiert ins Abdomen streuen (Miettinen et al. 2005). Etwa die Hälfte aller Patienten (40 - 60\%) weist bei Primärdiagnose bereits Metastasen auf, die vor allem in Leber und Peritoneum lokalisiert sind (Debiec-Rychter et al. 2004 b, DeMatteo 2002, Franquemont 1995). Knochen, Lunge und Lymphknoten sind nur selten von Metastasen betroffen (Liu et al. 2005, Nilsson et al. 2005). 


\subsection{Therapie und Prognose}

Die Standardtherapie (bei nicht metastasierten GIST) besteht in der radikalen chirurgischen (R0)-Resektion nach onkologischen Gesichtspunkten (Blay et al. 2005). Da GIST nur sehr selten lymphogene Metastasen setzen, kann in den allermeisten Fällen auf eine ausgedehnte Lymphadenektomie verzichtet werden (DeMatteo et al. 2001, Miettinen et al. 2005). Allerdings kommt es selbst bei radikaler Resektion in 40 $80 \%$ zu einem Rezidiv oder einer Metastasierung (DeMatteo et al. 2000).

\section{Therapie mit Imatinib}

Ausgehend von der Beobachtung, dass der Aktivierung des Tyrosinkinase-Rezeptors eine wesentliche Rolle bei GIST zukommt, erfolgte der Einsatz des TyrosinkinaseInhibitors Imatinib (kompetitiver ATP-Inhibitor am Rezeptor) bei einem bereits metastasierten GIST mit überragendem Erfolg (Joensuu et al. 2001). Imatinib, ein Phenylaminopyrimidin-Derivat, blockiert spezifisch die ATP-Bindungsstelle verschiedener Tyrosinkinasen (abl, Bcr-abl, c-kit, PDGF-Rezeptor) und verhindert so die Aktivierung der nachgeschalteten Signaltransduktion (Buchdunger et al. 2000). Weitere Studien mit größeren Fallzahlen bestätigten die Wirksamkeit von Imatinib (Debiec-Rychter et al. 2004 b, Demetri et al. 2002), so dass die Indikation für eine Therapie mit Imatinib zur Zeit CD-117-positive, nicht resezierbare und / oder metastasierte maligne GIST bei Erwachsenen sind, sowie die adjuvante Behandlung von CD-117 positiven GIST mit signifikantem Risiko für die Entwicklung eines Rezidivs (Fachinformation Glivec® Filmtabletten, Novartis Pharma, Stand der Information April 2009).

Die Ansprechraten einer Therapie mit Imatinib liegen bei bis zu 75 - 85\% (Blay et al. 2005, Heinrich et al. 2003 c), wobei GIST mit KIT-Exon-11-Mutation in 83,5\% ein Teilansprechen (partial response) zeigen. Bei GIST mit KIT-Exon-9-Mutation sinkt die Rate auf 47,8\% (Heinrich et al. 2003 b). Die Teilansprechraten der Phase I - III Studien lagen zwischen $48-71 \%$, eine Stabilisierung (stable disease) wurde in 18 $33 \%$ erreicht und eine komplette Remission nur in $3-5 \%$ der Fälle (Demetri et al. 2002, van Oosterom 2002, Verweij et al. 2003). 


\section{Resistenz gegenüber Imatinib}

Trotz des Erfolgs von Imatinib in der Behandlung zeigte es sich, dass nicht alle GIST mit einer aktivierenden Mutation im KIT-Gen auf eine Therapie mit Imatinib ansprechen. Bei 15\% der Patienten wird eine primäre Resistenz beobachtet (Antonescu et al. 2005, Demetri et al. 2002, Joensuu et al. 2001) und bei bis zu 50\% der bereits erfolgreich anbehandelten Patienten kommt es nach 18 - 24 Monaten plötzlich zu einer Verschlechterung und Tumorprogression (Antonescu et al. 2005, Ma et al. 2002, Verweij et al. 2003).

(Primär-) Resistenz gegenüber Imatinib zeigt sich u.a. bei der Substitution D842V (Exon 18 des PDGFRA-Gens), wobei teilweise eine Stabilisierung unter Therapie erreicht wird (Debiec-Rychter et al. 2004 a, Heinrich et al. 2003 c, Miettinen et al. 2005).

Manche Fälle können auf Sekundärmutationen zurückgeführt werden, die die Tyrosinkinase oder nachgeschaltete Signalkaskaden betreffen (Antonescu et al. 2005, Wakai et al. 2004). Antonescu et al. (2005) fand in 14 Patienten mit einer erworbenen Resistenz gegenüber Imatinib in 7 Patienten (46\%) Sekundärmutationen (darunter KIT Exon 17 (N822K, D820Y und Y823D), Exon 13 (V654A) und Exon 14 (T670I)).

Auch eine Amplifikation und Überexpression des KIT-Gens, die Aktivierung einer alternativen Rezeptortyrosinkinase mit Verlust der Expression von c-kit oder eine KITbzw. PDGFRA-Aktivierung außerhalb der Juxtamembran "Hotspot"-Region kann zu einer Resistenz führen (Antonescu et al. 2005).

Andere Möglichkeiten der Resistenz umfaßen z.B. Änderungen der zellulären Aufnahme des Wirkstoffs sowie Änderungen in der Pharmakokinetik (Judson et al. 2004).

\section{Weitere Therapiemodalitäten}

Die Strahlentherapie hat nur einen untergeordneten Stellenwert (Blanke 2003). Sie kann in fortgeschrittenen Stadien zur palliativen Therapie, z.B. bei chronischen Schmerzzuständen, eingesetzt werden. Tran et al. (2005) zeigten im Gegenteil sogar 
eine erhöhte 5-Jahres-Sterberate, verglichen mit operativer bzw. keiner Therapie. Auch die herkömmlichen Chemotherapien machen aufgrund der geringen Ansprechraten (ca. 7\%) gegenüber konventionellen Chemotherapeutika keinen Sinn in der Therapie des GIST (Blanke 2003). Adjuvante oder neoadjuvante Therapieansätze mit Imatinib sind zur Zeit Gegenstand klinischer Studien (Bumming et al. 2003, Loughrey et al. 2005, Shah et al. 2005).

\section{Prognose}

Angaben über 5-Jahres-Überlebensraten und andere prognostische Parameter sind nicht immer verwertbar. In vielen älteren Studien liegt es u.a. daran, dass auch Leiomyosarkome und Schwannome in die Statistik einbezogen wurden und in neueren Studien nicht zwischen Patienten mit und ohne Imatinib-Therapie getrennt wurde. Auch die begrenzte Follow-Up-Zeit seit Einführung von Imatinib in die Therapie des GIST (im Jahr 2000) erschwert eine sichere prognostische Aussage.

Einen Überblick über die mittlere Überlebenszeit nach einer Studie von DeMatteo et al. (2000) gibt Tabelle 1.7/1.

Tabelle 1.7/1

Prognose in Abhängigkeit vom Progress-Status bei Präsentation (nach DeMatteo et al. 2000)

\begin{tabular}{|c|c|c|c|c|}
\cline { 3 - 5 } \multicolumn{2}{c}{} & \multicolumn{2}{c|}{ Komplette Resektion } \\
\hline Präsentation & $\mathbf{n}$ & $\begin{array}{c}\text { Mediane } \\
\text { Überlebenszeit } \\
\text { (Monate) }\end{array}$ & $\mathbf{n}$ & $\%$ \\
\hline Primartumor & 93 & 60 & 80 & 86 \\
\hline Metastasen & 94 & 19 & 28 & 30 \\
\hline nur Metastasen & 51 & 22 & 16 & 31 \\
\hline $\begin{array}{c}\text { Primartumor }+ \\
\text { Metastasen }\end{array}$ & 26 & 23 & 4 & 24 \\
\hline $\begin{array}{c}\text { Lokalrezidiv }+ \\
\text { Metastasen }\end{array}$ & 17 & 9 & 6 & 46 \\
\hline Lokalrezidiv & 13 & 12 & 4 & \\
\hline
\end{tabular}


Die rezidivfreie 5-Jahres-Überlebenszeit bei Tumoren kleiner als $5 \mathrm{~cm}$ liegt bei $82 \%$, zwischen $5-10 \mathrm{~cm}$ bei $45 \%$ und bei Tumoren größer als $10 \mathrm{~cm}$ bei nur noch $27 \%$ (Singer et al. 2002).

\section{Prognose nach KIT- und PDGFRA- Mutationen}

Der KIT- und PDGFRA-Mutationsstatus stellt einen unabhängigen Faktor für das rezidivfreie Überleben dar (Heinrich et al. 2003 c, Singer et al. 2002). Bei Therapie mit Imatinib betrug die "median event free survival time" bei Mutationen in KIT Exon $11 \mathrm{im}$ Median 687 Tage, bei KIT Exon 9187 Tage und bei Fehlen von Mutationen (Wildtyp) nur 82 Tage (Heinrich et al. $2003 \mathrm{c}$ ).

Die rezidivfreie 5-Jahres-Überlebenszeit in einer Studie von Kim TW et al. (2004) lag bei Vorliegen von Mutationen in KIT bei $21 \%$ sowie $60 \%$ bei Abwesenheit von Mutationen, wobei Patienten mit Deletionen im Exon 11 des KIT-Gens signifikant mehr Fälle einer "Progressive Disease" zeigen als solche mit Punktmutationen im Exon 11 (Miettinen et al. 2005). Besonders eine Deletion in den Codons W557 und K558 ist mit einem malignen Verhalten der GIST assoziiert (Wardelmann et al. 2003). Aber auch Deletionen, Insertionen, Punktmutationen und komplexere Mutationen, die eins oder beide Codons einschließen, zeigen eine Assoziation zu malignen Verläufen (Wardelmann et al. 2003).

Mutationen in KIT Exon 9 haben im Vergleich mit Mutationen im Exon 11 eine schlechtere Prognose und sind häufiger mit größeren Tumoren, Lokalisation im Dünndarm und aggressiverem Verhalten assoziiert (Antonescu et al. 2003, DebiecRychter et al. 2004 b, Heinrich et al. 2003 b); dies trifft vor allem auf GIST mit einer ITD AY502-503 zu (Antonescu et al. 2003, Corless et al. 2004).

Mutationen im PDGFRA-Gen haben, im Vergleich mit KIT-Mutationen, eine bessere Prognose. Im Follow-Up (durchschnittlich 135 Monate) zeigten 83,5\% aller GIST mit PDGFRA-Mutationen einen benignen Verlauf (Lasota et al. 2004).

\section{Prognose nach chromosomalen Imbalanzen}

El-Rifai et al. (2000) zeigte, dass benigne GIST durchschnittlich 2,6, primär maligne 
GIST durchschnittlich 7,5 und metastasierte Tumoren 9,0 chromosomale Imbalanzen aufweisen. Benigne GIST zeigen dabei vor allem Verluste, während maligne und metastasierte GIST vermehrt auch Zugewinne und Amplifikationen enthalten. Zugewinne und Amplifikationen an 5p, 8q, 17q und 20q und Verluste an 9p, 13q, 15q und 19q korrelieren mit primär malignen und metastasierten GIST (EI-Rifai et al. 2000). Verluste an Chromosom $1 p$ und 9 zeigen eine Häufung bei malignen GIST (Chen $Y$ et al. 2004, Debiec-Rychter et al. 2001, Kim NG et al. 2000). Eine Übersicht über die signifikanten chromosomalen Veränderung nach El-Rifai et al. (2000) zeigt Tabelle $1.7 / 2$.

Tabelle $1.7 / 2$

Signifikante chromosomale Imbalanzen nach El-Rifai et al. (2000)

\begin{tabular}{|c|c|c|c|}
\hline Chromosom & Benigne GIST & Maligne GIST & Metastasen \\
\hline $8 q+$ & $8 \%$ & $33 \%$ & $57 \%$ \\
\hline $17 q+$ & $0 \%$ & $25 \%$ & $43 \%$ \\
\hline $20 q+$ & $0 \%$ & $11 \%$ & $26 \%$ \\
\hline $5 p+$ & $0 \%$ & $31 \%$ & $29 \%$ \\
\hline $9 p-$ & $0 \%$ & $36 \%$ & $63 \%$ \\
\hline $13 q-$ & $8 \%$ & $36 \%$ & $46 \%$ \\
\hline
\end{tabular}

\subsection{Zielstellung}

Das Ziel dieser Arbeit ist die Korrelation der aus der Mutationsanalyse des KIT und PDGFRA -Gens gewonnenen Daten mit den Ergebnissen der CGH, sowie die Bewertung der Ergebnisse, besonders im Hinblick auf die Prognose des Patienten. 


\section{Material und Methoden}

\section{$2.1 \quad$ Kollektiv}

Das Kollektiv umfaßt 64 Tumorproben von Patienten, die im Zeitraum von 1993 bis 2005 an einem GIST operiert worden sind. Die Diagnose eines GIST wurde histologisch und immunhistochemisch gestellt.

Die Referenz-DNA für die CGH stammt aus normalen Lebergewebe (hohe Zelldichte), welches nach Gewinnung der Proben in flüssigem Stickstoff schockgefroren und bei $80^{\circ} \mathrm{C}$ gelagert wurden.

Die klinischen Verlaufsdaten (Follow-Up) wurden anhand der jeweiligen Patientenakten, sowie in Zusammenarbeit mit den Hausärzten, erstellt.

\subsection{Methoden}

\subsubsection{Immunhistochemie}

Zur immunhistochemischen Diagnostik und differentialdiagnostischen Abgrenzung wurden pro Fall 5 immunhistochemische Färbungen angefertigt:

- $\mathrm{S} 100$ (Immunotech, Marseille, Frankreich)

- CD34 (Immunotech, Marseille, Frankreich)

- Aktin (Immunotech, Marseille, Frankreich)

- c-kit / CD117 (DAKOCytomation, Glostrup, Denmark)

- Desmin (Immunotech, Marseille, Frankreich).

Eine weitere immunhistochemische Färbung mit Ki-67/Clone MiB1 (DAKOCytomation, Glostrup, Denmark) wurde zur Risikoklassifizierung bzw. Dignitätsbeurteilung der GIST vorgenommen (siehe Kapitel 1.6). Die Antikörper wurden vor Verwendung nach folgenden Schema verdünnt (Verdünnungspuffer siehe Tabelle 2.2.1/1, S. 26): 


$\begin{array}{llll}\text { CD117 } & 1: 400 & \text { Desmin } & 1: 1 \\ \text { CD34 } & 1: 30 & \text { S100 } & 1: 20 \\ \text { Aktin } & 1: 30 & \text { Ki-67 } & 1: 150\end{array}$

Für S100 erfolgte vor der eigentlichen Färbung eine Vorbehandlung der Objektträger mit Protease (Protease XXIV, SIGMA; St. Louis; USA). Dazu wurden sie in eine Küvette mit $0,0125 \mathrm{~g}$ Protease in $30 \mathrm{ml}$ deionisiertem Wasser aufgenommen, für 10 min bei $40^{\circ} \mathrm{C}$ in den Wärmeschrank gestellt und anschließend mit deionisiertem Wasser gespült. Die Objektträger für Mib1 und c-kit erhielten eine Hitzevorbehandlung mit Citratpuffer (siehe Tabelle 2.2.1/1, S. 26). Dazu wurde der Citratpuffer $15 \mathrm{~min}$ im Dampfgarer (Multigourmet, Braun, Kronberg, Deutschland) erhitzt und anschließend die Schnitte in die Küvette mit dem Citratpuffer gesteckt und für 45 min im Dampfgarer gekocht. Es folgte eine 25 minütige Abkühlungsphase.

Die weitere Behandlung erfolgte für alle Antikörperfärbungen gleich. Nach ausreichender Spülung mit deionisiertem Wasser und einem Bad für maximal 5 Minuten in einer Küvette mit Tween-TBS-Puffer (siehe Tabelle 2.2.1/1, S. 26) kamen die Schnitte in die feuchte Kammer (Hybrite TM; Vysis; Stuttgart-Fasanenhof, Deutschland).

Unspezifische Bindungsstellen wurden nun durch eine 10 minütige Behandlung mit 100 $\mu \mathrm{l}$ 2\%-BSA-Lösung (siehe Tabelle 2.2.1/1, S. 26) blockiert. Anschließend wurde für weitere $30 \mathrm{~min} 100 \mu \mathrm{l}$ des eigentlichen Antikörpers, in verdünnter Lösung, auf die Gewebeschnitte aufgetragen. Die Inkubationszeit fand bei beiden Schritten in der feuchten Kammer statt.

Nach dreimaliger Spülung mit dem Tween-TBS-Puffer zur Entfernung ungebundener Antikörper folgte eine Inkubation für 20 min mit dem biotinylierten Zweitantikörper. Dabei wurden $100 \mu \mathrm{l}$ Link (Biotinylated Secondary Antibodies) aus dem ChemMate Detection Kit (K 5005, DAKOCytomation, Glostrup, Denmark) auf den Gewebeschnitt pipettiert. 
Tabelle 2.2.1/1

Materialen - Immunhistochemie

\begin{tabular}{|c|c|c|}
\hline Name & Zusam & mensetzung \\
\hline Verdünnungspuffer & $\begin{array}{l}12 \mathrm{~g} \\
18 \mathrm{~g} \\
0,6 \mathrm{ml} \\
\mathrm{ad} \\
\mathrm{pH} 7,4\end{array}$ & $\begin{array}{l}\text { Tris (Roth, Karlsruhe, Deutschland) } \\
\text { NaCl (Merck, Darmstadt, Deutschland) } \\
\text { Tween } 20 \text { (Merck, Darmstadt, Deutschland) } \\
\text { 2000ml Aqua bidest. }\end{array}$ \\
\hline Citratpuffer & $\begin{array}{l}18 \mathrm{ml} \\
82 \mathrm{ml} \\
900 \mathrm{ml} \\
\mathrm{pH} 6,0\end{array}$ & $\begin{array}{l}\text { Lösung A } \\
\text { Lösung B } \\
\text { deionisiertes Wasser }\end{array}$ \\
\hline Lösung A & $\begin{array}{l}21 \mathrm{~g} \\
900 \mathrm{ml} \\
\mathrm{ad}\end{array}$ & $\begin{array}{l}\text { Citronensäure (Merck, Darmstadt, Deutschland) } \\
\text { deionisiertes Wasser } \\
1000 \mathrm{ml} \text { Aqua bidest }\end{array}$ \\
\hline Lösung B & $\begin{array}{l}29,4 \mathrm{~g} \\
\mathrm{ad}\end{array}$ & $\begin{array}{l}\text { Tri-Natriumcitratdihydrat } \\
\text { (Merck, Darmstadt, Deutschland) } \\
1000 \mathrm{ml} \text { Aqua bidest }\end{array}$ \\
\hline Tween-TBS-Puffer (Stammlösung) & $\begin{array}{l}121,2 \mathrm{~g} \\
175,2 \mathrm{~g} \\
240 \mathrm{ml} \\
6 \mathrm{ml} \\
\mathrm{ad} \\
\mathrm{pH} 7,4\end{array}$ & $\begin{array}{l}\text { Tris (Roth, Karlsruhe, Deutschland) } \\
\mathrm{NaCl} \text { (Merck, Darmstadt, Deutschland) } \\
\mathrm{HCl} 3,5 \mathrm{~mol} \\
\text { (Merck, Darmstadt, Deutschland) } \\
\text { Tween } 20 \text { (Merck, Darmstadt, Deutschland) } \\
1600 \mathrm{ml} \text { Aqua bidest }\end{array}$ \\
\hline Tween-TBS-Puffer & $\begin{array}{l}200 \mathrm{ml} \\
\mathrm{ad} \\
\mathrm{pH}\end{array}$ & $\begin{array}{l}\text { Tween-TBS-Puffer (Stammlösung) } \\
1800 \mathrm{ml} \text { Aqua bidest } \\
7,4\end{array}$ \\
\hline 2\% BSA-Lösung & $\begin{array}{l}2 \mathrm{~g} \\
100 \mathrm{ml}\end{array}$ & $\begin{array}{l}\text { BSA (SIGMA; St. Louis, USA) } \\
\text { Tween-TBS-Puffer }\end{array}$ \\
\hline
\end{tabular}

Nach erneuter dreimaliger Spülung mit dem Tween-TBS-Puffer wurden $100 \mu \mathrm{l}$ Label (Streptavidin Alkaline Phosphatase, ChemMate Detection Kit) auf den Schnitt pipettiert und die Objektträger für 20 min bei Raumtemperatur inkubiert.

Es schloß sich eine dreimalige Spülung mit dem Tween-TBS-Puffer an, darauf folgend für 20 min ein Färbebad mit $100 \mu \mathrm{l}$ Chromogen Red (ChemMate Detection Kit) pro Schnitt.

Nun wurde mit deionisiertem Wasser gespült und anschließend zur Gegenfärbung der Zellkerne für 30 Sekunden in einer Küvette mit Hämalaun (Tabelle 2.2.1./2) inkubiert. Abschließend erfolgte das Eindeckeln mit Aquamount (BDH Laboratories, Poole, England). 
Tabelle 2.2.1/2

Materialen - Immunhistochemie

\begin{tabular}{|l|ll|}
\hline Name & Zusammensetzung \\
\hline Saures Hämalaun nach Mayer & $1 \mathrm{~g}$ & Hämatoxylin (Merck, Darmstadt, Deutschland) \\
(Stammlösung) & $0,2 \mathrm{~g}$ & Natriumjodat (Merck, Darmstadt, Deutschland) \\
$50 \mathrm{~g}$ & Kalialaun (Merck, Darmstadt, Deutschland) \\
$\mathrm{ad}$ & $1000 \mathrm{ml}$ Aqua bidest \\
& $100 \mathrm{ml}$ & Saures Hämalaun nach Mayer (Stammlösung) \\
Hämalaun-Lösung & $5 \mathrm{~g}$ & Chloralhydrat (Merck, Darmstadt, Deutschland) \\
& $0,1 \mathrm{~g}$ & Zitronensäure (Merck, Darmstadt, Deutschland) \\
\hline
\end{tabular}

\subsubsection{DNA-Isolierung}

\section{Isolierung der Referenz-DNA und Tumor-DNA aus Frischgewebe}

Die bei $-80{ }^{\circ} \mathrm{C}$ gelagerten Lebergewebsproben wurden auf Raumtemperatur erwärmt und ein ca. $5 \mathrm{~mm}^{3}$ großes Stück mit einem Skalpell (Technocut, Horsham, Deutschland) zu einem Brei zerkleinert und in ein Eppendorf-Cup (Eppendorf, Hamburg, Deutschland) gegeben. Die folgenden Schritte erfolgten analog der Isolierung aus Paraffingewebe (siehe Kapitel 2.2.1.3).

\section{Isolierung der Tumor-DNA aus Paraffin}

Um einen möglichst hohen Prozentsatz an Tumorzellen im Ausgangsmaterial zu haben, wurden auf den HE-Schnitten (von den entsprechenden Paraffinblöcken) die Tumorzellen enthaltenden Bereiche markiert und die Paraffinblöcke anschließend mit einem Skalpell so bearbeitet, dass die folgenden mit dem Mikrotom (Reichert-Jung (Leica Microsystems AG), Wetzlar, Deutschland) hergestellten Schnitte möglichst kein tumorfreies Gewebe enthielten.

Zum Entparaffinieren wurde nun je $1 \mathrm{ml}$ Xylol (Merck, Darmstadt, Deutschland) in die Eppendorf-Cups pipettiert (Eppendorf, Hamburg, Deutschland), der Ansatz kurz gevortext (Vortex Genie 2, Scientific Industries, Bohemia, USA) und anschließend für 10 min bei Raumtemperatur inkubiert. Nach 1 min Zentrifugieren (Centrifuge 5417R, Eppendorf, Hamburg, Deutschland) bei 10000 rpm wurde der Überstand abpipettiert und verworfen. Mit $1 \mathrm{ml}$ Xylol wurde dieser Schritt nun wiederholt. 
Um die Xylolreste zu entfernen wurde jetzt $1 \mathrm{ml}$ 100\% Ethanol (Roth; Karlsruhe, Deutschland) dazugegeben, kurz gevortext und der Ansatz wiederum 10 min bei Raumtemperatur inkubiert. Nach 1 min Zentrifugieren bei 10000 rpm wurde der Überstand abpipettiert und verworfen. Auch dieser Schritt wurde wiederholt.

Nach Trocknung des Gewebes für 1 Stunde bei $60{ }^{\circ} \mathrm{C}$ im Wärmeschrank (Memmert, Schwabach, Deutschland) wurden $240 \mu \mathrm{l}$ DNA-Isolierungspuffer (siehe Tabelle. 2.2.2/1) und $40 \mu \mathrm{l}$ Proteinase $\mathrm{K}(50 \mathrm{U} / \mathrm{ml}$, Roche Diagnostics $\mathrm{GmbH}$, Mannheim, Deutschland) zum Gewebe in das Eppendorf-Cup pipettiert (für Frischgewebe $360 \mu \mathrm{l}$ DNA-Isolierungspuffer und $40 \mu \mathrm{l}$ Proteinase K) und anschließend bei $55^{\circ} \mathrm{C}$ über Nacht im Thermomixer mit einer Schüttelfrequenz von $850 \mathrm{rpm}$ (Thermomixer comfort, Eppendorf, Hamburg, Deutschland) inkubiert, um die Zellproteine aufzuspalten und die DNA freizulegen (u.a. zelluläre DNAsen werden durch die Proteinase $\mathrm{K}$ inaktiviert).

Tabelle 2.2.2/1

Materialien - DNA-Isolierung

\begin{tabular}{|c|c|}
\hline Name & Zusammensetzung \\
\hline DNA-Isolierungspuffer & $\begin{array}{ll}50 \mathrm{mM} & \text { Tris-HCl (MBI Fermentas; St. Leon-Rot, Deutschland) } \\
1 \mathrm{mM} & \text { EDTA (Serva, Heidelberg, Deutschland) } \\
0,5 \% & \text { Tween20 (Merck, Darmstadt, Deutschland) } \\
\text { ph 8,5 } & \text { (pH-Meter: Schott, Mainz, Deutschland) }\end{array}$ \\
\hline
\end{tabular}

Am nächsten Tag erfolgte die anschließende Inaktivierung der Proteinase K über 8 min bei $95{ }^{\circ} \mathrm{C}$ im Thermomixer. Nach einer folgenden 10 minütigen Zentrifugation bei 13500 rpm wurde der DNA-enthaltende flüssige Überstand in ein neues EppendorfCup überpipettiert, um eine Restkontamination mit Paraffin und Geweberesten zu vermeiden. Die weitere Isolierung bzw. Aufreinigung der DNA erfolgte mit Hilfe eines Qiagen-Kit (QIAamp (DNA Mini Kit (250); Qiagen; Hilden, Deutschland) gemäß den Angaben des Herstellers. Die extrahierte DNA wurde bis zur Verwendung bei $4{ }^{\circ} \mathrm{C}$ aufbewahrt.

\section{Photometrische Messung}

Um die Konzentration und Reinheit der DNA zu überprüfen, wurde eine photometrische Messung (Photometer: Eppendorf, Hamburg, Deutschland) mit Einmalplastikküvetten 
(UVette, Eppendorf, Hamburg, Deutschland) durchgeführt.

\section{Gelelektrophorese}

Um die Molekülgrößen der fragmentierten DNA zu bestimmen, wurde eine Gelelektrophorese (1,5\%-Agarose-Gel; für PCR-Gelproben 2\%) mit der extrahierten DNA durchgeführt. Die Bestimmung der Fragmentlängen erfolgte mit dem LambdaMarker (Fragmentlänge: 21-0,56 kb MBI-Fermentas; St. Leon-Rot, Deutschland) als Längenstandard, der parallel zur DNA in eine Geltasche pipettiert wurde. Zum Sichtbarmachen der DNA wurde Ethidiumbromid (SIGMA; St. Louis; USA) verwendet, welches in die DNA interkaliert und im UV-Licht $(312 \mathrm{~nm})$ fluoresziert. Zur weiteren Verwendung für die CGH sollte die Länge der einzelnen Fragmente zwischen 600 bis 2000bp (Kallioniemi O et al. 1994) liegen.

Für die Vorbereitung der Gelproben wurden jeweils $5 \mu \mathrm{l}$ DNA-Lösung und $3 \mu \mathrm{l}$ Loading Dye (MBI-Fermentas; St. Leon-Rot, Deutschland) in die Vertiefungen der Mikrotiterplatte pipettiert. Für den Längenstandard wurden neben den $3 \mu$ L Loading Dye statt der DNA $5 \mu \mathrm{l}$ Ampuwa und $1.5 \mu \mathrm{l}$ Lambda-DNA $(0,5 \mu \mathrm{g} / \mu \mathrm{l})$ pipettiert. Der Zusatz von Bromphenolblau im Loading-Dye ermöglicht während der Elektrophorese den Lauf der DNA optisch verfolgen zu können.

\subsubsection{Komparative genomische Hybridisierung}

Die Komparative Genomische Hybridisierung (CGH) wurde aus Paraffin- sowie aus schockgefrorenen Frischgewebsproben durchgeführt. In allen 64 Fällen aus dem Kollektiv lag vor dieser Arbeit bereits ein Ergebnis der CGH vor. Die Auswertung wurde anhand der alten Daten in allen 67 Fällen (64 Primär-GIST + 3 Metastasen) erneut durchgeführt und das Ergebnis der ersten CGH reevaluiert.

Die CGH ist eine auf der Fluoreszenz-in-situ-Hybridisierung (FISH) beruhende, erstmals 1992 beschriebene, molekularzytogenetische Methode, mittels der man einen Überblick über die gesamten chromosomalen und subchromosomalen Verluste und Zugewinne eines Tumors erlangen kann (Kallioniemi A et al. 1992). Die so gewonnenen Erkenntnisse können u.a. zur Identifizierung / Lokalisation von 
spezifischen Genen benutzt werden, die an Tumorgenese bzw. -progression beteiligt sind (z.B. Proto-Onkogene und Tumorsuppressorgene).

Die Größenordnung des Auflösungsvermögens der auswertbaren Veränderungen liegt bei etwa 10 MB (Megabasen) (Petersen et al. 1996), hin zu maximal 100 Kilobasen bei Amplifikationen, d.h. mehrfachen Zugewinnen (Kallioniemi O et al. 1994).

Für eine CGH-Analyse sind folgende Schritte notwendig:

1) DNA-Isolierung aus Gewebe

2) Markierung der Tumor- und Referenz-DNA mit unterschiedlichen

Fluoreszenzfarbstoffen durch die Nick-Translation

3) Hybridisierung der markierten Tumor- und Referenz-DNA mit Metaphase-Chromosomen

4) Auswertung der $\mathrm{CGH}$.

Bei der Hybridisierung konkurrieren dabei Tumor- und Referenz-DNA um die Bindungsstellen auf den Metaphase-Chromosomen. Beim Überwiegen von TumorDNA (Zugewinn) bindet diese statistisch häufiger an den Chromosomen als die Referenz, bei einem Verluste innerhalb des Tumor-Genoms überwiegt die ReferenzDNA. Durch quantitative Messung des roten und grünen Fluoreszenzsignals über die Längsachse eines jeden Chromosoms läßt sich nun eine Aussage treffen über Verluste, Zugewinne und Amplifikationen der Tumor-DNA.

\section{Nick-Translation}

Während der Nick-Translation wird in die extrahierte DNA als Marker Biotin (TumorDNA) und Digoxigenin (Referenz-DNA) eingebaut, die im Detektionsschritt mit fluoreszenzmarkiertem Antikörper gekoppelt werden (grün bei der Tumor- und rot bei der Referenz-DNA). Mit Hilfe der DNAse I werden bei diesem Prozess Einzelstrangsbrüche in die DNA geschnitten ("nicks"), die dann durch die DNAPolymerase I unter Einbau von Biotin bzw. Digoxigenin wieder aufgefüllt werden.

Für die Nick-Translation wurde zügig nach folgendem Schema in vorbereitete Eppendorf-Cups pipettiert: 


$\begin{array}{ll}3 \mu \mathrm{g} & \text { Tumor-DNA / Referenz-DNA } \\ 10 \mu \mathrm{l} & \text { DNA-Puffer (10x konzentriert) } \\ & \text { MBI Fermentas; St. Leon-Rot, Deutschland } \\ 2 \mu \mathrm{l} & \text { dATP, dCTP, dGTP } \\ & \text { Pharmacia Biotech; Freiburg, Deutschland } \\ 1 \mu \mathrm{l} & \text { dTTP } \\ & \text { Pharmacia Biotech; Freiburg, Deutschland } \\ 1 \mu \mathrm{l} & \text { 1 mM Biotin-16-dUTP/1 mM Digoxigenin-11-dUTP } \\ & \text { Roche; Mannheim, Deutschland } \\ 2 \mu \mathrm{l} & \text { DNA-Polymerase I } \\ & \text { MBI Fermentas; St. Leon-Rot, Deutschland } \\ 1 \mu \mathrm{l} & \text { DNAse I - Verdünnung } \\ & \text { siehe Tabelle 2.2.3/1 } \\ 100 \mu \mathrm{l} & \text { Ampuwa. }\end{array}$

Die $3 \mu \mathrm{g}$ an benötigter DNA pro Ansatz wurden anhand der, während der DNAIsolierung gewonnenen, DNA-Konzentrationswerte errechnet. Die bei $-20{ }^{\circ} \mathrm{C}$ gelagerten Nukleotide wurden langsam auf Eis erwärmt.

Tabelle 2.2.3/1

Materialien - Nick-Translation

\begin{tabular}{|l|l|}
\hline Name & Zusammensetzung / Hersteller \\
\hline $\begin{array}{l}\text { DNAse I - Verdünnung } \\
\text { (1:50 verdünnt) }\end{array}$ & $98 \mu \mathrm{I}$ TRIS-HCl, $100 \mathrm{mM}, \mathrm{pH} 7,5$ \\
$2 \mu \mathrm{l}$ Dnase (Boehringer; Mannheim, Deutschland)
\end{tabular}

Die Eppendorf-Cups wurden anschließend nach kurzem Vortexen bei $15{ }^{\circ} \mathrm{C}$ und 800 rpm für 50 min (Tumor-DNA) bzw. 60 min (Referenz-DNA) mit dem Thermomixer inkubiert.

Nach der Nick-Translation sollten die einzelnen DNA-Fragmente eine Länge von 500 1500 bp besitzen. Zur Überprüfung wurde eine Gelelektrophorese durchgeführt. Diese erfolgte analog der Gelelektrophorese bei der DNA-Isolierung (siehe Kapitel 2.2.2 DNA-Isolierung, S. 27). Als Längenstandard wurde abweichend pUC19 (Fragmentlängen: 501-26 bp; MBI Fermentas; St. Leon-Rot, Deutschland) verwendet. 
Im Falle zu langer DNA-Fragmente wurde eine zweite Inkubationszeit für 5 - 10 min bei $15^{\circ} \mathrm{C}$ auf dem Thermomixer angeschlossen. Zum Abstoppen der Reaktion wurden die Proben bei $-20{ }^{\circ} \mathrm{C}$ eingefroren.

\section{Hybridisierung}

Auf die Nick-Translation folgte die Hybridisierung sowohl der markierten Tumor- als auch der Referenz-DNA auf die vorgefertigten Objektträger (CGH Target Slides; Vysis Inc.;Downers, Grove, IL) mit den Metaphasechromosomen. Die Objektträger wurden zur Beseitigung von Kondenswasser zu Beginn bei $37^{\circ} \mathrm{C}$ auf die Wärmeplatte der feuchten Kammer (Hybrite TM; Vysis; Stuttgart-Fasanenhof, Deutschland) gelegt.

Zum Abstoppen der DNAse und Polymerase wurde nun die Nick-DNA-Lösung mit $5 \mu \mathrm{l}$ EDTA (Serva, Heidelberg, Deutschland) versetzt und für 5 min bei $37^{\circ} \mathrm{C}$ und $1400 \mathrm{rpm}$ im Thermomixer inkubiert. In die vorbereiteten Eppendorf-Cups wurden jetzt die Tumor- und Referenz-DNA, sowie die repetitive Sequenzen enthaltene humane Cot-1DNA (1 $\mu \mathrm{g} / \mu \mathrm{l}$, Boehringer, Mannheim, Deutschland) zusammengeführt und mit $12 \mu \mathrm{l} 3$ M Natriumacetatlösung pH 4,8 (Merck, Darmstadt, Deutschland) sowie $570 \mu$ Ethanol bei -80 ${ }^{\circ} \mathrm{C}$ für 0,5 - 2 Stunden präzipitiert. Aufgrund der im Mengenvergleich zur Tumor- und Referenz-DNA im starken Überschuß vorliegenden Cot-1-DNA blockiert diese die repetitiven Sequenzen, vor allem um das Zentromer und in Bereichen mit einem hohem Anteil von Heterochromatin.

Pipettierschema:

$67 \mu \mathrm{l} \quad$ Nick-Tumor-DNA

$67 \mu \mathrm{l} \quad$ Nick-Referenz-DNA

$80 \mu \mathrm{l} \quad$ Cot-1 DNA

$12 \mu \mathrm{l} \quad \mathrm{NaAc} / 3 \mathrm{M} / \mathrm{pH} 4,8$

$570 \mu \mathrm{l} \quad 100 \%$ Ethanol $\left(-20^{\circ} \mathrm{C}\right)$.

Der Ansatz wurde nach kurzem Vortexen der Eppendorf-Cups für 30 min bei $-80{ }^{\circ} \mathrm{C}$ präzipitiert. Nach dem Fällen der DNA wurden die Ansätze 30 min bei $4{ }^{\circ} \mathrm{C}$ und 14000 rpm zentrifugiert. Nach dem Abpipettieren und Verwerfen des Überstands wurden zum verbleibenden DNA-haltigen Pellet zur Reinigung $800 \mu \mathrm{l} 70 \%$ Ethanol pipettiert und bei $45{ }^{\circ} \mathrm{C}$ mit $1400 \mathrm{rpm}$ im Schüttelinkubator inkubiert. Anschließend wurde erneut für 5 
min bei $4{ }^{\circ} \mathrm{C}$ mit 14000 rpm zentrifugiert, danach der flüssige Überstand verworfen und das Pellet für 30 min bei Raumtemperatur unter dem Abzug getrocknet.

Das Pellet wurde nun mit $6 \mu \mathrm{l}$ deionisiertem Formamid (Fluka Biochemika; Buchs, $\mathrm{CH}$ ) resuspendiert und im Thermomixer bei $37^{\circ} \mathrm{C}$ und 1400 rpm für 60 min inkubiert.

Da auf den Objektträgern die noch vorhandenen Proteinrückstände des Zellkerns die spätere Auswertung aufgrund unspezifischer Hybridisierung beeinflussen könnten, wurden die Objektträger im Vorfeld einer proteolytischen Pepsin-Behandlung unterzogen. Dazu wurde eine Glasküvette mit $70 \mathrm{ml}$ Aqua dest. Im Wasserbad auf 37 ${ }^{\circ} \mathrm{C}$ erwärmt. Nach dem Hinzufügen von $20 \mu \mathrm{l}$ Pepsin $(100 \mathrm{mg} / \mathrm{ml}$, Sigma, St. Louis, USA) und von $700 \mu \mathrm{l} 1 \mathrm{~N} \mathrm{HCl}$ (Merck, Darmstadt, Deutschland) in eine Glasküvette wurden die Objektträger für 5 min darin belassen. Zum Abstoppen der Reaktion folgte für 5 min eine Küvette mit 2x SSC (siehe Tabelle 2.2.3/2, S. 34) und die Dehydrierung in aufsteigender Alkoholreihe mit $70 \%, 85 \%$ und $100 \%-20{ }^{\circ} \mathrm{C}$ kaltem Ethanol für je 5 min. Die Objektträger wurden nun für 30 min bei Raumtemperatur getrocknet.

Zur Hybridisierung des Ansatzes an DNA-Einzelsträngen muss die in den Chromosomen bisher noch vorliegende Doppelhelix aufgetrennt (denaturiert) werden. Die Denaturierungslösung (siehe Tabelle 2.2.3/2, S. 34) wurde in einer Glasküvette im Wasserbad auf $69{ }^{\circ} \mathrm{C}$ gebracht und jeweils 2 Objektträger aus der feuchten Kammer (Hybrite) genommen und für $2 \mathrm{~min}$ bei $69{ }^{\circ} \mathrm{C}$ in der Lösung belassen. Die anschließende Dehydrierung erfolgte nun in einer Küvette mit aufsteigender Alkoholreihe für jeweils 5 min mit 70\%, 85\% und 100\% $-20^{\circ} \mathrm{C}$ kaltem Ethanol. Bei Raumtemperatur wurden die Objektträger getrocknet und bei $37{ }^{\circ} \mathrm{C}$ wiederum auf die Wärmeplatte der feuchten Kammer gelegt.

Den Proben im Eppendorf-Cup wurden $7 \mu \mathrm{l}$ Master Mix (siehe Tabelle 2.2.3/2, S. 34) zur Stabilisierung der DNA hinzugefügt und im Anschluss für 6 min bei $78{ }^{\circ} \mathrm{C}$ im Thermomixer denaturiert. Nach Zentrifugation wurden $13 \mu \mathrm{l}$ des DNA-Mix zur Hybridisierung auf den Objektträger pipettiert. Der Objektträger wurde nun mit einem 15 x $15 \mathrm{~mm}$ Deckglas luftblasenfrei eingedeckelt, mit Fixogum (Marabu, Tamm, Deutschland) verschlossen, sowie anschließend für 72 Stunden in der feuchten Kammer belassen. In dieser Zeit fand die Hybridisierungsreaktion statt, in der die einzelnen DNA-Fragmente, sowohl der Tumor- als auch der Referenz-DNA, um die 
homologen Bindungsstellen auf den Metaphase-Chromosomen konkurrieren und, je nach Mengenverhältnis, binden.

Tabelle 2.2.3/2

Materialien - Hybridisierung

\begin{tabular}{|c|c|}
\hline Name & Zusammensetzung \\
\hline $\begin{array}{l}\text { 20xSSC } \\
\text { (Strong Salt Concentration) }\end{array}$ & 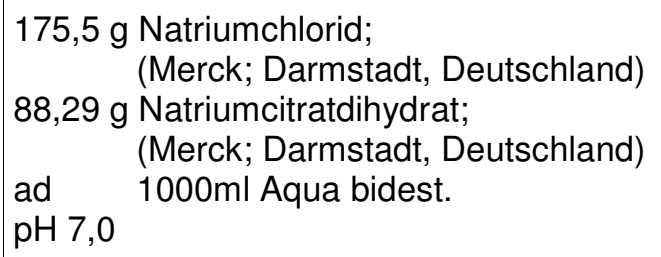 \\
\hline Denaturierungslösung & $\begin{array}{ll}5 \mathrm{ml} & 20 \times \mathrm{SSC}, \mathrm{pH} 7,0 \\
5 \mathrm{ml} & 0,5 \mathrm{M} \mathrm{NaH}_{2} \mathrm{PO}_{4}, \mathrm{pH} 7 \\
& \text { (Merck, Darmstadt, Deutschland) } \\
5 \mathrm{ml} & \text { Aqua bidest } \\
35 \mathrm{ml} & \text { deionisiertes Formamid } \\
& \text { (Merck, Darmstadt, Deutschland) } \\
\mathrm{pH} \mathrm{7,0} & \end{array}$ \\
\hline Master-Mix & $\begin{array}{ll}30 \% & \text { Dextransulfat } \\
& \text { (Merck; Darmstadt, Deutschland) }\end{array}$ \\
\hline
\end{tabular}

Nach 72 Stunden wurde (nach Entfernung des Deckgläschens) zur Entfernung von Rückständen, sowie unspezifisch hybridisierter DNA, ein dreimaliger Waschvorgang im Schüttelbad bei $42{ }^{\circ} \mathrm{C}$ in einer Küvette mit Waschlösung $A$ (siehe Tabelle 2.2.3/3, S. 35) durchgeführt. Es folgte ein dreimaliger Waschvorgang bei $42{ }^{\circ} \mathrm{C}$ mit Waschlösung B (siehe Tabelle 2.2.3/3, S. 35).

Unspezifische Bindungen durch die Fluoreszenz-Antikörper wurden durch $300 \mu \mathrm{l}$ Blockinglösung (siehe Tabelle 2.2.3/3, S. 35) blockiert und nach Inkubation für $30 \mathrm{~min}$ bei $37^{\circ} \mathrm{C}$ in der feuchten Kammer erfolgte die Deckelung der Objektträger.

Lichtgeschützt wurden nun, nach einem Waschvorgang mit $2 \mathrm{ml}$ der Waschlösung $\mathrm{C}$ (siehe Tabelle 2.2.3/3, S. 35), $300 \mu \mathrm{l}$ der Detektionslösung (siehe Tabelle 2.2.3/3, S. 35) mit den lichtempfindlichen fluoreszierenden Antikörpern gegen Biotin und Digoxigenin auf die Objektträger pipettiert und erneut bei $37{ }^{\circ} \mathrm{C}$ für $60 \mathrm{~min}$ in der feuchten Kammer inkubiert. 
Tabelle 2.2.3/3

Materialien - Hybridisierung

\begin{tabular}{|c|c|c|}
\hline Name & Zusam & imensetzung \\
\hline Waschlösung A & $\begin{array}{l}70 \% \\
2 x\end{array}$ & $\begin{array}{l}\text { deionisiertes Formamid } \\
\text { SSC }\end{array}$ \\
\hline Waschlösung B & $\begin{array}{l}0,1 \% \\
2 x\end{array}$ & $\begin{array}{l}\text { Tween } 20 \\
\text { SSC }\end{array}$ \\
\hline Waschlösung C & $\begin{array}{l}0,1 \% \\
2 x\end{array}$ & $\begin{array}{l}\text { Tween } 20 \\
\text { SSC }\end{array}$ \\
\hline Blockinglösung & $\begin{array}{l}3 \% \\
0,1 \% \\
4 x\end{array}$ & $\begin{array}{l}\text { bovines Serumalbumin (BSA), } \\
\text { (SIGMA; St. Louis, USA) } \\
\text { Tween } 20 \\
\text { SSC }\end{array}$ \\
\hline Detektionspuffer & $\begin{array}{l}4 \mathrm{x} \\
1 \% \\
0,1 \%\end{array}$ & $\begin{array}{l}\text { SSC } \\
\text { BSA } \\
\text { Tween } 20\end{array}$ \\
\hline Detektionslösung & $\begin{array}{l}300 \mu \mathrm{l} \\
1,5 \mu \mathrm{l} \\
5 \mu \mathrm{l}\end{array}$ & $\begin{array}{l}\text { Detektionspuffer } \\
\text { Fluoresceinisothiocyanat-Avidin } \\
\text { (Vector; Burlingame, USA) } \\
\text { anti-Digoxiginin-Rhodamin } \\
\text { (Roche; Mannheim, Deutschland) }\end{array}$ \\
\hline DAPI-Eindeckelungsmedium & $\begin{array}{l}1 \mathrm{ml} \\
50 \mu \mathrm{l} \\
1 \mu \mathrm{l}\end{array}$ & $\begin{array}{l}\text { Vectashield (Vector Laboratories; Burlingame, USA) } \\
\text { Actinomycin (SIGMA; St. Louis, USA) } \\
\text { Diamino-2-phenylindol (SIGMA; St. Louis, USA) }\end{array}$ \\
\hline
\end{tabular}

Um die ungebundenen Antikörper zu entfernen, wurde ein dreimaliger Waschvorgang von je 5 min bei $42^{\circ} \mathrm{C}$ mit Waschlösung $C$ in einem Schüttelwasserbad angeschlossen.

Die Präparate wurden mit je $20 \mu \mathrm{l}$ DAPI-Eindeckelungsmedium (siehe Tabelle 2.2.3/3) eingedeckelt, die zur Gegenfärbung der einzelnen Chromosomen DAPI enthielt. Das langsame Ausbleichen der Fluochrome beschränkt die Fluoreszenzaufnahme auf ca. 14 Tage. Die Objektträger wurden anschließend bei $4^{\circ} \mathrm{C}$ lichtgeschützt gelagert.

\section{Auswertung}

Die Auswertung der Metaphasen erfolgte nach Aufnahme monochromer Bilder mit dem Programm SmartCapture2 (Vysis, Downers Grove, USA) durch eine computergekoppelte CCD-Kamera (Sensys Photometrics SENSYS; München, Deutschland) bei 880facher Vergrößerung und 8bit-Farbtiefe (256 Graustufen) mittels der Software Quips Karyotyping/CGH (Vysis, Downers Grove, USA). Als Mikroskop 
kam ein Axioskop 2 (ZEISS, Göttingen, Deutschland) mit 10er, 20er und 63er Objektiv (10x, 20x, 63x Ölimmersion, ZEISS, Göttingen, Deutschland) zum Einsatz. Die Ausleuchtung erfolgte durch eine Quecksilberdampflampe (HBO mit selbstjustierender Ausleuchtung; ZEISS, Göttingen, Deutschland), deren Licht durch ein softwareseitig gesteuertes Filterrad (Ludl-Filterrad, Ludl, Hawthorne, USA) mit einem anti-DigoxigininRhodamin(FITC)-Filter, einem Fluoresceinisothiocyanat(TRITC)-Filter und einem DAPIFilter geschickt wurde.

\section{Summeninterpreter}

Durch die Generierung eines Summeninterpreters mittels der CGH-Software aus durchschnittlich 15 - $20 \mathrm{CGH}$-Profilideogrammen wurden unerwünschte Rauscheffekte minimiert. Die Schwellenwerte für Verluste und Gewinne wurden für jede Hybridisierung individuell festgelegt (für Gewinne zwischen 1,15 bis 1,20 und für Verluste 0,80 bis 0,85$)$. Von einer Amplifikation, einer höheren Kopienzahlvermehrung, wurde bei einem Wert ab 1,5 gesprochen. In Einzelfällen wurden diese Schwellenwerte verändert, wenn anhand des Interpreters eine deutlicher Trend zu beobachten war, der durch die Werte des 95\% Konfidenzintervalls als signifikant angezeigt wurde. Die Beschreibung der Veränderungen erfolgte entsprechend der Nomenklatur für humane Chromosomen für in-situ-Hybridisierung (Mitelmann 1995).

Nicht bewertet wurden chromosomale Imbalanzen auf Chromosom 1p32-pter, 13p, 14p, 15p, 19, 21p, 22p, den Telomeren, den Zentromeren und in heterochromatinreichen Abschnitten auf 1q, 9q, 16q, Yq (Kallioniemi O et al. 1994).

\subsubsection{Mutationsanalyse}

Für die Mutationsanalyse wurden schockgefrorene Gewebeproben verwendet. Diese wurden, nach Amplifikation der entsprechenden Genabschnitte mittels PCR, nach dem Sanger-Vefahren sequenziert. Bei diesem Verfahren wird an den zu sequenzierenden DNA-Einzelstrang ein Primer hybridisiert, an dem die DNA-Polymerase die Synthese des komplementären Strangs beginnt. In 4 Ansätzen wird neben den Nukleosidtriphosphaten als Bausteinen der DNA nun eine kleine Menge Dideoxynukleosidtriphosphat (ddATP, ddGTP, ddCTP und ddTTP) beigemischt. Der 
Einbau eines ddNTP stoppt die DNA-Polymerase und es kommt zum Kettenabbruch. Es entstehen so in den vier Ansätzen unterschiedlich lange Ketten, die jeweils mit dem entsprechenden ddNTP enden. Die Ansätze werden letztlich nebeneinander gelelektrophoretisch aufgetrennt und autoradiographisch identifiziert. Die Sequenz läßt sich so aus dem Gel direkt ablesen.

\section{PCR}

Das Prinzip der PCR beruht auf einer exponentiellen Vermehrung spezifischer DNASequenzen, bei der ein DNA-Doppelstrang denaturiert und die Einzelstränge dann mit Hilfe der DNA-Polymerase des thermophilen Bakteriums Thermus aquaticus (Taq) wieder zu jeweils einem neuen Doppelstrang hybridisiert werden. Die PCR ermöglicht die Amplifikation spezifischer DNA-Fragmente selbst aus einer sehr kleinen Ausgangsmenge DNA. Die so gewonnene DNA kann dann auf Mutationen untersucht werden.

Schema der einzelnen PCR-Sequenz:

a) Denaturierung ("Aufspaltung") des DNA-Doppelstrangs durch Erhitzen auf $94{ }^{\circ} \mathrm{C}$

b) Hybridisierung (,Annealing“) von zwei komplementären Primern an die DNA-Einzelstränge bei $57^{\circ} \mathrm{C}$

c) Elongation der DNA-Einzelstränge durch die Polymerase bei $72{ }^{\circ} \mathrm{C}$.

Die PCR erfolgte vollautomatisch mit dem Thermocycler Primus 25 (MWG-Biotech, Ebersberg, Deutschland). Die DNA für die PCR wurde nach dem in Kapitel 2.2.2 beschriebenen Verfahren aus schockgefrorenen Gewebeproben extrahiert.

Zur Amplifikation des gewünschten DNA-Abschnitts wurden für die zu untersuchenden Exone folgende Primer (MWG BioTech AG, Ebersberg, Deutschland) verwendet: 
- KIT Exon 9

- Größe der Amplifikate ca. 300 bp

- Forward: 5‘- ATT TAT TTT CCT AGA GTA AGC CAG G -3‘

- Revers: 5' ATC ATG ACT GAT ATG GTA GAC AGA GC -3،

- KIT Exon 11

- Größe der Amplifikate ca. 232 bp

- Forward: 5‘-GTG CTC TAA TGA CTG AGA C-3،

- Revers: 5'-TAC CCA AAA AGG TGA CAT GG-3،

- KIT Exon 13

- Größe der Amplifikate ca. 330 bp

- Forward:: 5'- GCT TGA CAT CAG TTT GCC AG -3“

- Revers: 5'-GCA AGA GAG AAC AAC AGT CTG GGT AA-3،

- KIT Exon 17

- Größe der Amplifikate ca. 450 bp

- Forward: 5'- TGA ACA TCA TTC AAG GCG TAC TTT TG -3“

- Revers: 5' TTG AAA CTA AAA ATC CTT TGC AGG AC -3‘

-PDGFRA Exon 12

- Größe der Amplifikate ca. 250 bp

- Forward: 5'- TCC AGT CAC TGT GCT GCT TC -3‘

- Revers: 5'- GCA AGG GAA AAG GGA GTC TT -3‘

- PDGFRA Exon 18

- Größe der Amplifikate ca. 250 bp

- Forward: 5‘- ACC ATG GAT CAG CCA GTC TT -3،

- Revers: 5'- TGA AGG AGG ATG AGC CTG ACC -3‘

Unter Vermeidung einer Fremd-DNA-Kontamination wurde der PCR-Ansatz nach

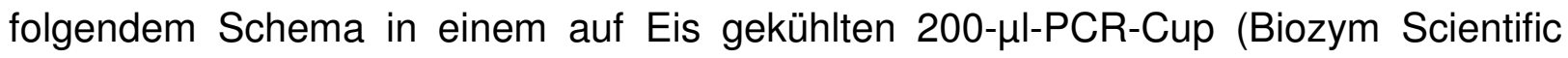
$\mathrm{GmbH}$, Hess, Oldendorf, Deutschland) pipettiert: 


$$
\begin{aligned}
& 37,0 \mu \mathrm{l} \quad \mathrm{H}_{2} \mathrm{O} \\
& 5,0 \mu \mathrm{l} \quad 10 x \text { Puffer } \\
& \text { (Life Technologies, Invitrogen, Karlsruhe, Deutschland) } \\
& 1,5 \mu \mathrm{l} \quad \mathrm{MgCl}_{2}(50 \mathrm{mM} \text {, } \\
& \text { (Life Technologies, Invitrogen, Karlsruhe, Deutschland) } \\
& 2,0 \mu \mathrm{l} \quad \text { Forward Primer }(10 \mathrm{pmol} / \mu \mathrm{l}) \\
& \text { 2,0 } \mu \mathrm{l} \quad \text { Reverse Primer (10 pmol/ } / \mathrm{l}) \\
& 1,0 \mu \mathrm{l} \quad \text { dNTP's }(10 \mathrm{mM}) \\
& \text { (Life Technologies, Invitrogen, Karlsruhe, Deutschland) } \\
& 1,0 \mu \mathrm{l} \quad \text { Template DNA } \\
& \text { bzw. für die Negativkontrolle 1,0 } \mu \text { l Ampuwa } \\
& 0,2 \mu \mathrm{l} \quad \text { Platinium Taq Polymerase }(5 \mathrm{U} / \mu \mathrm{l}) \\
& \text { (Life Technologies, Invitrogen, Karlsruhe, Deutschland). }
\end{aligned}
$$

Der Ansatz wurde für $10 \mathrm{~s}$ kräftig geschüttelt, $1 \mathrm{~s}$ abzentrifugiert und je $49 \mu \mathrm{l}$

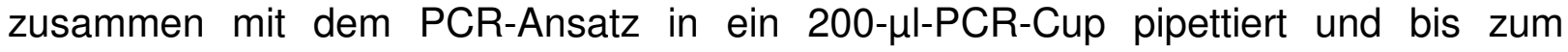
vollständigen Hochheizen des Thermocyclers auf Eis belassen.

PCR-Bedingungen im Thermocycler:
a) Initiale Denaturierung $94{ }^{\circ} \mathrm{C}$
$3 \min$
b) 35 - 40 Amplifikations-Zyklen:

$\begin{array}{rll}\text { 1) } & 94^{\circ} \mathrm{C} & 40 \mathrm{~s} \\ \text { 2) } & 57^{\circ} \mathrm{C} & 40 \mathrm{~s} \\ \text { 3) } & 72{ }^{\circ} \mathrm{C} & 35 \mathrm{~s} \\ \text { c) Letzte Extension } & 72^{\circ} \mathrm{C} & 5 \mathrm{~min} .\end{array}$

Nach der PCR wurden die PCR-Produkte bei $-20{ }^{\circ} \mathrm{C}$ bis zur weiteren Verwendung gelagert.

Im Anschluss an die PCR erfolgte eine Gelelektrophorese zur Kontrolle der Quantität und der Fragmentlängen analog der Gelelektrophorese bei der DNA-Isolierung (siehe Kapitel 2.2.2 DNA-Isolierung). Als Längenstandard wurde pUC19 DNA/Mspl (Hpall) Marker, 23 (\#SM0221, MBI-Fermentas; St. Leon-Rot, Deutschland) verwendet. Stellte sich in der Gelelektrophorese heraus, dass die mitgeführte Negativkontrolle positiv war, wurden alle Ansätze dieser PCR verworfen. 
Die Aufreinigung der PCR-Produkte erfolgte mit dem Wizard SV Gel and PCR CleanUp System (Promega, Mannheim, Deutschland) nach den Angaben des Herstellers. Die DNA wurde anschließend bis zur weiteren Verwendung bei $4{ }^{\circ} \mathrm{C}$ gelagert.

\section{DNA-Sequenzierung}

Die Sequenzierung wurde durch die Seqlab GmbH (Göttingen, Deutschland) nach dem Sanger-Verfahren mit fluoreszenzfarbstoffmarkierten BigDye-Terminatoren (Version 3.1) auf automatischen Sequenzierern (Modell 3100, Applied Biosystems, Darmstadt, Deutschland) vorgenommen.

\subsubsection{Statistische Auswertung}

Die statistische Auswertung der Ergebnisse wurde mit dem Programm SPSS Version 16 (SPSS Inc., Chicago, USA) vorgenommen. Zur Anwendung kamen für die

lokalisationsabhängigen Auswertungen der klinisch-pathologischen Parameter und chromosomalen Imbalanzen der exakte Test nach Fisher sowie der WilcoxonRangsummen-Test. Für die Überlebenszeit- bzw. Progressanalysen wurden der LogRank-Test und Kaplan-Meier-Analysen angewandt. 


\section{Ergebnisse}

\subsection{Kollektiv}

Es wurden 67 GIST (64 Primär-GIST, 3 Metastasen) von 64 Patienten (56,3\% Männer und $43,8 \%$ Frauen) im Alter von 35 - 86 Jahren (Median 66 Jahre) bei Diagnosestellung untersucht (einen Überblick gibt Tabelle 6.1/1 im Anhang, S. 91). Das Erkrankungsalter der Frauen lag mit 39 - 86 Jahren (Median 70 Jahre) höher ( $p=$ 0,047) als das der Männer zwischen 35 - 84 Jahren (Median 64 Jahre).

Bei den vorliegenden 3 Metastasen handelt es sich bei der Nr. 38m um eine Peritonealmetastase des Primärtumortumors Nr. 38. Die Nr. 50m und 59m sind jeweils Lebermetastasen zu den Primärtumoren Nr. 50 bzw. 59.

\subsubsection{Lokalisation}

1,6\% (1 / 64) der Primärtumoren lagen im Ösophagus, 67,2\% (43 / 64) im Magen, 18,8\% (12 / 64) im Dünndarm, 6,3\% (4 / 64) im Dickdarm, 6,3\% (4 / 64) im Peritoneum. Damit lagen 68,8\% (44 / 64) der Primär-GIST proximal des Dünndarms und 25\% (16 / 64) im Dünn- bzw. Dickdarm.

\subsubsection{Tumorgröße}

Die Primärtumorgröße betrug im Median 6,5 $\mathrm{cm}(1,6$ bis $30 \mathrm{~cm})$ und war bei Männern leicht größer als bei Frauen (Median 7,0 vs. $5,25 \mathrm{~cm}$ ). In einem Fall (Nr. 10) lag keine Angabe zur Tumorgröße vor. In Abhängigkeit von der Lokalisation war die Tumorgröße der proximalen GIST kleiner $(p=0,036)$ als die der distal des Magens gelegenen Tumoren (Median 6,0 vs. 8,0 cm). Dabei war der Anteil der "high-risk"-Tumoren (nach Fletcher) in den proximalen Tumoren (14/44) signifikant niedriger $(p=0,017)$ als in den distalen (11/16). Die Metastasen hatten eine Größe von im Median 1,2 cm (0,6 $7,0 \mathrm{~cm})$. 


\subsubsection{Immunhistochemie}

Die im Dünn- und Dickdarm gelegenen GIST waren zu 100\% CD117-positiv, ebenso die 4 im Peritoneum gelegenen und der 1 ösophageale GIST (Tabelle 3.1.3/1). Bei den Tumoren im Magen waren 97,7\% CD117-positiv.

90,7\% der Magen-, 33,3\% der Dünndarm- und 100\% der Dickdarm-GIST waren CD34positiv ( $p<0,001)$. Dabei wiesen die proximalen Tumoren signifikant häufiger ( $p=$ $0,003)$ eine Anfärbung von CD34 auf (39/44) als die distal gelegenen (8/16).

Die Anfärbung mit SMA schwankte je nach Lokalisation zwischen 46,5\% (Magen) und $58,3 \%$ (Dünndarm) bis hin zu 75,0\% bei den Dickdarm-GIST. Der vorliegende Fall eines ösophagealen GIST (Fall 1) war SMA-positiv. Bei 41,8\% (28/67) der GIST ergab die Anfärbung mit Desmin kein auswertbares Ergebnis, so dass auf die Darstellung der Ergebnisse hier verzichtet wird.

Tabelle 3.1.3/1

Immunhistochemische Ergebnisse von 64 Primär-GIST

\begin{tabular}{|c|c|c|c|c|}
\cline { 2 - 5 } \multicolumn{1}{c|}{} & CD117 & CD34 & SMA & S100 \\
\hline Magen (n = 43) & $97,7 \%$ & $90,7 \%$ & $46,5 \%$ & $2,3 \%$ \\
\hline Dünndarm (n= 12) & $100 \%$ & $33,3 \%$ & $58,3 \%$ & $0 \%$ \\
\hline Dickdarm (n = 4) & $100 \%$ & $100 \%$ & $75 \%$ & $50 \%$ \\
\hline Peritoneum ( $\mathbf{n = 4 )}$ & $100 \%$ & $50 \%$ & $50 \%$ & $0 \%$ \\
\hline Ösophagus ( $\mathbf{n = 1 )}$ & $100 \%$ & $0 \%$ & $100 \%$ & $0 \%$ \\
\hline
\end{tabular}

Tabelle 3.1.3/2 zeigt die Ergebnisse der Immunhistochemie bei den 3 im Kollektiv vorhandenen Metastasen. 
Tabelle 3.1.3/2

Immunhistochemische Ergebnisse der Metastasen

\begin{tabular}{|c|c|c|c|c|c|}
\cline { 2 - 5 } \multicolumn{1}{c|}{} & CD117 & CD34 & Aktin & Desmin & S100 \\
\hline Nr. 38 - Primärtumor & 3 & 3 & 0 & 0 & 1 \\
\hline Nr. 38m - Metastase & 3 & 3 & 0 & NA & 1 \\
\hline
\end{tabular}

\begin{tabular}{|c|c|c|c|c|c|}
\hline Nr. 50 - Primärtumor & 3 & 0 & 0 & NA & 0 \\
\hline Nr. 50m - Metastase & 3 & 0 & 3 & NA & 0 \\
\hline
\end{tabular}

\begin{tabular}{|c|c|c|c|c|c|}
\hline Nr. 59 - Primärtumor & 3 & 3 & 2 & NA & 2 \\
\hline Nr. 59m - Metastase & 3 & 3 & 2 & NA & 1 \\
\hline
\end{tabular}

$0=$ negativ, 1 = einzelne Zellen posiiv, 2 = fokale Herde positiv, $3=$ homogen positiv

Zum Vergleich sind zu den Metastasen noch die Ergebnisse der jeweiligen Primärtumoren dargestellt.

\subsubsection{Histomorphologische Dignitätsmerkmale}

Ingesamt zeigten 56,3\% (36/64) der Primär-GIST < 2 Mitosen/10 HPF. Bei der Auswertung von $50 \mathrm{HPF}$ zeigten 66,7\% (34 / 51) < 5 Mitosen / $50 \mathrm{HPF}$. In 20,3\% (13 / 64) lagen keine Daten für die Zahl der Mitosen / 50 HPF vor. Einen Überblick über die Risikoklassifikation der GIST nach Franquemont, nach Fletcher und nach Miettinen gibt Tabelle 3.1/3 sowie Tabelle 6.2/1 im Anhang.

Tabelle 3.1.4/1

Risiko- und Dignitätsklassifikation

\begin{tabular}{|c|c|c|c|c|c|}
\hline \multicolumn{2}{|c|}{$\begin{array}{c}\text { Risikoklassifikation } \\
\text { nach Franquemont }\end{array}$} & \multicolumn{2}{|c|}{$\begin{array}{l}\text { Risikoklassifikation } \\
\text { nach Fletcher }\end{array}$} & \multicolumn{2}{|r|}{ Dignität nach Miettinen* } \\
\hline$n=29$ & $\begin{array}{l}\text { High-risk } \\
\text { (16 männl., } 13 \text { weibl.) }\end{array}$ & $\mathrm{n}=29$ & $\begin{array}{l}\text { High-risk } \\
\text { (17 männl., } 12 \text { weibl.) }\end{array}$ & $n=15$ & $\begin{array}{l}\text { Wahrscheinlich benigne } \\
\text { (7 männl., } 8 \text { weibl.) }\end{array}$ \\
\hline \multirow[t]{3}{*}{$\mathrm{n}=35$} & $\begin{array}{l}\text { Low-risk } \\
\text { (20 männl., } 15 \text { weibl.) }\end{array}$ & $n=18$ & $\begin{array}{l}\text { Intermediate-risk } \\
\text { (12 männl., } 6 \text { weibl.) }\end{array}$ & $n=15$ & $\begin{array}{l}\text { Niedrig malignane } \\
\text { (10 männl., } 5 \text { weibl.) }\end{array}$ \\
\hline & & $n=15$ & $\begin{array}{l}\text { Low-risk } \\
\text { (6 männl., } 9 \text { weibl.) }\end{array}$ & $n=29$ & $\begin{array}{l}\text { Wahrscheinlich maligne } \\
\text { (17 männl., } 12 \text { weibl.) }\end{array}$ \\
\hline & & $n=2$ & $\begin{array}{l}\text { Very low-risk } \\
\text { (1 männl., } 1 \text { weibl.) }\end{array}$ & & \\
\hline
\end{tabular}

*5 Primär-GIST wurden aufgrund ihrer Lokalisation (1x Ösophagus (Fall 1), 4x Peritoneum (Fall 61 - 64)) nicht nach Miettinen klassifiziert. 
Abbildung 3.1.4/1 veranschaulicht die wesentlichen Kriterien (Tumorgröße und Mitosenzahl / 10 HPF) für die Risiko-/Dignitätsklassifikation.

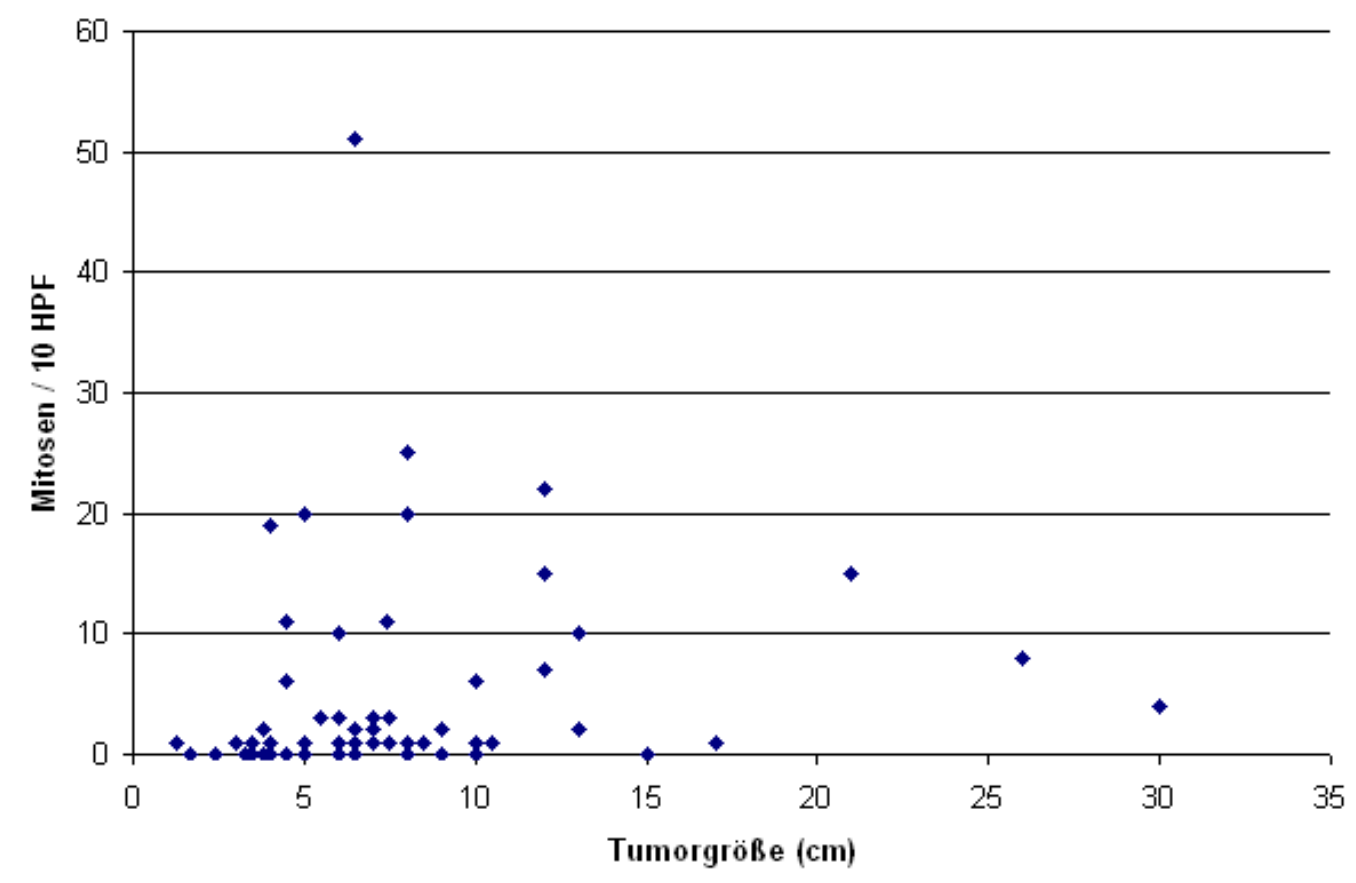

Abbildung 3.1.4/1

Zusammenhang zwischen Tumorgröße und Mitosenzahl / 10 HPF

$77,8 \%$ (14 / 18) der Tumoren < $5 \mathrm{~cm}$ wurden nach Miettinen als benigne bzw. niedrig maligne eingestuft, bei einer Größe >= $5 \mathrm{~cm}$ sank der Anteil auf 37,5\% (15/40) ( $p=$ $0,0096)$. Die Anzahl der Mitosen in der Gruppe der niedrig malignen und benignen Tumoren lag in allen 30 Fällen < 2/10 HPF, während 24 / 29 malignen Tumoren Mitoseraten $>=2 / 10$ HPF aufwiesen $(p<0,001)$. Die proximal gelegenen GIST zeigten einen signifikant $(p=0,041)$ geringeren Anteil $(14 / 44)$ Tumoren mit $>=2$ Mitosen/10 HPF als die distalen Tumoren (10 / 16). "High-risk"-GIST nach Franquemont zeigten in 93,1\% (27 / 29) und "low-risk"-GIST in 2,9\% (1 / 35) >= 2 Mitosen/10 HPF $(p<0,001)$.

\subsubsection{Therapie}

Alle 64 Patienten wurden primär einer operativen Therapie zugeführt. In 56 Fällen konnte eine R0-, in 5 Fällen ein R1- und in 1 Fall ein R2-Resektionsergebnis erreicht werden. In 3 Fällen (Nr. 8 und 17) war keine Angabe zum Resektionsergebnis verfügbar. 
16 Patienten erhielten postoperativ eine Therapie mit Imatinib (Glivec®). Je nach Resektionsstatus wurden die Patienten in folgende Gruppen eingeteilt:

- Imatinib-Gruppe 1: nach R0-Resektion:

3 Patienten: Fall 11 und 49 bei intraoperativer Perforation des Tumors, Fall 57 mit knapper R0-Resektion

- Imatinib-Gruppe 2: nach R0-Resektion mit synchronen Metastasen:

4 Patienten: Fall 41, 50, 51 und 54

- Imatinib-Gruppe 3: nach R0-Resektion bei Rezidiv im Follow-Up :

5 Patienten: Fall 37, 39, 40, 53 und 58

- Imatinib-Gruppe 4: nach R1-Resektion:

4 Patienten: Fall 18, 38, 59 und 60.

\subsubsection{Follow-Up}

Der Follow-Up-Zeitraum betrug zwischen 1 und 112 Monate (Median 39 Monate). In 1 Fall lag keine Angabe zum Follow-Up vor (Nr. 35). Der Median bei den Frauen $(n=27)$ lag dabei bei 28 Monaten, bei den Männern $(n=36)$ bei 43,5 Monaten. 28,1\% (18 / 64) der Primärtumoren zeigten im Follow-Up einen Progress. Bei diesen Tumoren handelte es sich in 10,9\% (7 / 64) um Magen-, in 6,3\% (4 / 64) um Dünndarm-, in 4,7\% (3 / 64) um Dickdarm- und in 6,3\% (4/64) um Peritoneal-GIST. Von den 64 Patienten verstarben 7,8\% (5/64) nach einem Verlauf von 2 bis 76 Monaten (Median 19 Monate) am Tumorleiden (Nr. 41, 59, 61, 62 und 64). Insgesamt 10,9\% (7 / 64) erlagen einem Zweitleiden (Fall 20 am Rezidiv eines Barrettkarzinoms, Fall 26 an den Folgen eines metastasierten Bronchialkarzinoms, Fall 27 an den Folgen eines metastasierten papillären Ovarialkarzinoms, Fall 31 an den Folgen einer KHK und Fall 63 an den Folgen einer nicht näher bekannten kardialen Erkrankung. In den Fällen 30 und 48 lagen keine näheren Angaben zum Zweitleiden vor). 


\section{Follow-Up und Lokalisation}

15,9\% ( 7 / 44) der proximalen und 43,8\% (7 / 16) der distalen Primär-GIST zeigten einen Progress im Laufe des Follow-Up $(p=0,038)$. Alle peritonealen GIST $(n=4)$ waren progredient.

Tabelle 3.1.6/1

Primärtumorgröße und Progress bei den Primär-GIST

\begin{tabular}{|c|c|c|}
\hline Größe & Häufigkeit in $\%$ & Progress \\
\hline$<5 \mathrm{~cm}$ & $27,6 \%(18 / 63)$ & $0,0 \%(0 / 18)$ \\
\hline $5-10 \mathrm{~cm}$ & $54,0 \%(34 / 63)$ & $32,4 \%(11 / 34)$ \\
\hline$>10 \mathrm{~cm}$ & $17,5 \%(11 / 63)$ & $63,6 \%(7 / 11)$ \\
\hline
\end{tabular}

Die Magen-GIST ( $n=43$ ) zeigten mit im Median 34,0 vs. 14,0 Monaten eine signifikant längere rezidivfreie Überlebenszeit $(p=0,002)$ im Vergleich mit dem Restkollektiv.

\section{Follow-Up und Tumorgröße}

In der Gruppe mit Progress (18 / 63) war die Tumorgröße mit $8 \mathrm{~cm}$ (Median) signifikant größer $(p=0,0036)$ als in der Gruppe ohne Tumorprogress (45/63) mit im Median 6 $\mathrm{cm}$ (Tabelle 3.1.6/1). Bei den Primärtumoren $>=5 \mathrm{~cm}$ lag das rezidivfreie Überleben bei 25,0 Monaten (Median), bei den Tumoren $<5 \mathrm{~cm}$ bei 26,5 Monaten (Median). Keiner von 18 Patienten, bei denen der Tumor $<5 \mathrm{~cm}$ war, verstarb im Follow-Up von 7 bis 104 Monaten am Tumorleiden (Median 27 Monate). In der Gruppe der Primärtumoren $>=5 \mathrm{~cm}$ verstarben $11,1 \%(5 / 45)$ am Tumorleiden $(p=0,31$; im Fall Nr. 35 lag keine Angabe zum Überleben vor).

\section{Follow-Up und Mitosen}

Patienten mit Progress zeigten in 88,9\% $(16 / 18)>=2$ Mitosen/10 HPF; bei den Patienten ohne Progress fanden sich nur 26,1\% (12 / 46) GIST >= 2 Mitosen/10 HPF $(p<0,001)$. Das rezidivfreie Überleben bei den GIST mit Mitoseraten $<2 / 10$ HPF war dabei signifikant länger mit im Median 32,0 vs. 19,0 Monaten $(p<0,001)$. 


\section{Follow-Up und Risikoklassifikationen}

Die allgemeine 5-Jahres-Überlebensrate lag bei $80 \%$. Bei den progredienten Primärtumoren handelte es sich in 94,4\% (17 / 18) um zuvor als "high-risk" klassifizierte Tumoren nach Fletcher und nach Franquemont $(p<0,001)$. Bei den nicht progredienten Primärtumoren betrug der Anteil 26,1\% (12/46). Betrachtet man die Klassifikation nach Miettinen, so waren bei den progredienten Tumoren 92,9\% (13 / 14) und bei den nicht progredienten 35,6\% (16/45) als maligne eingestuft worden ( $p<$ $0,001)$. Es zeigte sich eine signifikant kürzere rezidivfreie Überlebenszeit bei den "highrisk"-GIST nach Franquemont und nach Fletcher $(p<0,001)$ sowie bei den malignen GIST nach Miettinen $(p=0,001)$.

Die mediane Überlebenszeit der "high-risk" klassifizierten (nach Fletcher und nach Franquemont) Patienten lag bei 53,5 Monaten. 17,9\% (5 / 28) der Patienten mit "highrisk"-GIST und keiner (0 / 35) der Patienten mit "low-risk"-GIST nach Franquemont und "very-low", "low-" und "intermediate-risk" nach Fletcher verstarben im Verlauf am Tumorleiden ( $p=0,009$ bzw. $p=0,017$ ). Im Fall 35 lag keine Angabe zum Überleben vor. Bei den 5 verstorbenen Patienten handelte es sich in den Fällen 45 und 52 um "high-risk"-GIST nach Fletcher und "low-risk" nach Franquemont (Follow-Up von 105 bzw. 86 Monaten) sowie in den Fällen 31 und 57 um "intermediate-risk" nach Fletcher und "high-risk"-GIST nach Franquemont (Follow-Up von 4 bzw. 19 Monate). Von den malignen GIST nach Miettinen verstarben 7,1\% (2 / 28). Von den restlichen nach Miettinen klassifizierten GIST verstarb kein Patient (0 / 30) im Laufe des Follow-Up ( $p=$ 0,185). 3 der am Tumorleiden verstorbenen Patienten (Fall 61, 62 und 64) konnten nicht nach Miettinen klassifiziert werden, da es sich um peritoneale GIST handelte.

\section{Follow-Up und Metastasen}

Von den 3 Patienten mit Metastasen erhielten alle eine Therapie mit Imatinib. Einer verstarb nach 19 Monaten am Tumorleiden (Fall 59), die beiden anderen zeigten eine "stable disease" (Fall 38 und 50).

\section{Follow-Up und Imatinib}

Die 3 Fälle der Imatinib-Gruppe 1 zeigten im Follow-Up von 19 bis 42 Monaten keinen 
Progress. Von den 4 Fällen der Imatinib-Gruppe 2 (Follow-Up 20 bis 53 Monate) verstarb ein Patient am Tumorleiden (Fall 41), in einem Fall (Fall 54) kam es zu einer partiellen Regression der Lebermetastase und in den restlichen 2 Fällen (Fall 50 und 51) der Gruppe 2 zu einer "stable disease". Innerhalb der Gruppe 3 (Follow-Up 54 bis 111 Monate) kam es im Fall 58 zur Regression, Fall 53 wies eine "stable disease" auf. Von den 4 Fällen der Imatinib-Gruppe 4 (Follow-Up von 19 bis 78 Monate) verstarb ein Patient am Tumorleiden (Fall 59), zwei (Fall 38 und 60) zeigten im Verlauf eine "stable disease" und im Fall 18 zeigte sich kein weiteres Anzeichen eines GIST.

\subsection{Ergebnisse der CGH}

Einen Überblick über die Einzelergebnisse der CGH gibt die Tabelle 6.3/1 (S. 95).

\subsubsection{Chromosomale Imbalanzen}

Die Abbildung 3.2.1/1 zeigt die relativen Häufigkeiten chromosomaler Imbalanzen innerhalb der Gruppe der Primärtumoren. Bei einem Primärtumor (Fall 10) lag kein CGH-Ergebnis vor (technisch nicht gelungen).

Bei den Primärtumoren wurden mit der CGH im Median 4,0 chromosomale Imbalanzen ( 0 bis 21) und in den Metastasen im Median 8,0 ( 0 bis 11) nachgewiesen. Mit im Median 3,0 chromosomalen Verlusten ( 0 bis 12) kamen diese bei den Primärtumoren häufiger vor als Zugewinne oder Amplifikationen mit im Median 0,0 Zugewinnen bzw. Amplifikationen ( 0 bis 13). Bei den Metastasen lag der Median der Verluste bei 5,0 ( 0 bis 8) bzw. bei den chromosomalen Zugewinnen und Amplifikationen bei 0,0 ( 0 bis 6 ).

\subsubsection{Lokalisation}

Die proximalen Primär-GIST $(n=43)$ wiesen im Median 3,0 $(0-21)$ chromosomale Imbalanzen auf. Bei den distalen Tumoren lag der Median bei 5,5 (0 - 17) Imbalanzen. Die Anzahl der chromosomalen Verluste in den proximalen GIST (Median 2,0) lag dabei signifikant ( $p=0,017$ ) unter denen der distalen GIST (im Median 4,0). 


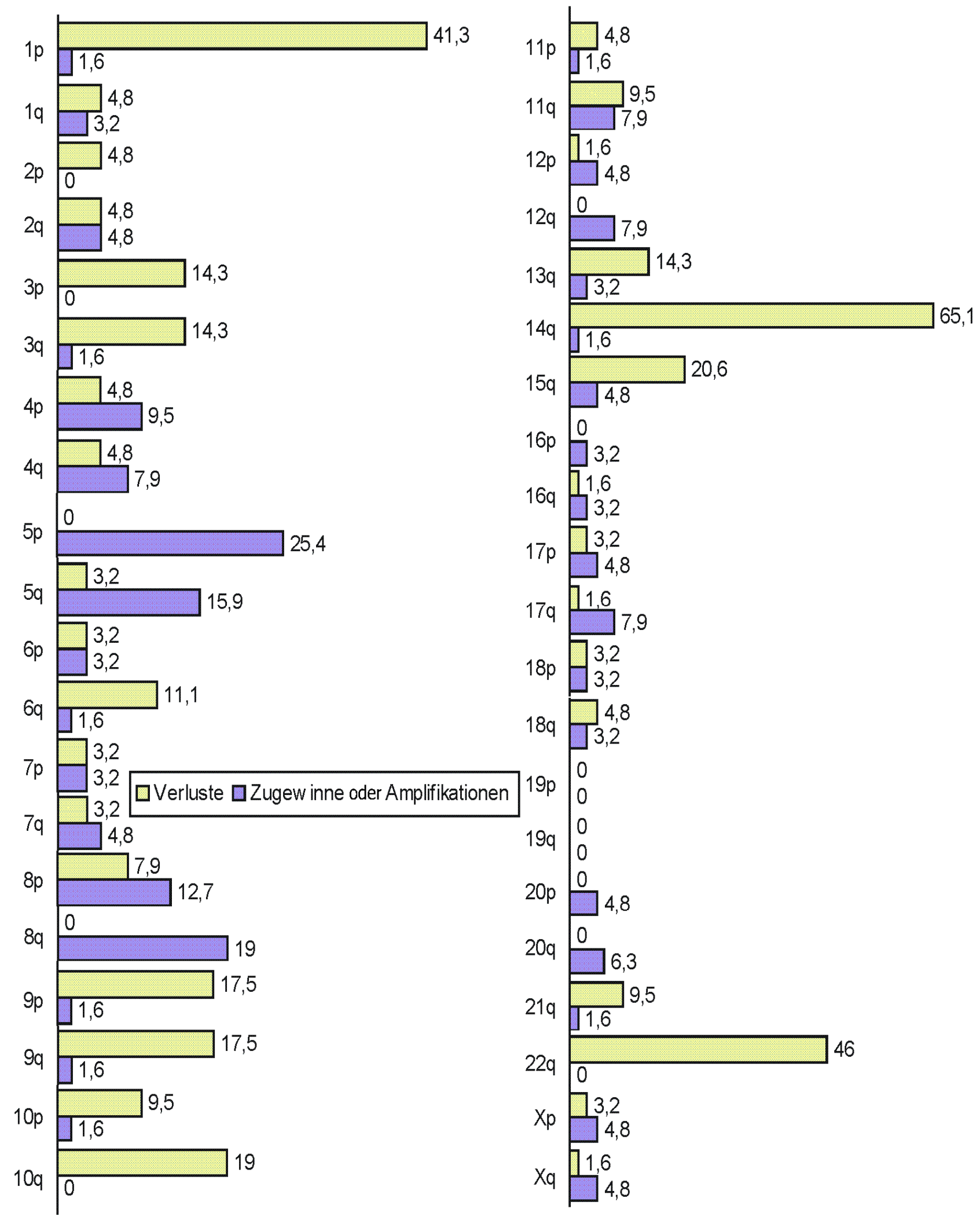

Abbildung 3.2.1/1

CGH - Häufigkeitsverteilung in \% (Primär-GIST) 
Abhängig von der jeweiligen chromosomalen Imbalanz zeigte sich eine unterschiedliche Häufigkeit in proximalen vs. distalen GIST. Tabelle 3.2.2/1 zeigt die Ergebnisse für einige ausgesuchte Imbalanzen.

Am untersuchten Kollektiv ließen sich signifikante Unterschiede bzgl. der Lokalisation für einen Verlust an $14 q(p=0,027 ; 76,7 \%$ vs. $43,8 \%), 1 p(p=0,001 ; 26,2 \%$ vs. $75,0 \%)$ und $15 q(p<0,001 ; 7,0 \%$ vs. $56,3 \%)$ aufzeigen. Der Verlust an $22 q$ erbrachte kein signifikantes Ergebnis $(p=0,139)$.

Tabelle 3.2.2/1

Häufigkeit spezifischer chromosomaler Imbalanzen in Abhängigkeit von der Lokalisation

\begin{tabular}{|c|c|c|c|}
\hline Chromosomale Imbalanz & proximale GIST & distale GIST & $\mathbf{p}$ \\
\hline $\mathbf{- 1 p}$ & $26,2 \%$ & $75,0 \%$ & 0,001 \\
\hline $\mathbf{- 1 4 q}$ & $76,7 \%$ & $43,8 \%$ & 0,027 \\
\hline $\mathbf{- 1 5 q}$ & $7,0 \%$ & $56,3 \%$ & $<0,001$ \\
\hline $\mathbf{- 2 2 q}$ & $37,2 \%$ & $62,5 \%$ & 0,139 \\
\hline
\end{tabular}

\subsubsection{Tumorgröße und Mitosen}

Die Abbildung 3.2.3/1 zeigt die Anzahl der chromosomalen Imbalanzen in Abhängigkeit von der Primärtumorgröße. Dabei ließ sich kein signifikanter Zusammenhang zwischen Tumorgröße $(<5,0 \mathrm{~cm}$ und $>=5,0 \mathrm{~cm})$ und der Anzahl der Imbalanzen feststellen $(p=$ $0,22)$.

Bei 55,6\% (35 / 63) der Primär-GIST < 2 Mitosen/10 HPF lag der Median in der Anzahl chromosomaler Imbalanzen bei 3,0 (0 - 15), bei 44,4\% (28 / 63) der Tumoren $>=2$ Mitosen/10 HPF lag der Median bei 8,0 (0 - 21). Abbildung 3.2.3/2 veranschaulicht diesen Zusammenhang $(p<0,001)$. 


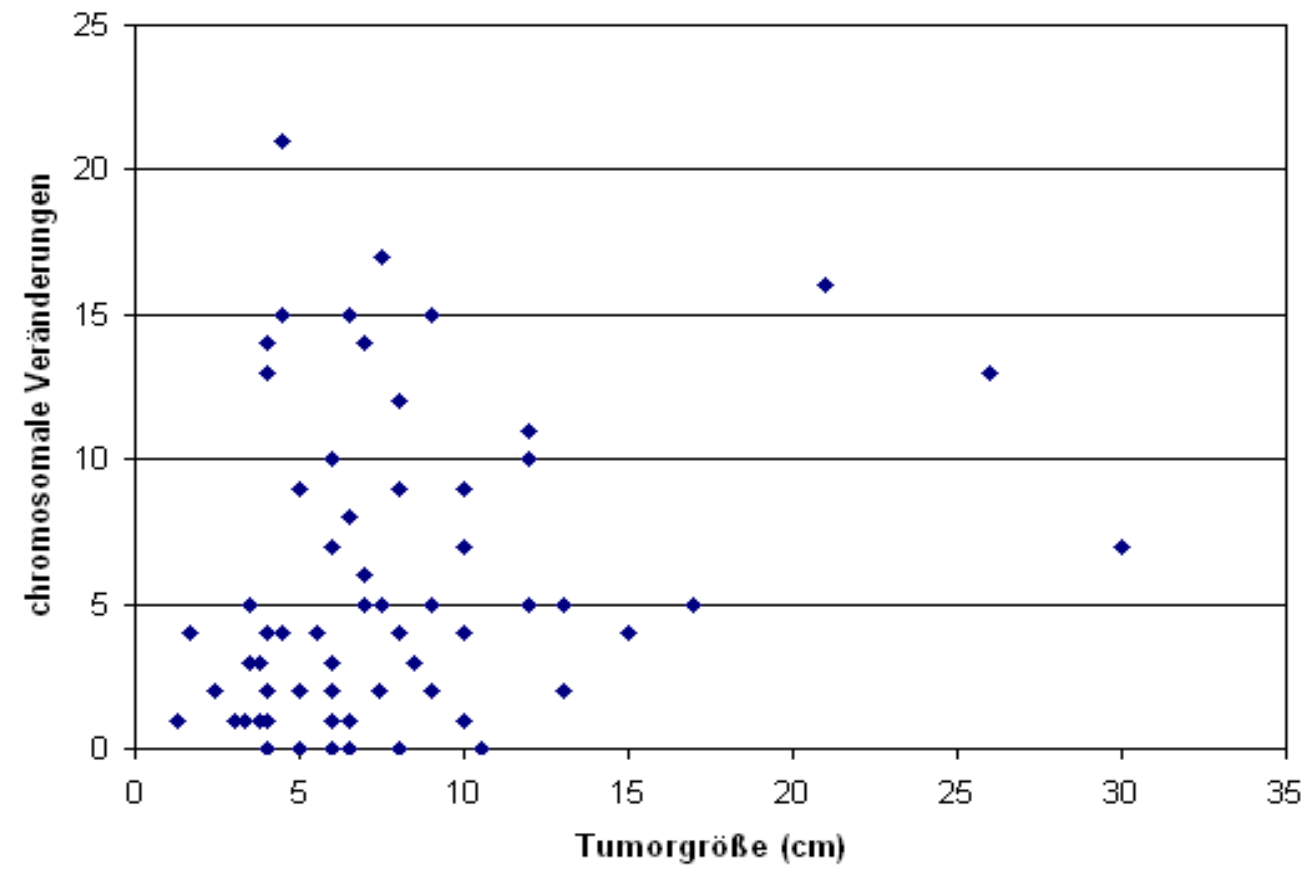

Abbildung 3.2.3/1

Anzahl chromosomaler Veränderungen in Abhängigkeit von der Tumorgröße

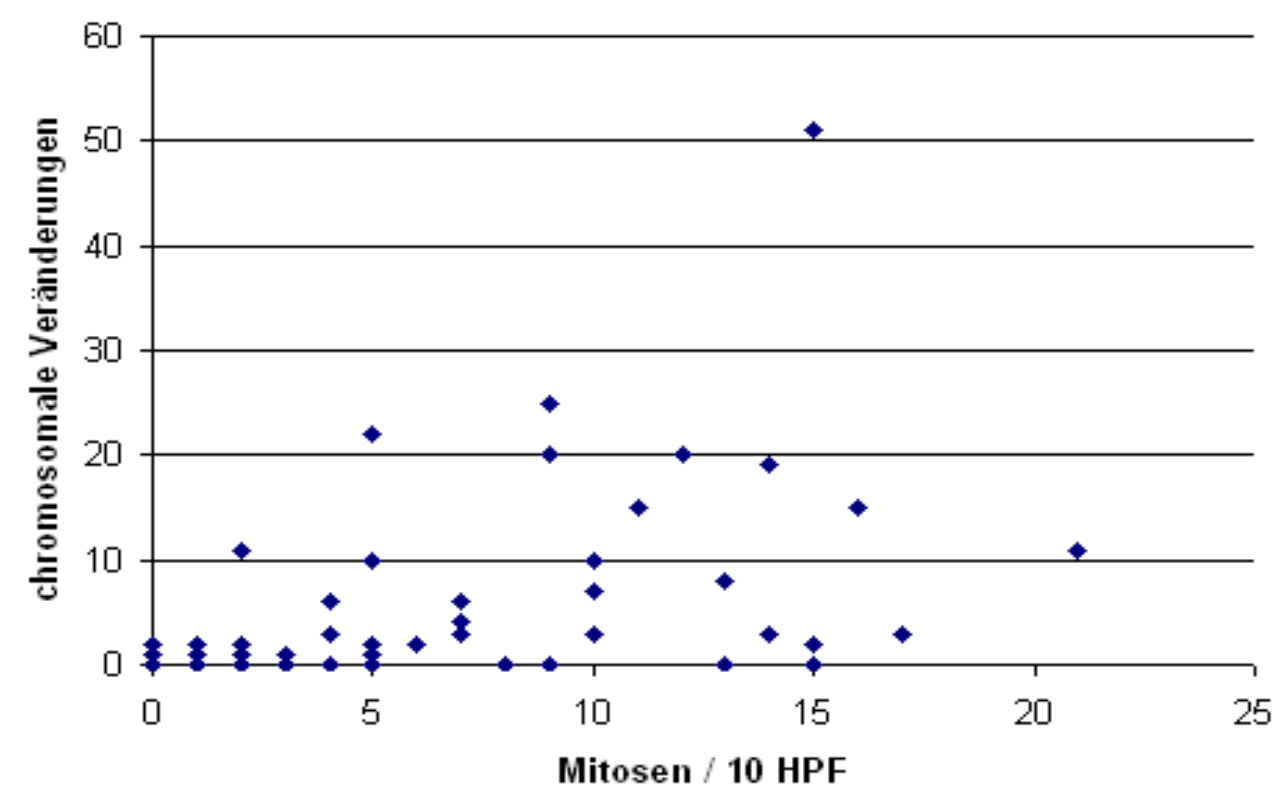

Abbildung 3.2.3/2

Anzahl chromosomaler Veränderungen in Abhängigkeit von der Anzahl an Mitosen / 10 HPF

\subsubsection{Dignität und Prognose}

18,8\% (6 / 32) der Primär-GIST < 5 chromosomale Imbalanzen zählten zu den "highrisk"-GIST sowohl nach Franquemont als auch nach Fletcher, bei den Primär-GIST mit $>=5$ Imbalanzen waren es 74,2\% (23/31) $(p<0,001)$. Bei der Dignitätsbeurteilung nach Miettinen wurden 29\% (9 / 31) der Primär-GIST < 5 chromosomale Imbalanzen 
als maligne klassifiziert, im Gegensatz zu 74,1\% (20/27) bei den Tumoren >= 5 Imbalanzen ( $p=0,001$ ). Tabelle 3.2.4/1 zeigt, dass bei den Risikoklassifikationen nach Franquemont, nach Fletcher und nach Miettinen statistisch signifikante Ergebnisse bzgl. des Medians der chromosomalen Gesamtveränderungen, Verluste und Zugewinne erzielt werden.

Bei Betrachtung der Anzahl chromosomaler Imbalanzen lag der Median der nicht progredienten Primär-GIST $(n=45)$ bei 3,0 $(0-21)$, bei den progredienten Tumoren $(n$ = 18) bei 8,5 (5 - 17; $\mathrm{p}<0,001)$. Wenn man nur die Verluste betrachtet, so lag der Median der nicht progredienten Primär-GIST bei 2,0 (0 - 12) und bei den progredienten bei 5,0 (1 - 11; $p<0,001)$. Bei den Zugewinnen oder Amplifikationen lag der Median bei den nicht progredienten Tumoren bei 0,0 (0 - 13), bei den progredienten bei 2,0 (0 8; $p=0,0026)$. Kein GIST $(0 / 32)<5$ chromosomale Imbalanzen zeigte einen Progress im Laufe des Follow-Up. 58,1\% (18/31) der Tumoren >= 5 Imbalanzen war im Verlauf progredient ( $p<0,001$ ), mit einer signifikant kürzeren rezidivfreien Überlebenszeit bei GIST >= 5 chromosomale Imbalanzen $(p<0,001)$ mit im Median 19,0 vs. 28,5 Monaten. Kein Patient (0 / 32) mit einem GIST < 5 chromosomale Veränderungen verstarb am Tumorleiden gegenüber 16,7\% (5/30) der Tumoren >= 5 Veränderungen $(p=0,015)$.

Tabelle 3.2.4/1

Anzahl der chromosomalen Imbalanzen nach den Risiko-/Dignitätsklassifikationen (Median)

\begin{tabular}{|c|c|c|c|c|c|c|}
\hline & \multicolumn{2}{|c|}{$\begin{array}{c}\text { Risiko } \\
\text { (Franquemont) }\end{array}$} & \multicolumn{2}{|c|}{$\begin{array}{c}\text { Risiko } \\
\text { (Fletcher) }\end{array}$} & \multicolumn{2}{|c|}{$\begin{array}{c}\text { Dignität } \\
\text { (Miettinen) }\end{array}$} \\
\hline & 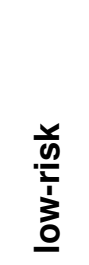 & $\begin{array}{l}\frac{y}{0} \\
\frac{1}{i} \\
\frac{1}{0} \\
\frac{0}{2}\end{array}$ & 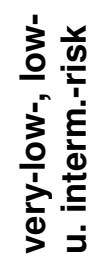 & 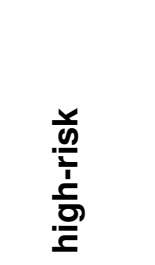 & 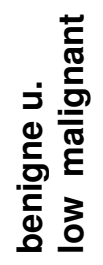 & 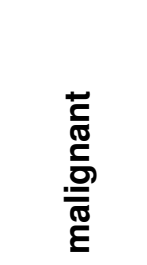 \\
\hline Gesamt & 2,5 & $\begin{array}{l}7,0 \\
p<0,001\end{array}$ & 2,0 & $\begin{array}{c}7,0 \\
p<0,001\end{array}$ & 2,0 & $\begin{array}{l}7,0 \\
p<0,001\end{array}$ \\
\hline Verluste & 2,0 & $\begin{array}{l}5,0 \\
p<0,001\end{array}$ & 1,5 & $\begin{array}{l}5,0 \\
p<0,001\end{array}$ & 2,0 & $\begin{array}{c}5,0 \\
p<0,001\end{array}$ \\
\hline $\begin{array}{l}\text { Zugewinne und } \\
\text { Amplifikationen }\end{array}$ & 0,0 & $\begin{array}{l}2,0 \\
p=0,0026\end{array}$ & 0,0 & $\begin{array}{c}2,0 \\
p=0,0010\end{array}$ & 0,0 & $\begin{array}{c}2,0 \\
p=0,0038\end{array}$ \\
\hline
\end{tabular}




\section{Chromosomale Imbalanzen an 6q}

GIST mit einem chromosomalen Verlust an $6 q$ waren in $85,7 \%$ "high-risk"-GIST nach Franquemont (6/7) und nach Fletcher (6/7), gegenüber 40,4\% (23/56) bei Fehlen des Verlustes $(p=0,042)$.

\section{Chromosomale Imbalanzen an $8 q$ und $8 p$}

Bei einem chromosomalen Zugewinn an $8 q$ handelte es sich in $83,3 \%(10 / 12)$ um "high-risk"-GIST nach Franquemont, 91,7\% (11/12) "high-risk"-GIST nach Fletcher und 90,9\% (10/11) maligne GIST nach Miettinen ( $p=0,008, p<0,001$ und $p=0,005)$. Tumoren mit einem Zugewinn an 8p gehörten in 87,5\% (7 / 8) zu den "high-risk"Tumoren nach Franquemont und nach Fletcher, gegenüber 40,0\% (22 / 55) "high-risk"GIST ohne den Zugewinn an $8 p(p=0,019)$. GIST mit einem Zugewinn an $8 q$ zeigten einen Progress in 58,3\% (7/12) der Fälle gegenüber 21,6\% (11/51) bei Fehlen dieser Veränderung $(p=0,028)$. Bei einem Zugewinn an $8 p$ betrug der Anteil der progredienten Tumoren 62,5\% (5/8), gegenüber 23,6\% (13/55) bei Fehlen des Zugewinns $(p=0,037)$ mit einer signifikant kürzeren rezidivfreien Überlebenszeit bei $8 p$ mit im Median 13,0 vs. 27,0 Monaten $(p=0,016)$ und bei $8 q$ mit 24,5 vs. 27,0 Monaten $(p=0,014)$.

\section{Chromosomale Imbalanzen an $9 q$ und $9 p$}

Bei einem Verlust an 9p fanden sich 100\% (11 / 11) "high-risk"-GIST nach Franquemont und nach Fletcher sowie 100\% (10/10) maligne GIST nach Miettinen, gegenüber 34,6\% (18 / 52) "high-risk"-Tumoren nach Franquemont und nach Fletcher sowie 39,6\% (19 / 48) maligne Tumoren nach Miettinen ohne den Verlust an $9 p(p<$ $0,001)$.

Ein Verlust an 9p oder 9q trat im Verlauf bei 72,7\% (8/11) der progredienten GIST auf und bei 19,2\% (10/52) ohne den chromosomalen Verlust $(p=0,0011)$ mit einer signifikant kürzeren rezidivfreien Überlebenszeit von im Median 8,0 vs. 27,5 Monaten für $9 q$ und 13,0 vs. 27,5 Monaten für $9 p(p<0,001)$. 


\section{Chromosomale Imbalanzen an 13q}

Die Klassifikation von GIST mit Verlust an 13q zeigte in 100\% "high-risk"-GIST nach Franquemont (9 / 9) und nach Fletcher (9/9) sowie in 100\% (8 / 8) maligne GIST nach Miettinen. Bei Fehlen des Verlustes lagen die Anteile bei 37,0\% (20/54) nach Franquemont und nach Fletcher sowie bei 42,0\% (21/50) nach Miettinen $(p<0,001$ für Franquemont und für Fletcher, $p=0,0045$ für Miettinen).

Der Anteil an progredienten Primär-GIST bei Verlust an Chromosom 13q lag bei 77,8\% (7 / 9) gegenüber 20,4\% (11/54) bei Fehlen dieser Veränderungen $(p=0,0014)$. Es zeigte sich eine signifikant kürzere rezidivfreie Überlebenszeit von im Median 13,0 vs. 28,0 Monaten $(p<0,001)$.

\section{Chromosomale Imbalanzen an 15q}

Die Betrachtung eines Verlustes an Chromosom 15q zeigte 71,4\% (10 / 14) "high-risk"GIST nach Franquemont, 78,6\% (11/14) "high-risk"-GIST nach Fletcher und 83,3\% (10 / 12) maligne GIST nach Miettinen. Lag dieser Verlust nicht vor, zeigten die Klassifikationen 38,8\% (19 / 49) "high-risk"-GIST nach Franquemont, 36,7\% (18 / 49) "high-risk"-GIST nach Fletcher und 41,3\% (19 / 46) maligne GIST nach Miettinen $(\mathrm{p}=$ $0,038, p=0,0071$ und $p=0,021$ ).

Der Anteil an progredienten Primär-GIST bei Verlust an Chromosom 15q lag bei 50,0\% (7 / 14) gegenüber 22,4\% (11/49) bei Fehlen dieser Veränderungen $(p=0,09)$ mit einer signifikant kürzeren rezidivfreien Überlebenszeit von im Median 15,5 vs. 28,0 Monaten $(p=0,022)$.

\section{Chromosomale Imbalanzen an 22q}

Ein Verlust an 22q ergab bei der Risikoklassifikation 67,9\% (19 / 28) "high-risk"-GIST nach Franquemont, 67,9\% (19 / 28) "high-risk"-GIST nach Fletcher und 73,1\% (19 / 26) maligne GIST nach Miettinen. Fehlte diese chromosomale Veränderung, wurden 28,6\% (10 / 35) als "high-risk"-GIST nach Franquemont, 25,7\% (8 / 35) als "high-risk"GIST nach Fletcher und 31,3\% (10 / 32) als maligne GIST nach Miettinen klassifiziert 
$(p=0,0025, p=0,044$ und $p=0,0033)$.

Bei Verlust an 22q waren 42,9\% (12 / 28) der GIST progredient, gegenüber 17,1\% (6 / $35)$ ohne den Verlust $(p=0,048)$. Auch hier ergab sich eine knapp signifikant kürzere rezidivfreie Überlebenszeit von im Median 24,0 vs. 27,0 Monaten ( $p=0,045)$.

\section{Chromosomale Imbalanzen an $1 p$ und $9 q$}

Bei einem Verlust an Chromosom 1p und 9q handelte es sich in 87,5\% (7 / 8) um "high-risk"-GIST nach Franquemont und nach Fletcher. Lag dieser kombinierte Verlust nicht vor, zeigten sich 40,0\% (22 / 55) "high-risk"-GIST nach Franquemont bzw. nach Fletcher $(p=0,019)$. Bei der Dignitätsklassifikation nach Miettinen ergab der kombinierte Verlust von $1 p$ und $9 q 85,7 \%(6 / 7)$ als maligne klassifizierte GIST, gegenüber 44,2\% (23 / 52) ohne den kombinierten Verlust $(p=0,052)$.

Der Verlust an $1 p$ und $9 q$ zeigte bei $75,0 \%(6 / 8)$ der GIST einen progredienten Verlauf. Tumoren ohne diesen kombinierten Verlust waren mit 21,8\% (12 / 55) signifikant seltener progredient $(p=0,0051)$. Es zeigte sich mit 4,0 vs. 27,0 Monaten eine signifikant kürzere rezidivfreie Überlebenszeit bei Vorliegen eines Verlustes an beiden Chromosomen $(p=0,0013)$.

\section{Chromosomale Imbalanzen an 1p und 15q}

Bei einem Verlust an $1 p$ und $15 q$ handelte es sich in 66,7\% (8 / 12) um "high-risk"GIST nach Franquemont und 75,0\% (9 / 12) "high-risk"-GIST nach Fletcher. Ohne den kombinierten Verlust fanden sich 41,2\% (21/51) "high-risk"-GIST nach Franquemont und 39,2\% (20/51) nach Fletcher $(p=0,050)$. Die Dignitätsklassifikation nach Miettinen ergab 80,0\% (8/10) als maligne klassifizierte GIST, gegenüber 43,8\% (21/ 48) bei Fehlen dieser Kombination ( $p=0,079$ ).

Ein kombinierter Verlust von $1 p$ und $15 q$ zeigte bei $50,0 \%$ (6/12) der Tumoren einen progredienten Verlauf, im Vergleich mit 23,5\% (12/51) progredienten GIST ohne den Verlust $(p=0,085)$ und eine signifikant kürzere rezidivfreie Überlebenszeit von im Median 13,5 vs. 28,0 Monaten ( $p=0,029$ ). 
Tabelle 3.2.4/2

Chromosomale Imbalanzen vs. Lokalisation vs. "high-risk"-GIST (nach Fletcher) vs. Prognose

\begin{tabular}{|c|c|c|c|c|}
\hline $\begin{array}{c}\text { Chromosomale } \\
\text { Imbalanz }\end{array}$ & Lokalisaton* $^{\star}$ & $\begin{array}{c}\text { high-risk GIST } \\
\text { (nach Fletcher) }\end{array}$ & Progression $^{\star}$ & $\begin{array}{c}\text { Rezidivfreie } \\
\text { Uberlebenszeit }\end{array}$ \\
\hline$-14 q$ & $p=0,024$ & $p=1,00$ & $p=0,25 n s$ & $p=0,231 \mathrm{~ns}$ \\
\hline$-22 q$ & $p=0,14 n s$ & $p<0,001$ & $p=0,048$ & $p=0,045$ \\
\hline$-1 p$ & $p=0,002$ & $p=0,318 n s$ & $p=0,053 n s$ & $p=0,067 n s$ \\
\hline$-9 q$ & $p=0,097 n s$ & $p=0,002$ & $p=0,001$ & $p<0,001$ \\
\hline$-15 q$ & $p<0,001$ & $p=0,007$ & $p=0,090 n s$ & $p=0,022$ \\
\hline$-1 p$ und $-15 q$ & $p<0,001$ & $p=0,050 n s$ & $p=0,085 n s$ & $p=0,029$ \\
\hline$-1 p$ und $-9 q$ & $p=0,083 n s$ & $p=0,019$ & $p=0,005$ & $p=0,0013$ \\
\hline$+5 p$ & $p=0,026$ & $p=0,154 n s$ & $p=0,052 n s$ & $p=0,036$ \\
\hline
\end{tabular}

*Signifikanz bezogen auf das Restkollektiv

ns $=$ nicht signifikant

\subsubsection{Metastasen}

Tabelle 3.2.5/1 zeigt die 3 Primär-GIST, bei denen sowohl Primärtumor als auch Metastase vorlagen. Die 3 Primär-GIST (Fall 38a, 50a und 59a) zeigten übereinstimmend einen Zugewinn an 8q, einen Verlust an 6q und einen Verlust an 22q. Die Metastase in Fall 38 zeigte dabei (fast) alle chromosomalen Veränderungen des Primärtumors (sowie zusätzlich Verluste an 3p, 9p und 9q). Die Metastase im Fall 50 zeigte als neue Veränderung gegenüber dem Primärtumor einen Zugewinn an 4q. Allerdings waren viele Veränderungen des Primärtumors in der Metastase nicht mehr nachweisbar $(+12 q,+20 p,+20 q,-6 q,-9 p,-9 q$ und $-10 p)$. Die größte Diskrepanz zeigte Fall 59. Während der Primärtumor 15 chromosomale Veränderungen aufwies, ließ sich keine einzige Veränderung in der Metastase nachweisen. 
Tabelle 3.2.5/1

Chromosomale Imbalanzen bei den Primär-GIST und zugehörigen Metastasen

\begin{tabular}{|c|c|}
\hline Fall & chromosomale Imbalanzen \\
\hline $38 a$ & $\begin{array}{l}+8 q, \quad-3 q,-6 q,-8 p, \quad-13 q,-14 q,-22 q \\
-3 p,-3 q,-6 q, \quad-9 p,-9 q,-13 q,-14 q,-22 q\end{array}$ \\
\hline $50 \mathrm{a}$ & 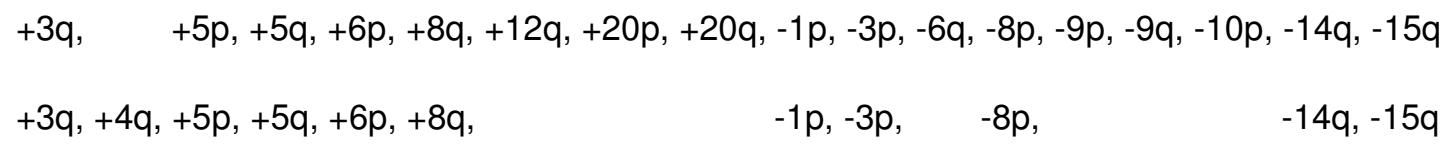 \\
\hline $\begin{array}{l}59 a \\
59 b\end{array}$ & $\begin{array}{l}+5 p,+5 q,+8 p,+8 q,+13 q,-1 p,-4 p,-4 q,-6 q,-9 p,-9 q,-10 p,-10 q,-14 q,-22 q \\
\text { keine chromosomalen Imbalanzen in der CGH }\end{array}$ \\
\hline
\end{tabular}

\subsubsection{Imatinib-Therapie}

Die Anzahl der chromosomalen Imbalanzen bei den mit Imatinib behandelten PrimärGIST $(n=17)$ lag im Median bei 9,0 (0 - 17). In den 4 Imatinib-Gruppen lag der Median in Gruppe 1 (nach R0-Resektion) bei 5,0, in Gruppe 2 (R0-Resektion bei synchronen Metastasen) bei 13,0, in Gruppe 3 (Rezidiv nach R0-Resektion) bei 9,0 und in Gruppe 4 (nach R1-Resektion) bei 11,0 chromosomalen Imbalanzen.

\subsection{Ergebnisse der Mutationsanalyse}

Untersucht wurden Mutationen in KIT Exon 9, 11, 13, 17 und PDGFRA Exon 12 und 18 (Einzelergebnisse siehe Tabelle 6.4/1, S. 97). Von den GIST lagen $81,0 \%$ als paraffineingebettete Proben (PF) vor sowie 76,5\% als Frischgewebsproben (FG). Von den 64 untersuchten Primärtumoren wurden in 85,9\% (55/64) Mutationen im KITbzw. PDGFRA-Gen gefunden. Dabei handelte es sich in 68,8\% (44/64) um Mutationen im KIT- und in 17,2\% (11/64) um Mutationen im PDGFRA-Gen. GIST mit Mutationen in beiden Genen wurden nicht gefunden. In 6,3\% der Tumoren lag die Mutation im KIT Exon 9 (4 / 64), in 64,1\% in KIT Exon 11 (41 / 64), in 14,1\% (9 / 64) in PDGFRA Exon 18 sowie in 3,1\% (2 / 64) in PDGFRA Exon 12. In den Metastasen der Primär-GIST Nr. 38, 50 und 59 fanden sich dieselben Mutationen im KIT Exon 11 wie im Primärtumor. Außer im Fall 61 (Mutation im KIT Exon 9 und 11) war kein Primär- 
GIST von Mutationen in mehr als einem Exon betroffen.

Je nach Mutationsstatus wurden die Tumoren zur Auswertung in 8 Gruppen eingeteilt (siehe auch Tabelle 3.3.1/1):

0 - KIT- und PDGFRA-Wildtyp (WT)

1 - PDGFRA-Mutation (Exon 18 und Exon 12)

2 - KIT-Exon-9-Mutation

3 - KIT-Exon-11-Mutation (Codons 550 - 556 betroffen)

4 - KIT-Exon-11-Mutation (Deletion in Codon 557 / 558)

5 - KIT-Exon-11-Mutation (Punktmutation in Codon 557 / 558)

6 - KIT-Exon-11-Mutation (Codons 559 - 561 betroffen)

7 - KIT-Exon-11-Mutation (3'Internal Tandem Repeats)

\subsubsection{Lokalisation}

90,9\% (10 / 11) der GIST mit Mutation in PDGFRA und 63,6\% (28 / 44) mit Mutation in KIT lagen proximal des Dünndarms (Tabelle 3.3.1/1). Von den 4 peritonealen GIST zeigten 3 Mutationen im KIT-Gen (1x WT). Trotz Lokalisation fast aller GIST mit Mutation in PDGFRA im Magen wurde keine statistische Signifikanz erreicht ( $p=$ $0,085)$.

Tabelle 3.3.1/1

Anzahl GIST in den Mutationsgruppen 0 - 7

\begin{tabular}{|r|c|c|c|c|c|c|c|c|}
\hline $\begin{array}{r}\text { Mutations- } \\
\text { gruppe }\end{array}$ & $\begin{array}{c}\text { Gruppe } \\
\mathbf{0}\end{array}$ & $\begin{array}{c}\text { Gruppe } \\
\mathbf{1}\end{array}$ & $\begin{array}{c}\text { Gruppe } \\
\mathbf{2}\end{array}$ & $\begin{array}{c}\text { Gruppe } \\
\mathbf{3}\end{array}$ & $\begin{array}{c}\text { Gruppe } \\
\mathbf{4}\end{array}$ & $\begin{array}{c}\text { Gruppe } \\
\mathbf{5}\end{array}$ & $\begin{array}{c}\text { Gruppe } \\
\mathbf{6}\end{array}$ & $\begin{array}{c}\text { Gruppe } \\
\mathbf{7}\end{array}$ \\
\hline alle GIST & 9 & 11 & 3 & 4 & 13 & 5 & 15 & 4 \\
\hline proximal & 6 & 10 & 2 & 3 & 9 & 1 & 9 & 4 \\
\hline distal & 2 & 1 & 1 & 1 & 3 & 3 & 5 & 0 \\
\hline Peritoneum & 1 & 0 & 0 & 0 & 1 & 1 & 1 & 0 \\
\hline
\end{tabular}




\subsubsection{Tumorgröße und Mitosen}

Die Primärtumorgröße bei Mutationen im KIT-Gen $(n=44)$ mit im Median 6,75 cm oder PDGFRA-Gen $(n=10)$ mit im Median $6,25 \mathrm{~cm}$ lag etwas über der von GIST ohne Mutation in diesen beiden Genen (Median 6,0 cm).

Tabelle 3.3.2/1

Mutationsraten in KIT und PDGFRA - Vergleich mit der Literatur

\begin{tabular}{|l|l|l|}
\hline Mutation & Kollektiv & Literatur \\
\hline KIT und PDGFRA & $85,9 \%$ & $85-90 \%(8)$ \\
\hline KIT & $68,8 \%$ & $70,9-72,7 \%(1)$ \\
\hline KIT Exon 11 & $64,1 \%$ & $57,6-69,9 \%(1)$ \\
\hline KIT Exon 9 & $6,3 \%$ & $5-13 \%(2)(7)$ \\
\hline PDGFRA & $17,2 \%$ & $2,8-7,2 \%(4)$ bzw. - 22,5\% (6) \\
\hline PDGFRA Exon 18 & $14,1 \%$ & $6-12,8 \%(3,5)$ \\
\hline PDGFRA Exon 12 & $3,1 \%$ & $1,1-3,7 \%(3,5)$ \\
\hline
\end{tabular}

1 - Andersson et al. 2006, Corless 2005, Du et al. 2008, Gomes et al. 2008

2 - Antonescu et al. 2003, Du et al. 2008, Koay et al. 2005, Wardelmann et al. 2004

3 - Corless et al. 2005, Wozniak et al. 2007 4 - DeMatteo et al. 2008, Keun Park et al. 2008, Wozniak et al. 2007

5 - Lasota et al. 2004

6 - Miettinen et al. 2005

7 - Penzel et al. 2005

8 - Rubin et al. 2007

Prozentangaben bezogen auf das Gesamtkollektiv

Tabelle 3.3.2/2

Mutationsraten im KIT Exon 11 - Vergleich mit der Literatur

\begin{tabular}{|l|l|l|}
\hline Mutation & Kollektiv & Literatur \\
\hline KIT Exon 11 & $64,1 \%$ & $\begin{array}{l}57,1-70,9 \% \\
(1,4,5,6)\end{array}$ \\
\hline Deletionen & $34,4 \%$ & $\begin{array}{l}25,0-49,5 \% \\
(1,2,4,5,6,7)\end{array}$ \\
\hline Punktmutationen & $23,4 \%$ & $\begin{array}{l}13,0-18,0 \% \\
(1,2,4,5,7,8)\end{array}$ \\
\hline $\begin{array}{l}\text { Codon 557 und / oder } \\
\text { 558 betroffen }\end{array}$ & $28,1 \%$ & $\begin{array}{l}26,7-29,1 \% \\
(7,8)\end{array}$ \\
\hline $\begin{array}{l}\text { Deletionen Codon 557 } \\
\text { und / oder 558 }\end{array}$ & $20,3 \%$ & $\begin{array}{l}20,0-33,3 \% \\
(5,7,8)\end{array}$ \\
\hline $\begin{array}{l}\text { Codon 559 - 561 } \\
\text { betroffen }\end{array}$ & $23,4 \%$ & $16,7 \%(7)$ \\
\hline $\begin{array}{l}\text { 3'Internal Tandem } \\
\text { Repeats }\end{array}$ & $6,3 \%$ & $\begin{array}{l}3,5-7,0 \% \\
(2,6)\end{array}$ \\
\hline
\end{tabular}

1 - Andersson et al. 2006

2 - Antonescu et al. 2003

3 - Corless et al. 2004

4 - Du et al. 2008

5 - Keun Park et al. 2008

6 - Kim TW et al. 2004

7 - Kontogianni-Katsarou et al. 2008

8 - Penzel et al. 2005

Prozentangaben bezogen auf das Gesamtkollektiv 
Eine Aufteilung in proximale und distale Tumoren ergab, dass bei den KIT-mutierten Primärtumoren (28 proximale und 13 distale) die größeren GIST distal lagen (Median $8,0 \mathrm{~cm}$ vs. $6,0 \mathrm{~cm}$ ). Der Median der 3 in KIT-mutierten peritonealen GIST betrug 12,0 $\mathrm{cm}$. Der eine distale GIST $(1 / 11)$ mit Mutation in PDGFRA war mit $9,0 \mathrm{~cm}$ größer als die proximalen GIST (Median 6,0 cm).

Tabelle 3.3.2/3 zeigt einen Überblick über die Anzahl der Mitosen $<2$ und $>=2 / 10$ HPF in den einzelnen Mutationsgruppen.

22,2\% (2 / 9) der WT-GIST zeigten >= 2 Mitosen/10 HPF, bei den mutierten GIST (KIT und PDGFRA) lag der Anteil bei 47,3\% (26/55) $(p=0,28)$. Dabei zeigten die in KITmutierten GIST in 52,3\%, und die in PDGFRA-mutierten in $27,3 \%$ der GIST $>=2$ Mitosen/10 HPF ( $p=0,14$ bzw. $p=1,00)$. Signifikant mehr GIST $>=2$ Mitosen/10 HPF zeigten die Tumoren der Mutationsgruppe 4 mit $76,9 \%$ (10/13) vs. $35,3 \%$ (18/51) in allen anderen Gruppen $(p=0,011)$.

Tabelle 3.3.2/3

Anzahl der Mitosen/10 HPF - gegliedert nach Mutationsgruppen

\begin{tabular}{|r|c|c|c|c|c|c|c|c|}
\hline $\begin{array}{r}\text { Mutations- } \\
\text { gruppe }\end{array}$ & Grp. 0 & Grp. 1 & Grp. 2 & Grp. 3 & Grp. 4 & Grp. 5 & Grp. 6 & Grp. 7 \\
\hline Alle & 9 & 11 & 3 & 4 & 13 & 5 & 15 & 4 \\
\hline $\begin{array}{r}\text { < 2 } \\
\text { Mitosen/10 HPF }\end{array}$ & 7 & 8 & 0 & 3 & 3 & 1 & 10 & 4 \\
\hline $\begin{array}{r}\text { >= 2 } \\
\text { Mitosen/10 HPF }\end{array}$ & 2 & 3 & 3 & 1 & 10 & 4 & 5 & 0 \\
\hline
\end{tabular}

\subsubsection{Dignität und Prognose}

51,9\% (27 / 52) der mutierten Primärtumoren waren zuvor nach Miettinen als maligne klassifiziert worden. Die Risiko-/Dignitätsklassifikationen, gegliedert nach Mutationsgruppen, sind in Tabelle 3.3.3/1 dargestellt. 
Tabelle 3.3.3/1

Risiko- / Dignitätsklassifikationen - gegliedert nach Mutationsgruppen

\begin{tabular}{|r|c|c|c|c|c|c|c|c|}
\hline Mutationsgruppe & Grp. 0 & Grp. 1 & Grp. 2 & Grp. 3 & Grp. 4 & Grp. 5 & Grp. 6 & Grp. 7 \\
\hline $\begin{array}{r}\text { High-risk GIST } \\
\text { (nach Franquemont) }\end{array}$ & $\begin{array}{c}33,3 \% \\
(3 / 9)\end{array}$ & $\begin{array}{c}18,2 \% \\
(2 / 11)\end{array}$ & $\begin{array}{c}100 \% \\
(3 / 3)\end{array}$ & $\begin{array}{c}25,0 \% \\
(1 / 4)\end{array}$ & $\begin{array}{c}76,9 \% \\
(10 / 13)\end{array}$ & $\begin{array}{c}80,0 \% \\
(4 / 5)\end{array}$ & $\begin{array}{c}33,3 \% \\
(5 / 15)\end{array}$ & $\begin{array}{c}25,0 \% \\
(1 / 4)\end{array}$ \\
\hline $\begin{array}{r}\text { High-risk GIST } \\
\text { (nach Fletcher) }\end{array}$ & $\begin{array}{c}33,3 \% \\
(3 / 9)\end{array}$ & $\begin{array}{c}18,2 \% \\
(2 / 11)\end{array}$ & $\begin{array}{c}100 \% \\
(3 / 3)\end{array}$ & $\begin{array}{c}25,0 \% \\
(1 / 4)\end{array}$ & $\begin{array}{c}69,2 \% \\
(9 / 13)\end{array}$ & $\begin{array}{c}80,0 \% \\
(4 / 5)\end{array}$ & $\begin{array}{c}40,0 \% \\
(6 / 15)\end{array}$ & $\begin{array}{c}25,0 \% \\
(1 / 4)\end{array}$ \\
\hline $\begin{array}{r}\text { Maligne GIST } \\
\text { (nach Miettinen) }\end{array}$ & $\begin{array}{c}28,6 \% \\
(2 / 7)\end{array}$ & $\begin{array}{c}27,3 \% \\
(3 / 11)\end{array}$ & $\begin{array}{c}100 \% \\
(3 / 3)\end{array}$ & $\begin{array}{c}25,0 \% \\
(1 / 4)\end{array}$ & $\begin{array}{c}69,2 \% \\
(9 / 12)\end{array}$ & $\begin{array}{c}75,0 \% \\
(3 / 4)\end{array}$ & $\begin{array}{c}50,0 \% \\
(7 / 14)\end{array}$ & $\begin{array}{c}25,0 \% \\
(1 / 4)\end{array}$ \\
\hline
\end{tabular}

58,5\% (24 / 41) der in KIT-mutierten Primär-GIST und 27,8\% (5 / 18) der Gruppen 0 (WT) und 1 (PDGFRA) wurden nach Miettinen als maligne klassifiziert $(p=0,047$ ). Nach den Risikoklassifikationen von Fletcher und Franquemont fanden sich 54,5\% (24 / 44) "high-risk"-Tumoren in den KIT-mutierten GIST. Hier lag der Anteil der "high-risk"Tumoren in den Gruppen 0 und 1 bei 25,0\% (5/20) signifikant niedriger ( $p=0,033)$. Alle GIST mit KIT-Exon-9-Mutation waren "high-risk" klassifiziert $(p=0,037)$, eine Einschränkung auf die Gruppen $4+5$ mit Mutationen im Codon 557 / 558 zeigte in $77,8 \%$ bzw. $72,2 \%$ "high-risk"-GIST ( $p=0,011$ ) nach Franquemont bzw. nach Fletcher.

Bei Vergleich der KIT-mutierten GIST mit dem Rest des Kollektivs zeigten 22,2\% (2 / 9) der WT-GIST, 0\% (0 / 11) der in PDGFRA-mutierten und 36,4\% (16 / 44) der in KITmutierten GIST einen Progress im Verlauf $(p=0,037)$ mit einer knapp signifikanten kürzeren rezidivfreien Überlebenszeit $(p=0,038)$ von im Median 25,5 vs. 34,5 Monaten und 26,0 vs. 29,0 bei Betrachtung von Mutationen in KIT Exon 11 ( $p=0,015)$. Eine Einschränkung auf die in KIT-mutierten GIST der Gruppen $4+5$ zeigte 50,0\% (9 / 18) progrediente GIST vs. $19,6 \%(9 / 46)$ in den anderen Mutationsgruppen ( $p=0,028)$. Auch hier fand sich eine signifikant kürzere rezidivfreie Überlebenszeit $(p=0,007)$ mit im Median 21,0 vs. 28,5 Monaten. Die rezidivfreie Überlebenszeit der WT-GIST unterschied sich nicht signifikant vom Rest des Kollektivs $(p=0,634)$.

GIST mit Mutation im PDGFRA-Gen zeigten eine signifikant längere rezidivfreie Überlebenszeit von 40,0 vs. 25,0 Monaten im Rest des Kollektivs ( $p=0,037$ ).

Eine Übersicht über den Anteil an progredienten Primär-GIST in den einzelnen 
Mutationsgruppen gibt Tabelle 3.3.3/2.

Tabelle 3.3.3/2

Progrediente Primär-GIST - gegliedert nach Mutationsgruppen

\begin{tabular}{|c|c|c|c|c|c|c|c|c|}
\hline Mutationsgruppe & Grp. 0 & Grp. 1 & Grp. 2 & Grp. 3 & Grp. 4 & Grp. 5 & Grp. 6 & Grp. 7 \\
\hline Progrediente GIST & $\begin{array}{l}20 \% \\
(2 / 9)\end{array}$ & $\begin{array}{c}0 \% \\
(0 / 11)\end{array}$ & $\begin{array}{c}0 \% \\
(0 / 3)\end{array}$ & $\begin{array}{c}0 \% \\
(0 / 4)\end{array}$ & $\begin{array}{c}38,5 \% \\
(5 / 13)\end{array}$ & $\begin{array}{c}80 \% \\
(4 / 5)\end{array}$ & $\begin{array}{c}40,0 \% \\
(6 / 15)\end{array}$ & $\begin{array}{c}25 \% \\
(1 / 4)\end{array}$ \\
\hline
\end{tabular}

Eine Übersicht über die Wahrscheinlichkeit des rezidivfreien Überlebens bei Mutation im KIT bzw. PDGFRA-Gen vs. WT zeigt Abbildung 3.3.3/1.

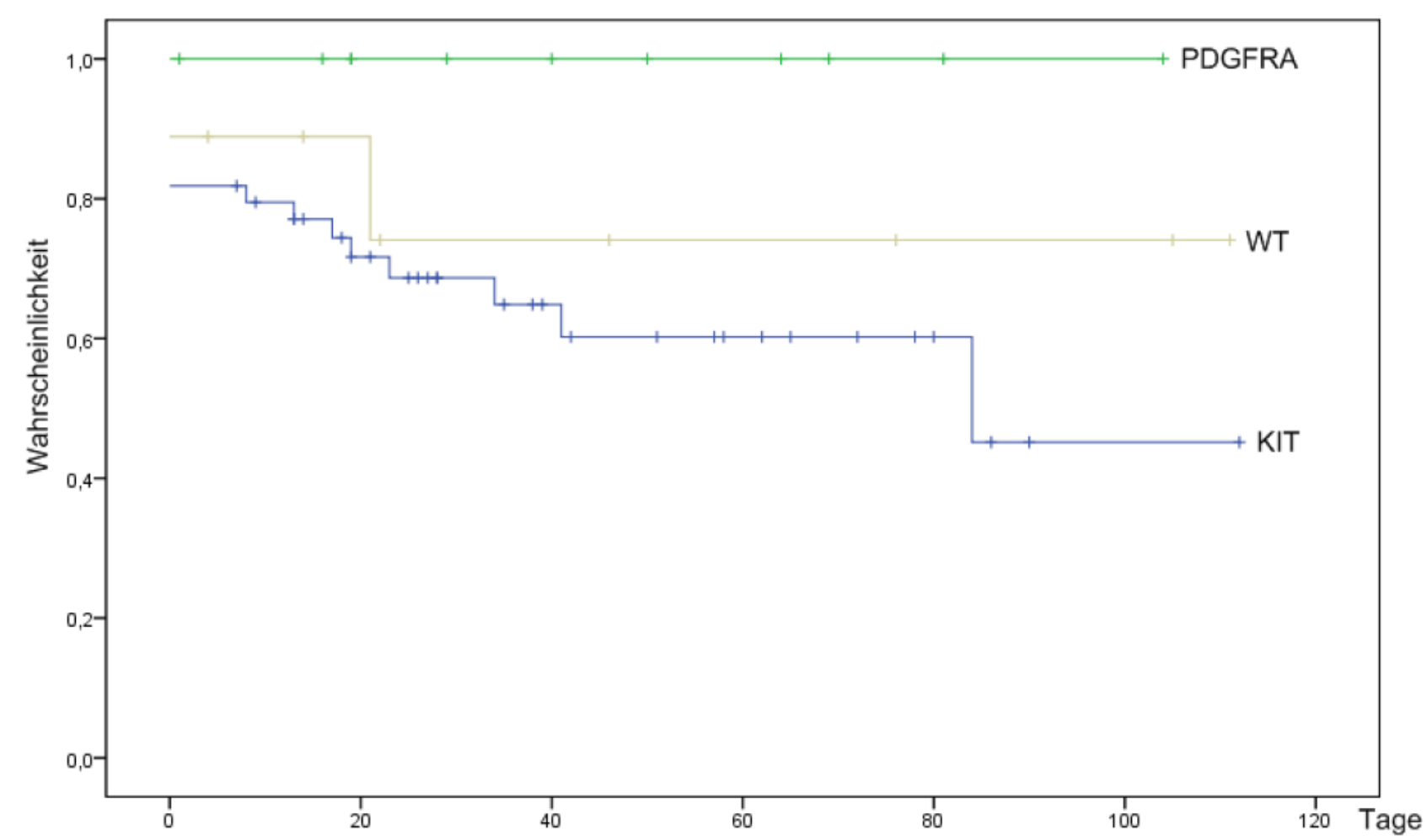

Abbildung 3.3.3/1

Rezidivfreie Überlebenszeit der Patienten mit Primär-GIST (Kaplan-Meier)

\subsubsection{Metastasen}

In den 3 vorliegenden Metastasen ( $z u$ Fall 38, 50 und 59) zeigte sich in der Mutationsanalyse eine identische Mutation im Vergleich mit dem Primärtumor. 


\subsubsection{Imatinib-Therapie}

Tabelle 3.3.5/1 zeigt die Verteilung der 17 mit Imatinib behandelten Patienten auf die einzelnen Mutationsgruppen. 64,7\% (11/17) der Fälle wiesen dabei Punktmutationen oder Deletionen in den Codons 557 / 558 auf (Mutationsgruppe 4 / 5). Eine Erweiterung auf die Mutationsgruppe 6 zeigte, dass 94,1\% (16/17) der Imatinibbehandelten Patienten sich auf 3 Gruppen (Gruppen 4, 5 und 6) aufteilten. Fall 41 zeigte im KIT- oder PDGFRA-Gen keine Mutationen (WT).

Tabelle 3.3.5/1

Verteilung der 17 Imatinib-behandelten Fälle

\begin{tabular}{|r|c|c|c|c|c|c|c|c|}
\hline Mutationsgruppe & Grp. 0 & Grp. 1 & Grp. 2 & Grp. 3 & Grp. 4 & Grp. 5 & Grp. 6 & Grp. 7 \\
\hline $\begin{array}{r}\text { Imatinib-behandelte } \\
\text { GIST }\end{array}$ & $\begin{array}{c}5,9 \% \\
(n=1)\end{array}$ & $\begin{array}{c}0 \% \\
(n=0)\end{array}$ & $\begin{array}{c}0 \% \\
(n=0)\end{array}$ & $\begin{array}{c}0 \% \\
(n=0)\end{array}$ & $\begin{array}{c}\mathbf{4 1 , 2} \% \\
(n=7)\end{array}$ & $\begin{array}{l}\mathbf{2 3 , 5} \% \\
(\mathrm{n}=4)\end{array}$ & $\begin{array}{c}\mathbf{2 9 , 4} \% \\
(\mathrm{n}=5)\end{array}$ & $\begin{array}{c}0 \% \\
(\mathrm{n}=0)\end{array}$ \\
\hline
\end{tabular}

Die rezidivfreie Überlebenszeit von allen mit Imatinib behandelten Patienten liegt bei 19,0 Monaten vs. 28,0 Monaten (Median) ohne Behandlung mit Imatinib $(p<0,001)$. Tabelle 3.3.5/2 zeigt die Unterschiede der rezidivfreien Überlebenszeit zwischen den einzelnen mit Imatinib behandelten Gruppen auf.

Tabelle 3.3.5/2

Rezidivfreie Überlebenszeit

\begin{tabular}{|c|c|}
\hline Imatinib-Gruppe & Rezidivfreie Überlebenszeit (Median) \\
\hline $\begin{array}{c}\text { Gruppe 1 } \\
\text { (nach R0-Resektion) }\end{array}$ & 39,0 Monate \\
\hline $\begin{array}{c}\text { Gruppe 2 } \\
\text { (nach R0-Resektion mit synchronen } \\
\text { Metastasen) }\end{array}$ & 0,0 Monate \\
\hline $\begin{array}{c}\text { Gruppe 3 } \\
\text { (nach R0-Resektion bei Rezidiv im } \\
\text { Follow-Up) }\end{array}$ & 19,0 Monate \\
\hline $\begin{array}{c}\text { Gruppe 4 } \\
\text { (nach R1-Resektion) }\end{array}$ & 30,5 Monate \\
\hline
\end{tabular}




\subsection{CGH und Mutationsanalyse}

\subsubsection{Mutation vs. Anzahl der chromosomalen Imbalanzen}

Abbildung 3.4.1/1 gibt einen Überblick über die Anzahl der chromosomalen Gesamtveränderungen in den einzelnen Mutationsgruppen. GIST mit Deletionen in KIT Codons 557 / 558 (Gruppe 4) und GIST mit Punktmutationen in diesen Codons (Gruppe 5) zeigten mit 9,0 bzw. 10,0 (Median) chromosomalen Gesamtveränderungen in der CGH die höchste Anzahl an Veränderung von allen 8 Gruppen $(p=0,008)$. Die WT-GIST zeigten dabei signifikant weniger Veränderungen als die Gruppen 1 bis 7 mit Mutation im PDGFRA- oder KIT-Gen $(p=0,045)$.

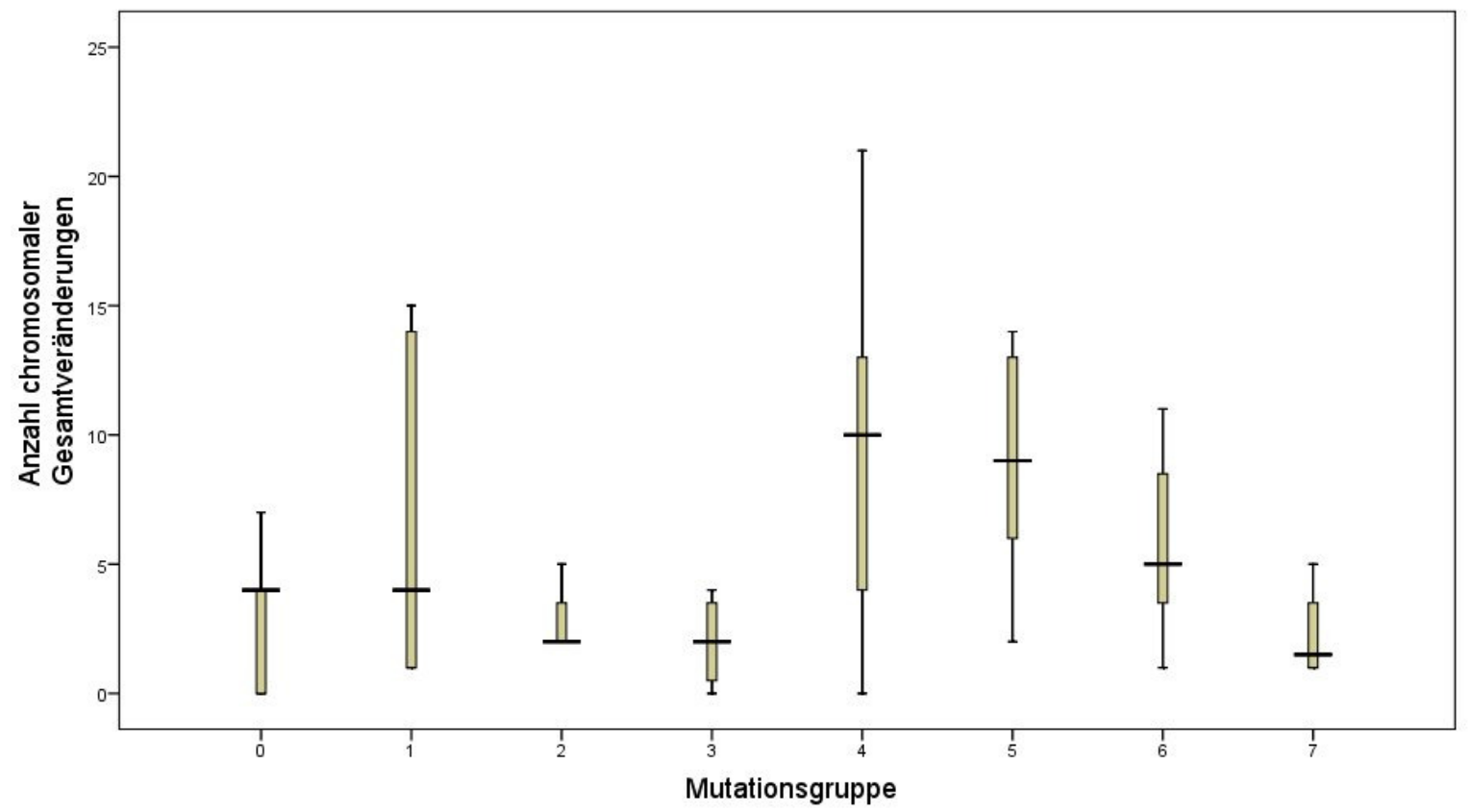

Abbildung 3.4.1/1

Anzahl der chromosomalen Gesamtveränderungen - gegliedert nach Mutationsgruppen (Box-Plot)

Keiner $(0 / 20)$ der in KIT-mutierten Primär-GIST < 5 chromosomalen Imbalanzen zeigte einen Progress. Bei >= 5 Imbalanzen zeigten sich 66,7\% (16/24) progredient ( $p$ $<0,001)$. Es ergab sich eine signifikant kürzere rezidivfreie Überlebenszeit $(p<0,001)$ von im Median 18,0 vs. 28,0 Monate.

Betrachtet man innerhalb der KIT-mutierten Tumoren nur die GIST mit Mutation in KIT Exon 11 Codon 557 / 558 (Gruppen 4 + 5), so zeigte kein (0 / 5) GIST < 5 und 69,2\% 
(9 / 13) der GIST mit >= 5 chromosomalen Imbalanzen einen Progress $(p=0,029)$ mit einer signifikant kürzeren rezidivfreien Überlebenszeit von im Median 23,0 vs. 27,5 Monate $(p=0,001)$.

Keiner $(0 / 5)$ der in PDGFRA-mutierten Primär-GIST $<5$ und keiner mit $>=5(0 / 5)$ chromosomalen Veränderungen zeigte einen Progress. Die rezidivfreie Überlebenszeit betrug 25,5 vs. 69,0 Monate (Median).

Bei den WT-GIST zeigte kein $(0 / 7)$ GIST $<5$ chromosomalen Imbalanzen einen Progress. Bei Tumoren $>=5$ Imbalanzen waren alle (2 / 2) GIST progredient $(p=$ 0,028 ). Es zeigte sich mit 10,5 vs. 27,0 Monaten eine signifikant kürzere rezidivfreie Überlebenszeit $(p=0,007)$.

\subsubsection{Chromosomale Imbalanzen an 1p}

Das Vorliegen eines chromosomalen Verlustes an $1 \mathrm{p}$ gemeinsam mit einer Mutation im KIT-Gen ( $n=19)$ war mit einer signifikant kürzeren rezidivfreien Überlebenszeit $(21,0$ bzw. 26,5 Monate) verknüpft ( $p=0,013)$. Eine Einschränkung auf Mutationen in KIT Exon 11 Codon 557 / 558 (Mutationsgruppe $4+5)$ erhöhte die Signifikanz deutlich $(p=$ $0,001)$ mit einer rezidivfreien Überlebenszeit von im Median 17,0 bzw. 26,0 Monaten.

\subsubsection{Chromosomale Imbalanzen an 9p und 9q}

Auch bei Vorliegen eines chromosomalen Verlustes an 9p bzw. 9q, zusammen mit einer Mutation im KIT-Gen, zeigte sich eine signifikant $(p<0,001)$ kürzere rezidivfreie Überlebenszeit (13,0 vs. 27,50 Monate für $9 p$ und 8,0 vs. 27,5 für $9 q)$ ). Im Gegensatz zum chromosomalen Verlust an $1 \mathrm{p}$ brachte die Einschränkung auf die Mutationsgruppen $4+5$ keine weitere Erhöhung der Signifikanz ( $p=0,010$ bzw. $p=$ 0,005 ) mit im Median 6,50 vs. 27,0 Monaten für einen Verlust an $9 p$ und 13,0 vs. 26,50 für 9q. 


\subsubsection{Chromosomale Imbalanzen an 14q}

Ein chromosomaler Verlust an 14q zeigte bei gleichzeitiger Mutation im KIT-Gen kein signifikantes Ergebnis bzgl. der rezidivfreien Überlebenszeit $(p=0,682)$. Auch eine Einschränkung auf die Mutationsgruppen $4+5$ ergab kein signifikantes Ergebnis $(p=$ $0,053)$, genauso wie eine Kombination des chromosomalen Verlustes mit einer Mutation im PDGFRA-Gen $(p=0,073)$.

\subsubsection{Chromosomale Imbalanzen an 15q}

Bei einem chromosomalen Verlust an $15 q$ fand sich bei gleichzeitiger Mutation im KITGen eine signifikant kürzere rezidivfreie Überlebenszeit $(p=0,014)$ mit im Median 17,0 vs. 28,0 Monaten. Lag neben einem chromosomalen Verlust an $15 q$ dabei noch ein Verlust an $1 p$ vor, betrug die rezidivfreie Überlebenszeit 13,0 vs. 28,0 Monate ( $p=$ 0,018). Im Gegensatz zum alleinigen Verluste an $15 q$ erhöhte sich hierbei die Signifikanz $(p=0,005)$ im Hinblick auf die rezidivfreie Überlebenszeit (Median 0,0 vs. 27,0 Monaten).

\subsubsection{Chromosomale Imbalanzen an 22q}

Ein chromosomaler Verlust an 22q zeigte bei Mutation im KIT-Gen mit 23,0 vs. 27,5 Monaten eine signifikant kürzere rezidivfreie Überlebenszeit $(p=0,028)$ im Vergleich mit dem Rest des Kollektivs. In den Mutationsgruppen $4+5$ betrug die rezidivfreie Überlebenszeit mit einem Verlust an $22 q 18,0$ vs. 27,5 Monate $(p=0,001)$.

Einen Überblick über die Anzahl der GIST bei einzelnen chromosomalen Imbalanzen und die Signifikanz der rezidivfreien Überlebenszeit bei Mutation im KIT- und PDGFRA-Gen bzw. WT gibt Tabelle 3.4.6/1. 
Tabelle $3.4 .6 / 1$

Mutationen im KIT- und PDGFRA-Gen bei ausgewählten chromosomalen Imbalanzen

\begin{tabular}{|c|c|c|c|c|}
\hline $\begin{array}{c}\text { Chromosomale } \\
\text { Imbalanz }\end{array}$ & $\begin{array}{c}\text { WT } \\
(n=9)\end{array}$ & $\begin{array}{c}\text { KIT } \\
(n=44)\end{array}$ & $\begin{array}{c}\text { PDGFRA } \\
(n=11)\end{array}$ & $\begin{array}{l}\text { Mutations- } \\
\text { gruppe } 4+5 \\
(n=18)\end{array}$ \\
\hline $\begin{array}{c}-1 p \\
(n=26)\end{array}$ & $\begin{array}{l}3 \\
p=0,695\end{array}$ & $\begin{array}{c}19 \\
p=0,013\end{array}$ & $\begin{array}{c}4 \\
p=0,223\end{array}$ & $\begin{array}{l}8 \\
p=0,001\end{array}$ \\
\hline $\begin{array}{c}-6 q \\
(n=7)\end{array}$ & 0 & $\begin{array}{c}6 \\
p=0,184\end{array}$ & $p=\begin{array}{c}1 \\
0,683\end{array}$ & $\begin{array}{l}5 \\
p=0,556\end{array}$ \\
\hline $\begin{array}{c}+8 q \\
(n=12)\end{array}$ & 0 & $\begin{array}{c}11 \\
p=0,006\end{array}$ & $p=\begin{array}{c}1 \\
0,529\end{array}$ & $p=0,005$ \\
\hline $\begin{array}{c}+8 p \\
(n=8)\end{array}$ & 0 & $\begin{array}{c}8 \\
p=0,014\end{array}$ & 0 & $\begin{array}{c}6 \\
p=0,017\end{array}$ \\
\hline $\begin{array}{c}-9 p \\
(n=11)\end{array}$ & $p=0,014$ & $\begin{array}{c}9 \\
p<0,001\end{array}$ & $p=0,529$ & $\begin{array}{c}6 \\
p=0,010\end{array}$ \\
\hline $\begin{array}{c}-9 q \\
(n=11)\end{array}$ & $p=\begin{array}{c}1 \\
0,014\end{array}$ & $\begin{array}{c}9 \\
p<0,001\end{array}$ & $p=\begin{array}{c}1 \\
0,453\end{array}$ & $\mathrm{p}=\stackrel{7}{0,005}$ \\
\hline $\begin{array}{c}-13 q \\
(n=9)\end{array}$ & $p=\begin{array}{c}1 \\
0,014\end{array}$ & $\begin{array}{c}6 \\
p<0,001\end{array}$ & $p=\stackrel{2}{0,451}$ & $p=\stackrel{3}{0,001}$ \\
\hline $\begin{array}{c}-14 q \\
(n=42)\end{array}$ & $p=\stackrel{2}{0,435}$ & $\begin{array}{c}31 \\
p=0,682\end{array}$ & $\begin{array}{c}9 \\
p=0,073\end{array}$ & $\begin{array}{c}12 \\
p=0,053\end{array}$ \\
\hline $\begin{array}{c}-15 q \\
(n=14)\end{array}$ & $p=0,649$ & $\begin{array}{c}13 \\
p=0,014\end{array}$ & 0 & $\begin{array}{l}5 \\
p=0,055\end{array}$ \\
\hline $\begin{array}{c}-22 q \\
n=28)\end{array}$ & 0 & $\begin{array}{c}27 \\
p=0,028\end{array}$ & $p=\begin{array}{c}1 \\
0,529\end{array}$ & $\begin{array}{c}13 \\
p=0,001\end{array}$ \\
\hline $\begin{array}{c}-1 p \text { und }-9 q \\
(n=8)\end{array}$ & $p=\begin{array}{c}1 \\
0,014\end{array}$ & $\begin{array}{c}6 \\
p<0,001\end{array}$ & $p=\begin{array}{c}1 \\
0,453\end{array}$ & $p=\begin{array}{c}4 \\
0,028\end{array}$ \\
\hline $\begin{array}{c}-1 p \text { und }-15 q \\
(n=12)\end{array}$ & $p=\begin{array}{c}1 \\
0,649\end{array}$ & $\begin{array}{c}11 \\
p=0,018\end{array}$ & 0 & $p=\begin{array}{l}4 \\
0,005\end{array}$ \\
\hline
\end{tabular}


Als frühes Stadium in der Tumorgenese eines gastrointestinalen Stromatumors bzw. als auslösendes Ereignis ist eine Mutation im KIT bzw. PDGFRA-Gen heutzutage anerkannt (Wozniak et al. 2007, Yang et al. 2008), wohingegen die durch komparative genomische Hybridisierung (CGH) nachgewiesenen chromosomalen Imbalanzen vermehrt im Rahmen der weiteren Tumorprogression auftraten. In der gängigen Literatur sind bis dato viele Zusammenhänge zwischen klinisch-pathologischen Parametern, chromosomalen Imbalanzen und Mutationen im KIT- bzw. PDGFRA-Gen gefunden und beschrieben worden. Einige davon kontrovers diskutiert und im Hinblick auf teils geringe Fallzahlen bedingt verwertbar. Die meisten Studien bezogen sich dabei entweder auf die Ergebnisse einer $\mathrm{CGH}$ oder die Ergebnisse einer Mutationsanalyse. Nur wenige Studien beinhalteten Daten zu beiden Verfahren. Auf den folgenden Seiten werden nun die gewonnenen Ergebnisse aus beiden Verfahren, unter Berücksichtigung der aktuellen Literatur, diskutiert und anschließend in Korrelation zueinander gebracht. Das Hauptaugenmerk lag dabei auf der Prognose (v.a. der rezidivfreien Überlebenszeit) des Patienten nach erfolgter operativer Tumorresektion.

\subsection{Kollektiv}

Im vorliegenden Kollektiv fand sich die für gastrointestinale Stromatumoren in der Literatur (Nilsson et al. 2005, Tran et al. 2005, Tryggvason et al. 2005) beschriebene leichte Tendenz hin zum männlichen Geschlecht (56,3\%), wobei das Alter bei Diagnosestellung mit im Median 4 Jahren eine knapp signifikante $(p=0,047)$ Benachteiligung der Männer zeigte. Dabei entsprach das gefundene Erkrankungsalter (im Median 66 Jahre) eher den bevölkerungsbasierten Studien von Nilsson et al. (2005) und Tryggvason et al. (2005) als u.a. den Studien von Antonescu et al. (2003), Miettinen et al. (2005) und Wong et al. (2003).

Die weiteren klinisch-pathologischen Parameter (Lokalisation, Tumorgröße, Immunhistochemie und Mitosenzahl) der Primärtumoren entsprachen weitgehend den in der Literatur beschriebenen Werten (Chen $Y$ et al. 2004, Emory et al. 1999, Gunawan et al. 2004, Miettinen et al. 1999 a, 2000 a). Knapp über zwei Drittel (67,2\%) 
der untersuchten GIST manifestierten sich im Magen. Mit wenigen Ausnahmen (1,6\% ösophageale und 6,3\% peritoneale GIST) lag das restliche Drittel distal des Magens. Auch bei den distalen GIST schnitten die Männer hinsichtlich der Tumorgröße schlechter ab als die Frauen (Median 7,0 cm vs. $5,25 \mathrm{~cm}$ ) mit einem signifikanten Trend zu größeren Tumoren distal des Magens $(p=0,036)$. Bis auf eine Ausnahme (Fall 1) waren alle Tumoren in der immunhistochemischen Färbung CD117-positiv $(98,4 \%)$. Fall 1 zeigte ebenfalls keine der für GIST typischen chromosomalen Imbalanzen. Auch eine Mutation im KIT- oder PDGFRA-Gen konnte bei diesem Fall nicht nachgewiesen werden, so dass die Diagnosestellung als GIST ggf. in Frage gestellt werden kann.

\subsubsection{Klassifikation und Prognose}

Knapp die Hälfte $(45,3 \%)$ der Tumoren wurden nach Franquemont und nach Fletcher als "high-risk" klassifiziert. Die Klassifikation der GIST nach Fletcher zeigte im vorliegenden Kollektiv signifikant mehr "high-risk"-Tumoren in den distalen als in den proximalen GIST ( $p=0,017)$. Im Vergleich mit der Literatur enthielt das untersuchte Kollektiv dabei einen höheren Anteil an "high-risk"-GIST (45,3\%) u.a. im Vergleich mit einer Studie von Wozniak et al. (2007) mit 37,9\% (25/66) und einer Studie von Nilsson et al. (2005) mit 29\% "high-risk"-GIST.

Der Beobachtungszeitraum für das Follow-Up betrug im Median 39,0 Monate. 81,3\% der Patienten (52 / 64) wiesen dabei eine Follow-Up-Zeit von mindestens 24 Monaten auf bzw. verstarben innerhalb dieses Zeitraums. In einer Studie von Nilsson et al. (2005) lag die mediane Überlebenszeit der nach Fletcher als "high-risk" klassifizierten GIST bei 40 Monaten (Median) im Vergleich zu den 53,5 Monaten bei den "high-risk"GIST im vorliegenden Kollektiv, wobei in der Studie von Nilsson et al. (2005) keine mit Imatinib behandelten Patienten einbezogen waren. Die 5-Jahres-Überlebensrate entsprach mit 80\% den beschriebenen Werten (Kim TW et al. 2004).

\section{$4.2 \quad \mathbf{C G H}$}

Chromosomale Verluste (im Median 3,0 Imbalanzen) traten im vorliegenden Kollektiv, 
wie in der Literatur beschrieben (Chen Y et al. 2004, El-Rifai et al. 1996, Wozniak et al. 2007), häufiger auf als Zugewinne bzw. Amplifikationen und mit Fortschreiten des Tumors, z.B. im Sinne einer Metastasierung (im Median 8,0 Imbalanzen), nahm die Anzahl der chromosomalen Imbalanzen zu (Chen Y et al. 2004, Debiec-Rychter et al. 2001, El-Rifai et al. 2000, Gunawan et al. 2004). Wie erwartet, zeigten die "high-risk"Tumoren bereits bei der Tumorklassifikation signifikant mehr chromosomale Imbalanzen als "low-risk"-Tumoren (Chen Y et al. 2004, Wozniak et al. 2007). Auch im Follow-Up zeigten die progredienten GIST signifikant mehr chromosomale Veränderungen als das Restkollektiv ( $p<0,001)$. Kein GIST mit $<5$ chromosomalen Imbalanzen wies einen Progress auf, verglichen mit 58,1\% bei den übrigen Tumoren ( $p$ $<0,001$ ). Die rezidivfreie Überlebenszeit betrug 28,5 vs. 19,0 Monaten (Median).

Größere Tumoren waren im Allgemeinen häufiger als "high-risk" klassifiziert und zeigten einen progredienten Verlauf. Zusammen mit der größeren Anzahl an chromosomalen Imbalanzen in progredienten GIST sollte man erwarten, dass große GIST dementsprechend auch mehr chromosomale Imbalanzen aufweisen. Dieser Zusammenhang ließ sich im Kollektiv nicht nachweisen ( $p=0,2159)$. Im Gegensatz dazu fand sich ein signifikantes Ergebnis $(p<0,001)$ bzgl. der Anzahl der Mitosen und der Anzahl an chromosomalen Imbalanzen. Auch der klinisch günstigere Verlauf von proximalen Tumoren (Chen Y et al. 2004, Emory et al. 1999, Gunawan et al. 2004) spiegelte sich in signifikant weniger chromosomalen Imbalanzen in diesen Tumoren wider $(p=0,017)$.

\subsubsection{Chromosomale Imbalanzen}

Die 5 häufigsten chromosomalen Imbalanzen im vorliegenden Kollektiv waren Verluste an $14 q(65,1 \%), 22 q(46,0 \%), 1 p(41,3 \%)$, sowie ein Zugewinn an $5 p(25,4 \%)$ und schließlich ein Verlust an $15 q$ (20,6\%). Die in der Literatur gefundenen Angaben schwanken je nach Studie, wobei die Reihenfolge, in absteigender Häufigkeit, im Vergleich zum Kollektiv annährend identisch ist (siehe Tabelle 4.2.1/1). 
Tabelle 4.2.1/1

Häufigkeit chromosomaler Imbalanzen im Vergleich mit der Literatur

\begin{tabular}{|c|c|c|}
\hline Chromosom & Kollektiv & Literatur \\
\hline $\mathbf{- 1 4 q}$ & $65,1 \%$ & $64-77 \%[2,3,4,5]$ \\
\hline $\mathbf{- 2 2 q}$ & $46,0 \%$ & $53-59 \%[3,4,5]$ \\
\hline $\mathbf{- 1 p}$ & $41,3 \%$ & $40-62 \%[1,3,4,5]$ \\
\hline $\mathbf{+ 5 p}$ & $25,4 \%$ & $14-25 \%[4,5]$ \\
\hline $\mathbf{- 1 5 q}$ & $20,6 \%$ & $29-38 \%[2,4,5]$ \\
\hline
\end{tabular}

1 - Bergmann et al. 1998

2 - Chen $Y$ et al. 2004

3 - El-Rifai et al. 2000

4 - Gunawan et al. 2004

5 - Wozniak et al. 2007

\subsubsection{Tumorlokalisation}

Wozniak et al. (2007) beschrieben ein signifikant geringeres Auftreten von Verlusten an $14 q$ ( $p<0,001 ; 87 \%$ vs. $35 \%$ ) sowie ein vermehrtes Auftreten von Verlusten an $1 p$ ( $p<$ 0,$001 ; 45 \%$ vs. $85 \%$ ) und $15 q$ ( $p<0,001 ; 17 \%$ vs. $69 \%$ ) an "non-gastric" GIST. Auch Gunawan et al. (2004) fanden im Zusammenhang mit der Lokalisation bereits 2004 signifikante Ergebnisse für chromosomale Verluste an 14q $(p=0,001), 22 q(p=0,02)$ und $1 p(p<0,001)$ sowie einen Verlust an $15 q(p=0,002)$. Am untersuchten Kollektiv ließen sich diese Aussagen für einen Verlust an $14 q(p=0,027 ; 76,7 \%$ vs. $43,8 \%), 1 p$ $(p=0,001 ; 26,2 \%$ vs. $75,0 \%)$ und $15 q$ ( $p<0,001 ; 7,0 \%$ vs. $56,3 \%$ ) bestätigen, wobei der Verlust an 14q nur knapp signifikant war.

Auf dieser Beobachtung basierend entwickelte sich die Theorie, dass GIST in Abhängigkeit von ihrer Lokalisation ein jeweils unterschiedliches "Profil" besitzen, was sich u.a. in ihrem Muster an chromosomalen Imbalanzen, ihren klinisch-pathologischen Parametern, sowie schließlich ihrer Risikoklassifikation und der Schwere des Weiteren klinischen Verlaufs widerspiegelt. Gunawan et al. (2007) sprechen von einem "Oncogenetic Tree Model", welches drei Hauptrichtungen aufweist. Die erste wird von 
einem chromosomalen Verlust an $14 q$ initiiert, die zweite von einem Verlust an $1 p$ und die dritte von einem Verlust an 22q. Die "14q"-Richtung ist v.a. von Magen-GIST mit einem günstigeren klinischen Verlauf charakterisiert, die "1p"-Richtung von intestinalen GIST mit komplexeren zytogenetischen Veränderungen und aggressiverem klinischen Verlauf, sowie die "22q"-Richtung, die mehr mit $1 p$ als mit 14q assoziiert ist, einen Übergang zu ungünstigen zytogenetischen Veränderungen kennzeichnet.

Eine in der Literatur beschriebene Koexistenz ist dabei das gemeinsame Auftreten der Verluste an 1p und 15q (Chen Y et al. 2004, El-Rifai et al. 2000, Gunawan et al. 2004, Wozniak et al. 2007). In diesen Studien zeigten $90,5 \%$ der GIST mit einem chromosomalen Verlust an $15 q$ ebenfalls einen Verlust an $1 p$. In der Studie von Gunawan et al. (2004) trat die Kombination signifikant $(p<0,001)$ häufiger in intestinalen GIST auf. Ein Blick in das vorliegende Kollektiv zeigte bei 14 GIST mit einem Verlust an $15 q$ in $85,7 \%$ (12 / 14) ebenfalls einen Verlust an 1p, d.h. der Verlust an $15 q$ tritt v.a. bei einer (Tumor-)Progression bei Tumoren mit einem Verlust an $1 p$ auf. Umgekehrt zeigten (nur) 48,0\% (12 / 25) der GIST mit einem Verlust an $1 p$ auch einen Verlust an 15q, d.h. nicht jeder Tumor mit einem Verlust an $1 p$ muss den ungünstigen klinischen Verlauf mit einem zusätzlichen Verlust an $15 q$ nehmen. Der gemeinsame chromosomale Verlust tritt signifikant häufiger $(p<0,001)$ bei intestinalen GIST auf (siehe Tabelle 3.2.4/2, S. 56).

Eine zweite von Gunawan et al. (2004) beschriebene Koexistenz ist ein Verlust an 1p und 9q, der v.a. an kolorektalen Tumoren auftrat $(p<0,001)$. Bei nur 4 vorliegenden kolorektalen GIST im Kollektiv läßt sich diese Aussage nur schwer bestätigen. Bei einem Verlust an beiden Chromosomen wird bzgl. der Lokalisation keine Signifikanz ( $p$ $=0,083$ ) erreicht (3x Magen, 2x Dünndarm, 2x Dickdarm, 1x Peritoneum). 50,0\% (2 / 4) der vorliegenden kolorektalen Tumoren zeigte diese Kombination. Betrachtet man nur den chromosomalen Verlust an 9q $(n=11)$, so betrug der Anteil 75,0\% (3 / 4).

\subsubsection{Klassifikation und Prognose}

Bei Betrachtung der rezidivfreien Überlebenszeit ließ sich der im "Oncogenetic Tree Model" (Gunawan et al. 2007) beschriebene günstigere klinische Verlauf von GIST mit einem chromosomalen Verlust an $14 q$ nicht bestätigen $(p=0,231)$ und auch die 
Risikoklassifikation nach Fletcher zeigte kein signifikant höheren Anteil an "high-risk"Tumoren.

Bei Betrachtung der Progression fand sich für die "1p"-Richtung des "Oncogenetic Tree Model" im vorliegenden Kollektiv bzgl. des beschriebenen aggressiveren klinischen Verlaufs nur eine knappe Signifikanz ( $p=0,047)$, ohne einen signifikanten Unterschied der rezidivfreien Überlebenszeit $(p=0,067)$. Auch ein Blick in die Literatur ergab widersprüchliche Angaben für den Verlust an 1p. El-Rifai et al. (2000) fanden keine prognostische Signifikanz im Gegensatz zu Debiec-Rychter et al. (2001) sowie Derre et al. (2001), die bei Verlust an 1p in einer univariaten Analyse einen Zusammenhang mit einem ungünstigeren Verlauf nachwiesen. Eine multivariate Analyse mit Berücksichtigung der Tumorlokalisation erbrachte dann keinen signifikanten Zusammenhang mehr. In einer Clusteranalyse waren bei einem Verlust an $1 \mathrm{p}$ im Rahmen des "Oncogenetic Tree Model" (Gunawan et al. 2007) als assoziierte zytogenetische Veränderungen u.a. noch chromosomale Verluste an $13 q$ sowie Zugewinne an 5p nachweisbar. Bereits El-Rifai et al. (2000) beschrieben, dass Zugewinne an $5 p$ signifikant seltener $(p<0,01)$ in benignen Tumoren vorkommen. Sowohl hinsichtlich der Lokalisation (signifikant mehr intestinale Tumoren bei $+5 p$ ) als auch hinsichtlich einer kürzeren rezidivfreien Überlebenszeit $(p<0,001$ für $-13 q$ und $p$ $=0,036$ für $+5 p$ ) fand sich eine Bestätigung für diesen Zusammenhang.

Bei Vergleich der Signifikanz für die rezidivfreie Überlebenszeit ( $p=0,231$ für $-14 q$ und $p=0,067$ für $-1 p$ ) und für die Lokalisation ( $p=0,024$ für $-14 q$ und $p=0,002$ für $-1 p$ ) ließen sich die Aussagen für das "Oncogenetic Tree Model" (Gunawan et al. 2007) zumindest teilweise (für die Lokalisation) bestätigen. Kam im Rahmen des Modells zum Verlust an 1p noch der Verlust an 15q, zeigte sich dann auch im vorliegenden Kollektiv ein signifikanter $(p=0,029)$ Zusammenhang mit der rezidivfreien Überlebenszeit. Wozniak et al. (2007) beschrieben es so, dass ein Verlust an $14 q$ seltener in intestinalen GIST vorkomme, aber durch einen Verlust an $1 p$ und $15 q$ substituiert sei. Auch bei der Risikoklassifikation von GIST konnten Chen Y et al. (2004) in einem mit Daten aus anderen Studien erweiterten Kollektiv (El-Rifai et al. 2000, Gunawan et al. 2002) ein signifikant häufigeres Auftreten von Verlusten an 15q (50,8 vs. 22,3\%; $p=$ $0,004)$ sowie $1 p(63,9 \%$ vs. 33,3\%; $p=0,003)$ und ein geringeres (nicht signifikantes) von Verlusten an 14q (70,6 vs. 54,5\%) an "high-risk"-GIST zeigen. In einer neueren Untersuchung bestätigte sich die Signifikanz von Verlusten an $1 p$ und $15 q$ bei der 
Entwicklung hin zu aggressiverem klinischen Verhalten (Chen Y et al. 2009).

In der Literatur fand sich neben einem frühzeitigen Verlust an $14 q$ im Zuge der weiteren Tumorprogression / -genese noch ein Verlust an 22q (Chen $Y$ et al. 2004, Wozniak et al. 2007). Im Kollektiv zeigte sich eine (knappe) Signifikanz $(p=0,045)$ für das Auftreten eines Rezidivs bei einem Verlust an 22q. Dies bestätigte (knapp) die Annahme des "Oncogenetic Tree Models", dass das Auftreten von -22q den Übergang zu eher ungünstigen zytogenetischen Veränderungen bzw. einem klinischen Verlauf kennzeichnet. Im Cluster mit -22q trat als assoziierte zytogenetische Veränderung u.a. noch ein chromosomaler Verlust an $9 q$ mit einer signifikant $(p=0,03)$ kürzeren rezidivfreien Überlebenszeit auf (Gunawan et al. 2004). Bereits Kim NG et al. (2000) zeigten auf, dass ein Verlust an 9q überwiegend in malignen GIST auftritt. Auch im vorliegenden Kollektiv ließ sich ein signifikanter $(p<0,001)$ Zusammenhang für die rezidivfreie Überlebenszeit finden. Ein Zusammenhang mit einer intestinalen Lokalisation dieser GIST fand sich nicht.

Die 3 untersuchten Metastasen zeigten alle einen chromosomalen Zugewinn an 8q sowie einen Verlust an $6 q$ und 22q. Der Zugewinn an $8 q$ ließ sich auch im Gesamtkollektiv mit einer signifikant kürzeren rezidivfreien Überlebenszeit $(p=0,016)$ als ungünstiger Faktor für die Prognose aufzeigen. Im Allgemeinen waren die Ergebnisse der 3 vorliegenden Metastasen sehr unterschiedlich. Eine Metastase (Metastase 38m) zeigte mehr chromosomale Imbalanzen (8 vs. 7) als der Primärtumor, eine zweite Metastase (Metastase $50 \mathrm{~m}$ ) weniger (11 vs. 17) und die dritte vorliegende Metastase (Metastase 59m) zeigte schließlich keine einzige chromosomale Imbalanz bei 15 Imbalanzen im Primärtumor (0 vs. 15).

\subsection{Mutationsanalyse}

Die Häufigkeit von Mutationen im KIT- oder PDGFRA-Gen in den untersuchten GIST lag bei 85,9\% (68,8\% Mutationen im KIT-Gen und 17,2\% Mutationen im PDGFRAGen), wobei sich in der Literatur eine große Schwankungsbreite fand. Von ca. 50\% (Miettinen et al. 2005) bis 92,9.\% (Heinrich et al. 2003 b). Die weitere Literaturrecherche zeigte, dass dabei v.a. auch das Alter und die Art der Tumorprobe (paraffineingebettetes Gewebe oder Frischgewebe) eine Rolle spielte. DeMatteo et al. 
(2008) fanden in 72 gefrorenen Frischgewebeproben (FG) eine Mutationsrate von 87\% und in 55 paraffineingebetteten Proben (PF) nur 64\% $(p=0,002)$. Dies wurde auf eine Degradierung der DNA im archivierten Material zurückgeführt (Andersson et al. 2006, Lasota et al. 2007, Miettinen et al. 2005). Im überwiegenden Teil der neueren Literatur lagen die Mutationsraten eher am oberen Ende (Rubin et al. 2007). Im vorliegenden Kollektiv unterschied sich die Mutationsrate in den PF- im Vergleich zu den FG-Proben nur unwesentlich ( $81,0 \%$ vs. $76,5 \%)$.

\subsubsection{Mutationen}

Eine Mutation in KIT Exon 11 war mit 64,1\% aller untersuchten GIST am häufigsten. Innerhalb des Exons traten mit $28,1 \%$ v.a. Mutationen (Deletionen und Punktmutationen) in den Codons 557 / 558 auf (Mutationsgruppe $4+5$ ). Der u.a. von Lasota und Miettinen (2008) sowie Antonescu et al. (2003) beobachtete "Hotspot" in den Codons 550 - 561, sowie die Häufung von Mutationen bei Codon 557 - 558, konnte bestätigt werden (s. Tabelle 3.3.2/2, S. 59). Ein zweiter in der Literatur beschriebener "Hotspot" mit "Internal Tandem Repeats" (ITD) am 3' Ende fand sich mit 6,3\% aller Mutationen im vorliegenden Kollektiv innerhalb der publizierten Angaben. Die Mutationen im KIT Exon 9 traten mit 4,7\% eher am unteren Ende im Vergleich mit der Literatur auf (bei Einschluß von Fall 61 mit einer Mutation in KIT Exon 11 und Exon 9 erhöhte sich der Anteil leicht). Das beschriebene, fast ausschließliche Vorkommen der ITD 502 - 503 bei Mutationen im KIT Exon 9, fand sich ebenfalls im untersuchten Kollektiv (Du et al. 2008, Lux et al. 2000, Sakurai et al. 2001). Auch der bei Mutationen im PDGFRA-Gen beschriebene "Hotspot" im Exon 18 (Codon 841 - 848) fand sich bei den vorliegenden Fällen wieder. Häufigste Mutation (62,6\% nach Corless et al. 2005) war dabei - konform mit den Literaturangaben - die Punktmutation D842V mit 63,6\% im untersuchten Kollektiv (Heinrich et al. 2003 a, Lasota und Miettinen 2008, Lasota et al. 2004). Die Mutation bei den zwei GIST mit Mutation im PDGFRA Exon 12 lag dabei teilweise außerhalb des von Lasota et al. (2004) beschriebenen "Minor Hotspot" (Codon 560 - 577).

Was die Exklusivität der Mutationen in Primär-GIST angeht, konnten die in der Literatur beschriebenen Angaben (Heinrich et al. 2003 a, Lasota et al. 2004, Miettinen et al. 2005) bestätigt werden. Keiner der untersuchten Tumoren, bis auf eine Ausnahme (Fall 
61), hatte gleichzeitig eine Mutation im KIT- und PDGFRA-Gen bzw. Mutationen in zwei verschiedenen KIT Exons. Bei der Ausnahme handelte es sich um einen der 4 peritonealen GIST mit einer Mutation sowohl in KIT Exon 11 als auch in Exon 9 mit bereits weit fortgeschrittenem Erkrankungsstadium und palliativer OP mit R2Resektionsstatus. Die gleichzeitige Mutation in KIT Exon 11 und Exon 9 war dabei wahrscheinlich Ausdruck der weit fortgeschrittenen Erkrankung und ggf. vergleichbar den sekundären Mutationen, wie sie auch bei der Resistenzentwicklung und Tumorprogression unter Imatinib-Therapie auftreten (Nishida et al. 2008). Evtl. handelte es sich auch um die Metastase eines unbekannten Primär-GIST.

Ein zweiter Faktor, der, neben dem Alter und der Art der Tumorprobe (FG oder PF), die Mutationsrate bzw. das Verhältnis von KIT- zu PDGFRA-Mutationen beeinflußt, hängt nach dem Review von Miettinen und Lasota (2006) am lokalisationsabhängigen Auftreten der Mutationen. KIT-Exon-9-Mutationen finden sich demnach überwiegend in Dünndarm-GIST und PDGFRA-Mutationen überwiegend in Magen-GIST. So zeigten Studien mit einem gehäuften Anteil an Magen-Tumoren auch eine höhere Mutationsrate in PDGFRA und eine geringere in KIT Exon 9. Tzen et al. (2007) führten als weitere Möglichkeit die ethnische Zusammensetzung ihres Kollektivs als Grund für die geringe Prävalenz von GIST mit Mutation in PDGFRA auf.

\subsubsection{Tumorlokalisation}

GIST mit KIT-Exon-11-Mutation scheinen nach Literaturrecherche keine Assoziation mit einer bestimmten Lokalisation zu haben, während GIST mit KIT-Exon-9-Mutation überwiegend im Dünndarm lokalisiert sind und Tumoren mit Mutation im PDGFRA-Gen fast ausschließlich im Magen (Kontogianni et al. 2008, Lasota et al. 2004, Penzel et al. 2005, Wozniak et al. 2007). Auch im vorliegenden Kollektiv fand sich keine signifikante Korrelation von GIST mit Mutation im KIT Exon 11 und Exon 9 mit der Tumorlokalisation, wobei sich die Präferenz von KIT-Exon-9-GIST mit einer Dünndarmlokalisation bei (nur) 3 gefundenen Mutationen im KIT Exon 9 nicht sicher feststellen ließ. 90,9\% (10/11) der GIST mit Mutation im PDGFRA-Gen (Exon 12 und 18) fanden sich im Magen, des weiteren auch 69,2\% (9 / 13) der Tumoren mit Deletion in Codon 557 / 558 (Mutationsgruppe 4). Die Korrelation von Mutationen im PDGFRAGen und Magenlokalisation erreichte im vorliegenden Kollektiv, u.a. entgegen einer 
Studie von Penzel et al. (2005), keine statistische Signifikanz ( $p=0,085)$. Dagegen lie $\beta$ sich die Aussage von Anderrson et al. (2006) bestätigen, nach der 3' ITD im KIT Exon 11 (Mutationsgruppe 7) ausschließlich im Magen vorkommen.

Die größeren GIST mit Mutation in KIT lagen distal des Magens. Allerdings wurde keine statistische Signifikanz erreicht (Median $8,0 \mathrm{~cm}$ vs. $6,0 \mathrm{~cm}$ ). Auch der eine Fall eines distalen GIST mit Mutation im PDGFRA-Gen spiegelte die Tendenz von distalen GIST hin zu größeren Tumoren wider (Gunawan et al. 2004, Koay et al. 2005). Eine Korrelation von Mutationen in KIT mit der Tumorgröße ließ sich nicht aufzeigen, insbesondere auch nicht der von Kontogianni-Katsarou et al. (2008) bei einer Mutation in KIT Exon 11 Codon 557 / 558 (Mutationsgruppe $4+5$ ) gefundene Zusammenhang mit größeren Tumoren (11,3 cm vs. 4,4 cm). Die Behauptung von Andersson et al. (2006), dass viele kleinere GIST keine Mutation in KIT oder PDGFRA aufweisen, ließ sich in dieser Studie nicht nachvollziehen. Selbst kleinste Tumoren scheinen bereits Mutationen aufzuweisen, bestätigt u.a. durch eine Studie von Corless et al. (2005), die in zufällig diagnostizierten GIST $<=1 \mathrm{~cm}$ Mutationen in KIT nachweisen konnten.

Bezüglich der Anzahl der Mitosen ließ sich, wie in der Literatur beschrieben (Kontogianni-Katsarou et al. 2008), kein signifikanter Zusammenhang von GIST mit einer Mutation in KIT oder PDGFRA bzw. WT-GIST finden $(p=0,28)$. Erst bei Betrachtung von KIT Exon 11 zeigten Tumoren mit Deletion in Codon 557 / 558 (Mutationsgruppe 4) in 76,9\% (10/13) >= 2 Mitosen/10 HPF gegenüber 35,3\% (18/ 51) der anderen Tumoren $(p=0,011)$ einen signifikanten Zusammenhang.

\subsubsection{Klassifikation und Prognose}

Im Hinblick auf die Risikoklassifikationen zeigte sich, dass im untersuchten Kollektiv eine Mutation im KIT-Gen knapp signifikant ( $p=0,033$ ) häufiger in "high-risk"-GIST auftrat (vgl. auch Andersson et al. 2006). Eine Einschränkung auf Mutationen im Codon 557 / 558 (Mutationsgruppe $4+5$ ) ergab dann, wie in der Literatur beschrieben, eine eindeutigere Signifikanz ( $p=0,011)$ mit $70-80 \%$ "high-risk"-GIST (siehe Tabelle 3.3.3/1, S. 61). Die KIT-Exon-9-GIST (Mutationsgruppe 2) zeigten nur eine knapp häufigere $(p=0,037)$ Einordnung in die Gruppe der "high-risk"-GIST (vgl. Kontogianni et al. 2008, Wardelmann et al. 2003), wobei die Aussagekraft bei nur 3 Tumoren im 
Kollektiv eher gering ist. GIST mit Mutation im PDGFRA-Gen hatten mit 18,2\% der Tumoren sogar weniger "high-risk"-GIST als die GIST ohne nachweisbare Mutation in beiden Genen (WT). Damit bestätigte sich die Aussage von Penzel et al. (2005) nicht, nach der Mutationen in KIT oder PDGFRA häufiger in "high-risk"-Tumoren vorkommen. Ein Blick in die Literatur der vergangenen Jahre zeigte widersprüchliche Ergebnisse bzgl. der Aussagekraft einer Mutation im KIT- oder PDGFRA-Gen für die Risikoklassifikation und Prognose. Einige Studien fanden einen signifikanten Zusammenhang (Kontogianni et al. 2008, Lasota et al. 1999, Taniguchi et al. 1999), andere Studien wiederum kamen zu dem Ergebnis, dass eine Mutation keine Auswirkung auf die Risikoklassifizierung und Prognose des Patienten habe (Corless et al. 2002, Rubin et al. 2001).

Eine Ursache für die in der Literatur beschriebenen Korrelationen könnte in der geringen Prävalenz von Mutationen in einigen Studien liegen (u.a. $57 \%$ bei Taniguchi et al. 1999), wobei in den Studien von Kontogianni et al. (2008) und Penzel et al. (2005) eine Mutationsrate von über $70 \%$ vorlag und sich eine eindeutige Signifikanz für das Vorliegen von Mutationen bei malignen GIST fand. Wenn man davon ausgeht, dass die Tumorgenese von GIST mit einer Mutation in KIT oder PDGFRA als tumorauslösendem Faktor beginnt, was inzwischen durch Knock-in-Mäuse belegt wurde (Nakai et al. 2008, Rubin et al. 2005, Sommer et al. 2003), so erscheint plausibel, dass selbst in kleinen (benignen) GIST im frühen Stadium Mutationen nachweisbar sind (Corless et al. 2005). Zu diesem Zeitpunkt, bei ggf. noch wenig nachweisbaren Mitosen/HPF, sollten auch die gängigen Risikoklassifikationen, bei Vorliegen einer Mutation, eher günstigere Ergebnisse ergeben, da alle drei Klassifikationen (nach Franquemont, nach Fletcher und nach Miettinen) hauptsächlich die beiden Parameter, Anzahl der Mitosen und Tumorgröße, mit einbeziehen. So wäre das Vorliegen einer Mutation per se noch kein Hinweis für eine ungünstige Prognose, sondern sollte immer im Zusammenhang mit den Parametern der Risikoklassifikationen (Mitosen, Tumorgröße und -lokalisation) bewertet werden. Ein Blick in die Literatur zeigte, dass je nach Studie ein breites Spektrum von scheinbaren Korrelationen gefunden wurde. Von keinem prognostischen Zusammenhang einer Mutationen im KIT-Gen mit dem Verlauf (Corless et al. 2002, Tzen et al. 2007) bis hin zu einer Studie von Penzel et al. (2005), in der jegliche Mutation in KIT mit "high-risk" bzw. malignen GIST assoziiert war. Im vorliegenden Kollektiv fand sich neben der häufigeren Einordnung von GIST mit Mutation in KIT in die Gruppe der "high-risk"- 
Tumoren, eine knapp signifikant kürzere rezidivfreie Überlebenszeit $(p=0,038)$.

\section{Mutation in KIT Exon 11}

Eine weitere Einschränkung auf Mutationen im Exon 11 des KIT-Gens ergab eine statistisch eindeutige Aussage. Es fand sich eine signifikant kürzere rezidivfreie Überlebenszeit $(p=0,015)$. Allerdings zeigte sich auch hier, dass einige Studien diesen Zusammenhang nicht fanden (Miettinen et al. 2006, Singer et al. 2002, Wardelmann et al. 2003). Die häufigsten Mutationen im KIT-Gen, die Codons 557 / 558 betreffend, zeigten eine signifikant kürzere rezidivfreie Überlebenszeit $(p=0,007)$, die in einigen Studien eine noch deutlichere Signifikanz als im vorliegenden Kollektiv erreichte (Martin et al. 2005, Wardelmann et al. 2003). Bei (nur) 4 vorliegenden GIST mit ITD im KIT Exon 11 (Mutationsgruppe 7) ließ sich der günstige Verlauf für GIST mit ITD (Antonescu et al. 2003, Lasota et al. 2003) nicht aufzeigen ( $p=0,932)$. Anderrson et al. (2006) konnten diese Beziehung bei 10\% $(n=10)$ der untersuchten GIST mit ITD im Exon 11 in ihrem Kollektiv nachweisen. Allerdings ließ sich bestätigen, dass sämtliche GIST dieser Gruppe im Magen auftreten und 75\% weiblichen Geschlechts waren. Nur in einem Fall fand sich eine synchrone Metastase, alle übrigen entwickelten während des Follow-Up von 7 - 51 Monaten kein Rezidiv.

\section{Mutation in KIT Exon 9}

Bei (nur) drei KIT-Exon-9-GIST ist eine statistische Aussage schwierig zu treffen. Die rezidivfreie Überlebenszeit unterschied sich nicht signifikant von den anderen GIST ( $p$ $=0,967)$. Des weiteren war auch die Tumorgröße nicht signifikant größer oder kleiner $(p=0,317) .66,6 \%$ (2/3) der Tumoren lagen im Magen. Dies widersprach einigen Aussagen der Literatur, wonach die meisten dieser GIST größer und im Dünndarm lokalisiert sind. Hinsichtlich der Überlebenszeit fanden sich in der Literatur gegensätzliche Aussagen. Antonescu et al. (2003) und Lasota et al. (2003 b) fanden eine signifikant kürzere rezidivfreie Überlebenszeit, wogegen die meisten neueren Studien keinen Zusammenhang feststellen konnten (Andersson et al. 2006, Keun Park et al. 2008, Kim TW et al. 2004, Miettinen et al. 2006, Tzen et al. 2007). Miettinen et al. (2006) führten den teilweise in den Studien vorhandenen Zusammenhang mit der Überlebenszeit auf das allgemein aggressivere Verhalten von Dünndarm-GIST zurück (vgl. auch Chen Y et al. 2004, Emory et al. 1999, Gunawan et al. 2004). 


\section{Mutation in PDGFRA}

Die Aussagen zur Prognose von GIST mit Mutation im PDGFRA-Gen sind widersprüchlich. Neben Studien mit einem überwiegend günstigen klinischen Verlauf (Lasota et al. 2004) fanden sich Studien, die keinen Zusammenhang einer Mutation mit dem klinischen Verlauf nachweisen konnten (Corless et al. 2005, DeMatteo et al. 2008, Tzen et al. 2007). DeMatteo et al. (2008) führten den in einigen Studien gefundenen Zusammenhang auf die Tatsache zurück, dass fast alle GIST mit Mutation in PDGFRA im Magen auftraten und Magen-GIST im Allgemeinen einen eher gutartigen klinischen Verlauf zeigen. Auch im Kollektiv findet sich eine signifikant längere rezidivfreie Überlebenszeit für Magen-GIST mit im Median 34,0 vs. 14,0 Monaten $(p=0,002)$. Bei den untersuchten Tumoren mit Mutation in PDGFRA fand sich eine knapp signifikant längere rezidivfreie Überlebenszeit ( $p=0,037$ ) von im Median 40,0 vs. 25,0 Monaten. Bei allen GIST zeigte sich kein Progress im Verlauf von 40 Monaten (Median). Lasota et al. (2004) fanden nach einem durchschnittlichen Follow-Up von 135 Monaten bei noch lebenden $45,1 \%$ der Patienten keinen weiteren Nachweis eines GIST. Die ebenfalls gefundene Korrelation von GIST mit Deletion bzw. Deletion und Punktmutation in PDGFRA und der rezidivfreien Überlebenszeit ließ sich bei nur zwei vorliegenden Tumoren mit diesen Mutationen nicht nachvollziehen (Fall 8 und 14).

\subsubsection{Imatinib-Therapie}

Die rezidivfreie Überlebenszeit (siehe Tabelle 3.3.5/2, S. 63) der mit Imatinib behandelten Patienten war signifikant $(p<0,001)$ kürzer als die der übrigen Patienten (im Median 19,0 vs. 28,0 Monate). Dabei zeigten die GIST der Imatinib-Gruppe 2 (R0Resektion mit synchronen Metastasen) die erwartete kürzeste Zeit bei bereits fortgeschrittener / metastasierten GIST zum OP-Zeitpunkt. Bemerkenswert war die mit 30,5 Monaten recht lange rezidivfreie Überlebenszeit der Imatinib-Gruppe 4 (nach R1Resektion), vergleichbar den nicht mit Imatinib-behandelten Patienten, sowie die längere Überlebenszeit (39,0 vs. 28,0 Monate) der Imatinib-Gruppe 1 (nach R0Resektion) ebenfalls bei Vergleich mit den nicht medikamentös behandelten Patienten. Von der Imatinib-Gruppe 3 (nach Ro-Resektion bei Rezidiv im Follow-Up) starb bis zum Ende des Follow-Up kein Patient bei einer medianen Follow-Up-Zeit von 38,0 
Monaten vom Auftreten des Rezidivs bis zum Ende des Follow-Up.

Bis auf 2 Fälle (1x WT, 1x KIT Exon 9) zeigten alle mit Imatinib-behandelten Patienten eine Mutation im KIT Exon 11, welche im Allgemeinen die beste Ansprechrate auf die Therapie mit Imatinib zeigen (Andersson et al. 2006, Tornillo et al. 2006, Tzen et al. 2007).

Bei den 3 neben dem Primärtumor (Fall 38, 50 und 59) vorliegenden Metastasen fanden sich erwartungsgemäß identische Mutationen und bestätigten damit die auch in der Literatur beschriebenen Fälle, in denen Metastasen eine zum Primärtumor identische Mutation aufwiesen. Erst im Rahmen der Resistenzentwicklung unter Imatinib-Therapie kommt es anscheinend vermehrt zu sekundären Mutationen (Wardelmann et al. 2006).

\subsection{CGH und Mutationsanalyse}

Die meisten chromosomalen Imbalanzen fanden sich in GIST mit einer Mutation in den Codons 557 / 558 mit im Median 9,5 chromosomalen Imbalanzen $(p=0,008)$. Bei Betrachtung der Anzahl chromosomaler Imbalanzen hatten Tumoren $>=5$ Imbalanzen mit im Median 19,0 vs. 28,5 Monaten, unabhängig von einer Mutation in KIT bzw. PDGFRA oder WT, eine signifikant kürzere rezidivfreie Überlebenszeit $(p<0,001)$. 41,9\% (13 / 31) aller GIST mit >= 5 Imbalanzen zeigten sich in den Mutationsgruppen 4 + 5 mit einer signifikant $(p<0,001)$ kürzeren rezidivfreien Überlebenszeit (im Median 23,0 vs. 27,5 Monate). Obwohl 50\% (5/10) der GIST mit Mutation im PDGFRA-Gen $>=5$ Imbalanzen aufwiesen, fand sich keine signifikant längere rezidivfreie Überlebenszeit (im Median 69,0 vs. 25,5 Monaten mit $p=0,169$ ). Die bessere Prognose der GIST mit Mutation im PDGFRA-Gen kann nicht nur auf die Lokalisation geschoben werden, denn auch 55,6\% $(n=10)$ der GIST aus den Mutationsgruppen 4 + 5 mit der signifikant kürzeren rezidivfreien Überlebenszeit waren im Magen lokalisiert. Somit zeigten sowohl 23,3\% (10 / 43) der Magen-GIST eine Mutation im PDGFRA-Gen als auch 23,3\% (10 / 43) der Magen-GIST eine Mutation im Codon 557 / 558 (Mutationsgruppe $4+5$ ). Das signifikant längere rezidivfreie Überleben bei MagenGIST $(p=0,002)$ scheint somit nicht mit einer Mutation in PDGFRA zusammenzuhängen. Ein Vergleich der restlichen Magen-GIST (5x WT, 18x sonstige 
KIT-Mutationen) offenbarte keine signifikant längere rezidivfreie Überlebenszeit ( $p=$ 0,362 ) im Vergleich mit dem Restkollektiv (im Median 28,0 vs. 22,0 Monate). Einen Überblick über die rezidivfreie Überlebenszeit bei Mutationen in Tumoren mit $>=5$ chromosomalen Imbalanzen gibt Tabelle 4.4/1. Erwartungsgemäß fand sich bei (fast) allen Mutationen eine (signifikant) kürzere rezidivfreie Überlebenszeit beim Vorliegen von >= 5 Imbalanzen. Nur bei den im PDGFRA-Gen mutierten Primär-GIST zeigte sich eine längere rezidivfreie Überlebenszeit (im Median 69,0 vs. 40,0 Monaten).

Tabelle 4.4/1

Rezidivfreie Überlebenszeit bei Primär-GIST >= 5 chromosomale Imbalanzen

\begin{tabular}{|c|c|c|c|}
\hline Primär-GIST & Anzahl & p-Wert ${ }^{\star *}$ & $\begin{array}{c}\text { rezidivfreie } \\
\text { Überlebenszeit } \\
\text { (Median) }\end{array}$ \\
\hline Alle Primär-GIST & 31 & $>=5 \mathrm{Cl}^{*}:<0,001$ & 19,0 vs. 28,5 Monate \\
\hline WT & 2 & $\begin{array}{l}>=5 \mathrm{Cl}^{*}: 0,007 \\
\text { alle WT: } 0,634\end{array}$ & $\begin{array}{l}10,5 \text { vs. } 27,0 \text { Monate } \\
22,0 \text { vs. } 27,0 \text { Monate }\end{array}$ \\
\hline KIT & 24 & $\begin{array}{c}>=5 \mathrm{Cl}^{*}:<0,001 \\
\text { alle KIT: } 0,038\end{array}$ & $\begin{array}{l}18,0 \text { vs. } 28,0 \text { Monate } \\
25,5 \text { vs. } 34,5 \text { Monate }\end{array}$ \\
\hline $\begin{array}{l}\text { Mutationsgruppe } \\
\qquad 4+5\end{array}$ & 13 & $\begin{array}{c}>=5 \mathrm{Cl}^{*}:<0,001 \\
\text { alle Grp. 4+5: 0,007 }\end{array}$ & $\begin{array}{l}23,0 \text { vs. } 27,5 \text { Monate } \\
21,0 \text { vs. } 28,5 \text { Monate }\end{array}$ \\
\hline PDGFRA & 5 & $\begin{array}{l}\qquad>5 \mathrm{Cl}^{*}: 0,169 \\
\text { alle PDGFRA: 0,037 }\end{array}$ & $\begin{array}{l}\text { 69,0 vs. } 25,5 \text { Monate } \\
40,0 \text { vs. } 25,0 \text { Monate }\end{array}$ \\
\hline
\end{tabular}

\subsubsection{Chromosomale Imbalanzen an $1 p$ und $15 q$}

Im vorliegenden Kollektiv fanden sich bei Vorliegen eines chromosomalen Verlustes an $1 p$ in $73,1 \%$ (19/26) aller GIST Mutationen im KIT-Gen. Das alleinige Vorliegen einer chromosomalen Imbalanz war nicht signifikant $(p=0,067)$ mit der rezidivfreien Überlebenszeit verknüpft. Nahm man die Mutation im KIT-Gen als zweiten Parameter hinzu, so zeigte sich mit im Median 21,0 vs. 26,5 Monaten eine signifikant kürzere rezidivfreie Überlebenszeit $(p=0,013)$. Schränkte man die Betrachtung auf Mutationen in KIT Exon 11 Codon 557 / 558 (Mutationsgruppe $4+5$ ) ein, so erhöhte 
sich die Signifikanz deutlich mit einer rezidivfreien Überlebenszeit von im Median 17,0 bzw. 26,0 Monaten ( $p=0,001)$. Im Rahmen des "Oncogenetic Tree Models" (Gunawan et al. 2007) ist die "1p"-Richtung v.a. von intestinalen GIST mit komplexeren zytogenetischen Veränderungen und einem aggressiveren klinischen Verlauf gekennzeichnet und läßt sich durch die Korrelation mit der Mutationsanalyse, im Hinblick auf die Prognose, nun weiter präzisieren. Eine Assoziation mit malignen GIST bei chromosomalem Verlust an 1p fanden Debiec-Rychter et al. (2001), entgegen den vorliegenden Ergebnissen, nur bei WT-GIST. Von insgesamt 26 untersuchten GIST mit einem Verlust an $1 \mathrm{p}$ fand sich nur in 26,9\% (7 / 26) keine Mutation im KIT-Gen. Diese Tumoren zeigten bzgl. der rezidivfreien Überlebenszeit keinen signifikanten Vor- oder Nachteil $(p=0,443)$. Alle GIST außerhalb des Magens mit Mutation im KIT-Gen (13/ 13) zeigten, wie bereits von Wozniak et al. (2007) beschrieben, einen Verlust an $1 p$ ( $p$ $<0,001)$. Die 21,4\% (6 / 28) der untersuchten Magen-GIST mit Mutation im KIT-Gen und Verlust an $1 \mathrm{p}$ hatten allerdings keine signifikant unterschiedliche rezidivfreie Überlebenszeit $(p=0,947)$.

46,2\% (12 / 26) der GIST mit einem chromosomalen Verlust an $1 p$ lagen im Magen. Betrachtet man die GIST mit Verlust an 1p und Mutation in KIT, lagen mit 31,6\% (6 / 19) prozentual weniger GIST im Magen als bei Betrachtung des chromosomalen Verlustes allein. Dies widerspricht der von Wozniak et al. (2007) gefundenen annährenden Gleichverteilung mit 45,0 vs. $43,5 \%$. Da eine Mutation im KIT-Gen knapp signifikant $(p=0,038)$ häufiger mit einer kürzeren rezidivfreien Überlebenszeit verknüpft war, scheint das Ergebnis aus dem vorliegenden Kollektiv plausibel, da eine erwartete Zunahme von GIST mit ungünstiger Prognose eine Zunahme an intestinalen GIST erwarten läßt. GIST außerhalb des Magens haben, wie bereits weiter oben dargestellt, eine signifikant kürzere rezidivfreie Überlebenszeit $(p=0,002)$. Schränkt man den Fokus noch weiter auf eine Gruppe von GIST mit Verlust an $1 \mathrm{p}$ und Mutation in KIT Exon 11 Codon 557 / 558 (Mutationsgruppe 4 + 5) ein, so würde man, aufgrund der noch schlechteren Prognose von GIST aus der Mutationsgruppe $4+5$ (im Vergleich mit den in KIT-mutierten GIST), eine weitere prozentuale Zunahme der GIST außerhalb des Magens erwarten. Entgegen dieser Überlegung fand sich mit 37,5\% (3 / 8) wieder eine leichte Zunahme der Magen-GIST (siehe Tabelle 4.4.4/1, S. 87).

Analog dem Verlust an $1 p$ fand sich, im Vergleich mit dem chromosomalen Verlust allein, bei GIST mit chromosomalen Verlust an 15q und Mutation im KIT-Gen eine 
höhere Signifikanz bzgl. der rezidivfreien Überlebenszeit ( $p=0,014$ vs. $p=0,022$ ) sowie ein annährend gleichbleibender Anteil an Magen-GIST (21,4\% vs. $23,1 \%)$. In der Studie von Wozniak et al. (2007) zeigte sich dabei eine noch stärker ausgeprägte Zunahme von Magen-GIST (17,5\% vs. $26,1 \%$ ). Unerwartet war allerdings, dass bei Einschränkung auf die Mutationsgruppen $4+5$, kein signifikanter Zusammenhang mit der rezidivfreien Überlebenszeit mehr bestand und der Anteil der Magen-GIST auf 40,0\% (2 / 5) anstieg. Die Ursache dafür liegt wahrscheinlich in der geringen Fallzahl ( $\mathrm{n}$ $=5$ ) von GIST mit einem Verlust an 15q und einer Mutation in KIT Exon 11 Codon 557 / 558 (Mutationsgruppe $4+5$ ). Da 85,7\% der GIST mit einem Verlust an 15q auch einen Verlust an $1 p$ aufwiesen, sollte sich die Prognose bei kombiniertem Verlust (-1p und $-15 q)$, im Hinblick auf die rezidivfreie Überlebenszeit, nicht groß unterscheiden. Hier zeigte sich die (erwartete) Zunahme der Signifikanz bei Einschränkung auf die Mutationsgruppen $4+5(p=0,005)$. Mit 25,0\% gab es dabei einen unerwartet hohen Anteil an Magen-GIST (vs. 8,3\% Magen-GIST bei kombiniertem Verlust ohne Berücksichtigung der Mutation). Die GIST der Mutationsgruppen $4+5$ unterschieden sich bei einem Verlust an 15q $(n=5)$ von der Gruppe mit einem Verlust an $1 p$ und 15q $(n=4)$ nur durch einen Fall (Nr. 24). Dieser zeigte, trotz einer für diese Kombination recht langen rezidivfreien Überlebenszeit von 72 Monaten (ursächlich wahrscheinlich durch die Magenlokalisation bedingt), eine "high-risk"-Klassifikation nach Fletcher und eine für die Prognose ungünstige Mutation in KIT (Mutationsgruppe 4).

Die Aussage von Wozniak et al. (2007), dass ein Verlust an 15q signifikant seltener in GIST mit Mutationen im PDGFRA-Gen als bei Mutationen im KIT-Gen vorkommt ( $p=$ $0,006)$, läßt sich im untersuchten Kollektiv nicht bestätigen $(p=0,095)$. Dabei wies kein GIST $(0 / 10)$ mit Mutation in PDGFRA einen chromosomalen Verlust an 15q auf (gegenüber 29,5\% (13 / 44) bei Mutation in KIT). Bei einer höheren Fallzahl im vorliegenden Kollektiv wäre das Signifikanzniveau wahrscheinlich erreicht worden.

\subsubsection{Chromosomale Imbalanzen an 9p und 9q}

Eine zweiter von Debiec-Rychter et al. (2001) gefundener Zusammenhang betrifft einen Verlust an Chromosom 9 mit gleichzeitiger Mutation im KIT-Gen bei malignen Tumoren. Im vorliegenden Kollektiv fanden sich, bei einem Verlust an Chromosom 9p bzw. 9q, in $81,8 \%(9 / 11)$ Mutationen im KIT-Gen. Allein das Vorliegen der 
chromosomalen Imbalanz war signifikant mit der rezidivfreien Überlebenszeit assoziiert $(p<0,001)$. Das Hinzuziehen der Mutation im KIT-Gen als zweiten Parameter brachte dabei keinen zusätzlichen Erkenntnisgewinn $(p<0,001)$. Es fand sich zwar ebenfalls eine statistisch signifikant kürzere rezidivfreie Überlebenszeit $(p=0,001)$, dabei war das Signifikanzniveau allerdings fast identisch mit dem Ergebnis der CGH (als einzigem Parameter). Im Gegensatz zum chromosomalen Verlust an $1 \mathrm{p}$ zeigte in diesem Fall auch die Beschränkung auf die Mutationsgruppe $4+5$ keine weitere Erhöhung der Signifikanz ( $p=0,010$ bzw. $p=0,005$ ) mit im Median 6,5 vs. 27,0 Monaten rezidivfreier Überlebenszeit für $9 p$ und 13,0 vs. 26,5 Monate für $9 q$.

Der Anteil an Magen-GIST nahm, entsprechend den Erwartungen, bei Kombination mit prognostisch ungünstigen Mutationen, angefangen vom chromosomalen Verlust allein, über den Verlust in Kombination mit einer Mutation in KIT, bis hin zur Kombination mit einer Mutation in KIT Exon 11 Codon 557 / 558, kontinuierlich ab.

\subsubsection{Chromosomale Imbalanzen an $\mathbf{1 4 q}$}

Wie bereits unter 4.2.3. dargestellt wurde, existiert kein signifikanter Zusammenhang eines chromosomalen Verlustes an $14 q(n=42)$ mit der rezidivfreien Überlebenszeit $(p$ $=0,231$ ). Auch bei Einengung des Betrachtungsfokus auf GIST mit Verlust an 14q und Mutation in KIT $(n=31)$ ergab sich keine Signifikanz $(p=0,682)$. Erst bei weiterer Einengung auf einen Verlust an 14q und Mutation in KIT Exon 11 Codon 557 / 558, den Mutationsgruppen $4+5(n=5)$, zeigte sich ein Trend in Richtung eines signifikanten Ergebnisses $(p=0,055)$, welches aber nicht erreicht wurde.

Der Anteil an Magen-GIST nahm von $78,6 \%$, bei chromosomalem Verlust allein, bis hin zu $66,7 \%$ in den Mutationsgruppen $4+5$, ab. So zeigte sich, trotz der Assoziation des Verlustes an 14q mit einer Lokalisation im Magen, eine prozentuale Zunahme der intestinalen GIST, was schon durch den Wegfall der GIST mit Mutation in PDGFRA (fast ausschließlich Magen-GIST), durch Einschränkung auf die in KIT-mutierten Tumoren, erklärlich ist. Ursprünglich geht, wie bereits von Wozniak et al. (2007) mit $87,5 \%$ vs. $87,0 \%$ beschrieben, eine Mutation im KIT-Gen, sowie eine Mutation im PDGFRA-Gen, annährend gleich häufig ( $85,7 \%$ vs. $88,9 \%)$ mit einem Verlust an $14 q$ einher. Bei Bewertung eines chromosomalen Verlustes an $14 q$ als sehr früh 
auftretende Imbalanz im Rahmen der Tumorprogression, erklärt sich die fehlende Signifikanz, wenn man davon ausgeht, dass auch Tumoren mit prognostisch günstigerem Verlauf diesen Verlust aufweisen. Trotz fehlender Signifikanz zeigte sich eine deutliche Abnahme der (im Vergleich zum Restkollektiv mit im Median 31,5 vs. 19,0 Monaten) ursprünglich längeren rezidivfreien Überlebenszeit auf 25,5 vs. 26,0 Monate bei Verlust an 14q und Vorliegen einer Mutation in den Gruppen $4+5$.

GIST, mit signifikant längerer rezidivfreier Überlebenszeit bei Mutation in PDGFRA (40,0 vs. 25,0 Monate), verloren, bei näherer Betrachtung der Tumoren mit einer Mutation in PDGFRA und einem chromosomalen Verlust an 14q, die Signifikanz bzgl. der Überlebenszeit mit im Median 29,0 vs. 25,5 ( $p=0,073$ ). Der Verlust an 14q ist somit zwar als sehr früher Faktor im Rahmen der Tumorprogression zu werten, geht aber selbst bei den prognostisch eher günstiger verlaufenden GIST (mit Mutation in PDGFRA) mit einem Verlust an rezidivfreier Überlebenszeit einher.

\subsubsection{Chromosomale Imbalanzen an 22q}

Ein chromosomaler Verlust an 22q zeigte, bei gleichzeitiger Mutation im KIT-Gen, mit 23,0 vs. 27,5 Monaten eine signifikant kürzere rezidivfreie Überlebenszeit als der Rest des Kollektivs $(p=0,028)$ und damit eine Zunahme der Signifikanz im Vergleich mit Tumoren ohne die Mutation. In den Mutationsgruppen $4+5$ betrug die rezidivfreie Überlebenszeit bei Verlust an 22q im Median 18,0 vs. 27,5 Monate ( $p=0,001$ ).

Bei einem chromosomalen Verlust an $22 q$ zeigte sich dabei eine annährende Gleichverteilung bzgl. der Lokalisation im Magen und außerhalb (57,1\% vs. $42,9 \%)$. Auch bei Einschränkung auf Mutationen in KIT bzw. KIT Exon 11 Codon 557 / 558 (Mutationsgruppen $4+5$ ) ergab sich mit 55,6 bzw. 53,8\% keine große Änderung in der Verteilung, so dass die mit der Einschränkung einhergehende, signifikante kürzere rezidivfreie Überlebenszeit, keine Präferenz im Hinblick auf die Lokalisation zeigt. Die durch einen Verlust an 22q gekennzeichnete Tumorprogression scheint also, im Gegensatz zu den anderen beschriebenen Imbalanzen, keinen Unterschied bzgl. der Lokalisation zu machen. Ein Verlust an 22q ist im Rahmen der Tumorprogression als relativ frühzeitige chromosomale Imbalanz beschrieben und erklärt so den oben gefundenen Zusammenhang wahrscheinlich hinreichend, obwohl im Rahmen des 
"Oncogenetic Tree Models" (Gunawan et al. 2007) ein Verlust an 22q den Übergang zu komplexeren zytogenetischen Veränderungen kennzeichnet (Gunawan et al. 2007) und damit wohl erst (relativ) spät in der Tumorgenese angesiedelt sein sollte.. Eine Klärung dieses Problems ließ sich mit den vorliegenden Daten nicht erreichen. Ausgehend von der Tatsache, dass im vorliegenden Kollektiv ein Verlust an 22q nur eine knappe Assoziation mit der rezidivfreien Überlebenszeit zeigte, scheint ein früher Zeitpunkt für diesen Verlust wahrscheinlich.

Tabelle 4.4.4/1

Rezidivfreie Überlebenszeit bei spezifischen Imbalanzen und Mutationen

\begin{tabular}{|c|c|c|c|c|c|}
\hline $\begin{array}{c}\text { Chromosomale } \\
\text { Imbalanz }\end{array}$ & Mutation & Anzahl & Magen-GIST & $\begin{array}{l}\text { Rezidivfreie } \\
\text { Überlebenszeit } \\
\text { (p-Wert) }\end{array}$ & $\begin{array}{c}\text { Rezidivfreie } \\
\text { Überlebenszeit } \\
\text { (Monate - Median) }\end{array}$ \\
\hline \multirow{3}{*}{$-1 p$} & alle & 26 & $46,2 \%(n=12)$ & 0,067 & 20,0 vs. 27,0 \\
\hline & $\mathrm{KIT}$ & 19 & $31,6 \%(n=6)$ & 0,013 & 21,0 vs. 26,5 \\
\hline & Grp. $4+5$ & 8 & $37,5 \%(n=3)$ & 0,001 & 17,0 vs. 26,0 \\
\hline \multirow{3}{*}{$-9 p /-9 q$} & alle & $11 / 11$ & $\begin{array}{c}54,5 \% / 36,4 \% \\
(n=6 / 4)\end{array}$ & $<0,001 /<0,001$ & $\begin{array}{l}13,0 \text { vs. } 27,5(9 p) \\
8,0 \text { vs. } 27,5(9 q)\end{array}$ \\
\hline & KIT & $9 / 9$ & $\begin{array}{c}44,4 \% / 22,2 \% \\
(n=4 / 2)\end{array}$ & $<0,001 /<0,001$ & $\begin{array}{c}13,0 \text { vs. } 27,5(9 p) \\
8,0 \text { vs. } 27,5(9 q)\end{array}$ \\
\hline & Grp. $4+5$ & $6 / 7$ & $\begin{array}{c}33,3 \% / 28,6 \% \\
(n=2 / 2)\end{array}$ & $0,010 / 0,005$ & $\begin{array}{c}6,5 \text { vs. } 27,0(9 p) \\
13,0 \text { vs. } 26,5(9 q)\end{array}$ \\
\hline \multirow{3}{*}{$-14 q$} & alle & 42 & $78,6 \%(n=33)$ & 0,231 & 31,5 vs. 19,0 \\
\hline & KIT & 31 & $77,4 \% \%(n=24)$ & 0,682 & 34,0 vs. 20,0 \\
\hline & Grp. $4+5$ & 12 & $66,7 \%(n=8)$ & 0,053 & 25,5 vs. 26,0 \\
\hline \multirow{3}{*}{$-15 q$} & alle & 14 & $21,4 \%(n=3)$ & 0,022 & 15,5 vs. 28,0 \\
\hline & KIT & 13 & $23,1 \%(n=3)$ & 0,014 & 17,0 vs. 28,0 \\
\hline & Grp. $4+5$ & 5 & $40,0 \%(n=2)$ & 0,055 & 0,0 vs. 26,5 \\
\hline \multirow{3}{*}{$-1 p$ und $-15 q$} & alle & 12 & $8,3 \%(n=1)$ & 0,029 & 13,5 vs. 28,0 \\
\hline & KIT & 11 & $9,1 \%(n=1)$ & 0,018 & 13,0 vs. 28,0 \\
\hline & Grp. $4+5$ & 4 & $25,0 \%(n=1)$ & 0,005 & 0,0 vs. 27,0 \\
\hline \multirow{3}{*}{$-22 q$} & alle & 28 & $57,1 \%(n=16)$ & 0,045 & 24,0 vs. 27,0 \\
\hline & $\mathrm{KIT}$ & 27 & $55,6 \%(n=15)$ & 0,028 & 23,0 vs. 27,5 \\
\hline & Grp. $4+5$ & 13 & $53,8 \%(n=7)$ & 0,001 & 18,0 vs. 27,5 \\
\hline
\end{tabular}




\subsubsection{Imatinib}

Bei der Korrelation von Mutationen mit chromosomalen Imbalanzen waren nicht alle gefundenen Ergebnisse plausibel, v.a. bei Mutationen in den Gruppen $4+5$.

Tabelle 4.4.5/1

Anteil mit Imatinib behandelter GIST bei Mutation in KIT bzW. Mutationsgruppe $4+5$

\begin{tabular}{|c|c|c|}
\hline $\begin{array}{c}\text { Chromosomale } \\
\text { Imbalanz }\end{array}$ & Mutation & Anteil Imatinib behandelter GIST (\%) \\
\hline \multirow{2}{*}{$-1 p$} & KIT & $62,5 \%$ \\
\hline & Grp. $4+5$ & $60,0 \%$ \\
\hline \multirow{2}{*}{$-9 p /-9 q$} & KIT & $43,8 \% / 37,5 \%$ \\
\hline & Grp. $4+5$ & $40,0 \% / 50,0 \%$ \\
\hline \multirow{2}{*}{$-14 q$} & KIT & $62,5 \%$ \\
\hline & Grp. $4+5$ & $60,0 \%$ \\
\hline \multirow{2}{*}{$-15 q$} & KIT & $50,0 \%$ \\
\hline & Grp. $4+5$ & $30,0 \%$ \\
\hline \multirow{2}{*}{$-1 p$ und $-15 q$} & KIT & $43,8 \%$ \\
\hline & Grp. $4+5$ & $30,0 \%$ \\
\hline \multirow{2}{*}{$-22 q$} & KIT & $68,8 \%$ \\
\hline & Grp. $4+5$ & $80,0 \%$ \\
\hline
\end{tabular}

Dazu zählten die fehlende Signifikanzzunahme bzgl. der rezidivfreien Überlebenszeit bei einem Verlust an $9 p$ oder $9 q$, die bei der prognostisch ungünstigen Mutationsgruppe $4+5$ fehlende Signifikanz bei einem Verlust an $14 q$ und schließlich der Verlust der Signifikanz bei einem chromosomalen Verlust an 15q. Ein Erklärungsversuch durch eine postulierte (signifikante) Zunahme von Imatinibbehandelten Patienten in diesen Gruppen brachte kein Ergebnis. Insgesamt 58,8\% (10 / 17) aller mit Imatinib behandelten Patienten zeigten eine Mutation in den Gruppen 4 + 5. Das entsprach 55,6\% (10 / 18) aller GIST mit Mutation in diesen Gruppen. Bei einem chromosomalen Verlust an 9p bzw. 9q und einer Mutation in KIT wurden 43,8\% (7 / 16) bzw. 37,5\% (6 / 16) mit Imatinib behandelt. Bei Mutation in den Gruppen $4+5$ erhöhte sich der prozentuale Anteil (nicht signifikant) auf 40,0\% (4 / 10) bzw. 50,0\% (5/ 10). 
Auch bei einem chromosomalen Verlust an 14q und einer Mutation in KIT, bzw. den Mutationsgruppen $4+5$, zeigte sich keine signifikante Änderung mit 62,5\% (10/16) bzw. 60,0\% (6/10). Ein chromosomaler Verlust an 15q, mit dem auffälligen Verlust der Signifikanz für die rezidivfreie Überlebenszeit bei den Mutationsgruppen $4+5$ ( $p=$ 0,055), zeigte die größte Änderung beim prozentualen Anteil der mit Imatinib behandelten GIST (50,0\% vs. 30,0\%). Einen Überblick gibt Tabelle 4.4.5/1. 


\section{Zusammenfassung}

Das Ziel dieser Arbeit ist die Korrelation der Ergebnisse einer komparativen genomischen Hybridisierung (CGH) mit den Ergebnissen einer Mutationsanalyse bei gastrointestinalen Stromatumoren (GIST) - insbesondere im Hinblick auf die Prognose (v.a. rezidivfreie Überlebenszeit) der betroffenen Patienten.

Ein erwartetes Ergebnis fand sich in der Assoziation von GIST mit Mutation in KIT Exon 11 Codon 557 / 558 (Mutationsgruppe $4+5$ ) bei >= 5 vorliegenden chromosomalen Imbalanzen mit einer signifikant kürzeren rezidivfreien Überlebenszeit. Beide Parameter ( $>=5$ chromosomale Imbalanzen und eine Mutation in den Gruppen 4 + 5) und ihr Zusammenhang mit einer ungünstigen Prognose sind bereits vielfach in der gängigen Literatur beschrieben worden. Mit der gefundenen Assoziation bestätigte sich nun auch der Zusammenhang beider Parameter untereinander. Darüber hinaus zeigte sich in den Mutationsgruppen $4+5$ auch die höchste Anzahl an chromosomalen Imbalanzen im Vergleich mit allen anderen untersuchten GIST. Als unerwartetes Ergebnis zeigten auch 50,0\% der in PDGFRA-mutierten GIST >= 5 chromosomale Imbalanzen. Es fand sich bei diesen Tumoren, im Gegensatz zum Restkollektiv bzw. den anderen Mutationen / WT, kein signifikanter Zusammenhang mit der rezidivfreien Überlebenszeit.

Eine klinisch relevante Fragestellung ist, ob eher die Durchführung einer Mutationsanalyse oder die Durchführung einer $\mathrm{CGH}$ für die Beurteilung der Prognose Sinn macht. Bei Korrelation beider Untersuchungen zeigte sich fast durchgehend ein signifikanteres Ergebnis als bei Beurteilung der Prognose mithilfe nur einer der beiden Untersuchungen. Ist man gezwungen, eine Wahl zu treffen, so macht v.a. eine Mutationsanalyse Sinn, da man mit den Ergebnissen ggf. den Sinn oder Unsinn einer Therapie mit Imatinib oder, bei Vorliegen einer resistenten Mutation, eines alternativen Tyrosinkinase-Inhibitors erwägen kann. Auch die Leitlinien der "European Society of Medical Oncology“ empfehlen u.a. aus diesen Gründen eine Mutationsanalyse bei allen GIST (Casali et al. 2009). Ausgehend von der Tatsache, dass schon kleinste GIST eine Mutation im KIT- oder PDGFRA-Gen aufweisen, läßt sich mithilfe des Musters an chromosomalen Imbalanzen aus einer CGH-Analyse eine Aussage über den Stand der klonalen Entwicklung bzw. der Tumorprogression des GIST treffen und damit ggf. über den Einsatz adjuvanter Therapien entscheiden. 


\section{Anhang}

\subsection{Klinisch-pathologische Parameter - Kollektivübersicht}

Tabelle 6.1/1 Klinisch-pathologische Parameter - Kollektivübersicht

\begin{tabular}{|c|c|c|c|c|c|}
\hline Fall & Alter & Geschlecht $^{\star}$ & Organ & $\begin{array}{l}\text { Tumorgröße } \\
\text { in cm (max.) }\end{array}$ & Mitosen/10 HPF \\
\hline 01 & 45 & w & Ösophagus & 6,0 & 0 \\
\hline 02 & 39 & w & Magen & 10,0 & 0 \\
\hline 03 & 45 & w & Magen & 4,5 & 0 \\
\hline 04 & 47 & $\mathrm{~m}$ & Magen & 6,0 & 1 \\
\hline 05 & 52 & $\mathrm{~m}$ & Magen & 3,0 & 1 \\
\hline 06 & 52 & $\mathrm{~m}$ & Magen & 4,0 & 0 \\
\hline 07 & 53 & $\mathrm{~m}$ & Magen & 9,0 & 0 \\
\hline 08 & 53 & $\mathrm{~m}$ & Magen & 7,0 & 1 \\
\hline 09 & 58 & $\mathrm{~m}$ & Magen & 7,5 & 1 \\
\hline 10 & 61 & $\mathrm{~m}$ & Magen & & 0 \\
\hline 11 & 64 & $\mathrm{~m}$ & Magen & 6,0 & 10 \\
\hline 12 & 64 & w & Magen & 5,5 & 3 \\
\hline 13 & 65 & $\mathrm{~m}$ & Magen & 6,5 & 1 \\
\hline 14 & 66 & $\mathrm{~m}$ & Magen & 4,0 & 19 \\
\hline 15 & 66 & $\mathrm{~m}$ & Magen & 6,0 & 1 \\
\hline 16 & 66 & $\mathrm{~m}$ & Magen & 10,0 & 1 \\
\hline 17 & 67 & $\mathrm{~m}$ & Magen & 6,0 & 0 \\
\hline 18 & 68 & $\mathrm{~m}$ & Magen & 21,0 & 15 \\
\hline 19 & 69 & w & Magen & 3,8 & 2 \\
\hline 20 & 69 & w & Magen & 1,7 & 0 \\
\hline 21 & 70 & w & Magen & 10,0 & 0 \\
\hline 22 & 72 & $\mathrm{~m}$ & Magen & 7,4 & 11 \\
\hline 23 & 72 & w & Magen & 3,3 & 0 \\
\hline 24 & 72 & w & Magen & 4,5 & 11 \\
\hline 25 & 73 & $\mathrm{~m}$ & Magen & 3,5 & 0 \\
\hline 26 & 77 & w & Magen & 4,0 & 0 \\
\hline 27 & 77 & w & Magen & 5,0 & 0 \\
\hline 28 & 78 & $\mathrm{~m}$ & Magen & 4,0 & 0 \\
\hline 29 & 78 & $w$ & Magen & 13,0 & 2 \\
\hline
\end{tabular}




\begin{tabular}{|c|c|c|c|c|c|}
\hline 30 & 79 & $w$ & Magen & 4,0 & 1 \\
\hline 31 & 80 & $\mathrm{~m}$ & Magen & 8,0 & 1 \\
\hline 32 & 82 & $w$ & Magen & 4,5 & 6 \\
\hline 33 & 85 & $w$ & Magen & 8,5 & 1 \\
\hline 34 & 86 & w & Magen & 5,0 & 1 \\
\hline 35 & 49 & $w$ & Magen & 17,0 & 1 \\
\hline 36 & 54 & $\mathrm{~m}$ & Magen & 6,5 & 0 \\
\hline 37 & 58 & $\mathrm{~m}$ & Magen & 6,0 & 3 \\
\hline 38 & 61 & $w$ & Magen & 30,0 & 4 \\
\hline 39 & 63 & $\mathrm{~m}$ & Magen & 13,0 & 10 \\
\hline 40 & 64 & $\mathrm{~m}$ & Magen & 12,0 & 7 \\
\hline 41 & 64 & $\mathrm{~m}$ & Magen & 6,0 & 3 \\
\hline 42 & 66 & $\mathrm{~m}$ & Magen & 1,3 & 1 \\
\hline 43 & 78 & $w$ & Magen & 2,4 & 0 \\
\hline 44 & 84 & $\mathrm{~m}$ & Magen & 3,5 & 1 \\
\hline 45 & 35 & $\mathrm{~m}$ & Dünndarm & 10,5 & 1 \\
\hline 46 & 54 & $\mathrm{~m}$ & Dünndarm & 8,0 & 0 \\
\hline 47 & 68 & $w$ & Dünndarm & 3,8 & 0 \\
\hline 48 & 71 & $w$ & Dünndarm & 9,0 & 2 \\
\hline 49 & 82 & $\mathrm{~m}$ & Dünndarm & 9,0 & 0 \\
\hline 50 & 54 & $w$ & Dünndarm & 7,5 & 3 \\
\hline 51 & 73 & $\mathrm{~m}$ & Dünndarm & 7,0 & 3 \\
\hline 52 & 57 & $\mathrm{~m}$ & Dünndarm & 15,0 & 0 \\
\hline 53 & 61 & $\mathrm{~m}$ & Dünndarm & 10,0 & 6 \\
\hline 54 & 62 & $w$ & Dünndarm & 8,0 & 20 \\
\hline 55 & 74 & $w$ & Dünndarm & 9,0 & 2 \\
\hline 56 & 70 & $w$ & Dünndarm & 4,0 & 0 \\
\hline 57 & 54 & $w$ & Dickdarm & 6,5 & 2 \\
\hline 58 & 43 & $\mathrm{~m}$ & Dickdarm & 8,0 & 25 \\
\hline 59 & 56 & $\mathrm{~m}$ & Dickdarm & 6,5 & 51 \\
\hline 60 & 67 & $\mathrm{~m}$ & Dickdarm & 7,0 & 2 \\
\hline 61 & 70 & $w$ & Peritoneum & 5,0 & 8 \\
\hline 62 & 45 & $\mathrm{~m}$ & Peritoneum & 5,0 & 20 \\
\hline 63 & 69 & $\mathrm{~m}$ & Peritoneum & 12,0 & 15 \\
\hline 64 & 60 & $w$ & Peritoneum & 12,0 & 22 \\
\hline
\end{tabular}




\subsection{Risikoklassifikation und Follow-Up - Kollektivübersicht}

Tabelle 6.2/1 Risikoklassifikation und Follow-Up - Kollektivübersicht

\begin{tabular}{|c|c|c|c|c|c|c|}
\hline Fall & Progress & $\begin{array}{l}\text { RF-Zeit* } \\
\text { (Monate) }\end{array}$ & \begin{tabular}{|c|} 
Follow- \\
Up \\
(Monate)
\end{tabular} & $\begin{array}{l}\text { Klassifikation } \\
\text { nach } \\
\text { Franquemont }\end{array}$ & \begin{tabular}{|l|} 
Klassifikation \\
nach \\
Fletcher \\
\end{tabular} & $\begin{array}{l}\text { Klassifikation } \\
\text { nach } \\
\text { Miettinen } \\
\end{array}$ \\
\hline 01 & nein & 111 & 111 & low-risk & intermediate & \\
\hline 02 & nein & 76 & 76 & low-risk & intermediate & low malignant \\
\hline 03 & nein & 104 & 104 & low-risk & low & benign \\
\hline 04 & nein & 78 & 78 & low-risk & intermediate & low malignant \\
\hline 05 & nein & 28 & 28 & low-risk & low & benign \\
\hline 06 & nein & 26 & 26 & low-risk & low & benign \\
\hline 07 & nein & 18 & 18 & low-risk & intermediate & low malignant \\
\hline 08 & nein & 81 & 81 & low-risk & intermediate & low malignant \\
\hline 09 & nein & 19 & 19 & low-risk & intermediate & low malignant \\
\hline 10 & nein & 40 & 40 & low-risk & low & benign \\
\hline 11 & nein & 39 & 39 & high-risk & high & malignant \\
\hline 12 & nein & 80 & 80 & high-risk & high & malignant \\
\hline 13 & nein & 64 & 64 & low-risk & intermediate & low malignant \\
\hline 14 & nein & 69 & 69 & high-risk & high & malignant \\
\hline 15 & nein & 29 & 29 & low-risk & intermediate & low malignant \\
\hline 16 & nein & 50 & 50 & low-risk & intermediate & low malignant \\
\hline 17 & nein & 51 & 51 & low-risk & intermediate & low malignant \\
\hline 18 & nein & 38 & 38 & high-risk & high & malignant \\
\hline 19 & nein & 19 & 19 & low-risk & intermediate & malignant \\
\hline 20 & nein & 22 & 22 & low-risk & very-low & benign \\
\hline 21 & nein & 112 & 112 & low-risk & intermediate & low malignant \\
\hline 22 & nein & 25 & 25 & high-risk & high & malignant \\
\hline 23 & nein & 7 & 7 & low-risk & low & benign \\
\hline 24 & nein & 72 & 72 & high-risk & high & malignant \\
\hline 25 & nein & 90 & 90 & low-risk & low & benign \\
\hline 26 & nein & 27 & 27 & low-risk & low & benign \\
\hline 27 & nein & 9 & 9 & low-risk & low & benign \\
\hline 28 & nein & 46 & 46 & low-risk & low & benign \\
\hline 29 & nein & 65 & 65 & high-risk & high & malignant \\
\hline 30 & nein & 58 & 58 & low-risk & low & benign \\
\hline 31 & nein & 4 & 4 & high-risk & intermediate & low malignant \\
\hline
\end{tabular}




\begin{tabular}{|c|c|c|c|c|c|c|}
\hline 32 & nein & 57 & 57 & high-risk & high & malignant \\
\hline 33 & nein & 35 & 35 & low-risk & intermediate & low malignant \\
\hline 34 & nein & 28 & 28 & low-risk & low & benign \\
\hline 35 & ja & 0 & & high-risk & high & malignant \\
\hline 36 & ja & 0 & 20 & low-risk & intermediate & low malignant \\
\hline 37 & ja & 34 & 72 & high-risk & high & malignant \\
\hline 38 & ja & 23 & 78 & high-risk & high & malignant \\
\hline 39 & ja & 17 & 54 & high-risk & high & malignant \\
\hline 40 & ja & 84 & 111 & high-risk & high & malignant \\
\hline 41 & ja & 0 & 20 & high-risk & high & malignant \\
\hline 42 & nein & 13 & 13 & low-risk & very-low & benign \\
\hline 43 & nein & 14 & 14 & low-risk & low & benign \\
\hline 44 & nein & 16 & 16 & low-risk & low & benign \\
\hline 45 & nein & 105 & 105 & low-risk & high & malignant \\
\hline 46 & nein & 62 & 62 & low-risk & intermediate & malignant \\
\hline 47 & nein & 21 & 21 & low-risk & low & low malignant \\
\hline 48 & nein & 1 & 1 & high-risk & high & malignant \\
\hline 49 & nein & 42 & 42 & low-risk & intermediate & malignant \\
\hline 50 & ja & 0 & 36 & high-risk & high & malignant \\
\hline 51 & ja & 0 & 26 & high-risk & high & malignant \\
\hline 52 & nein & 86 & 86 & low-risk & high & malignant \\
\hline 53 & ja & 19 & 95 & high-risk & high & malignant \\
\hline 54 & ja & 0 & 53 & high-risk & high & malignant \\
\hline 55 & nein & 13 & 13 & high-risk & high & malignant \\
\hline 56 & nein & 14 & 14 & low-risk & low & low malignant \\
\hline 57 & nein & 19 & 19 & high-risk & intermediate & malignant \\
\hline 58 & ja & 13 & 76 & high-risk & high & malignant \\
\hline 59 & ja & 0 & 19 & high-risk & high & malignant \\
\hline 60 & ja & 41 & 45 & high-risk & high & malignant \\
\hline 61 & ja & 0 & 2 & high-risk & high & \\
\hline 62 & ja & 21 & 76 & high-risk & high & \\
\hline 63 & ja & 8 & 8 & high-risk & high & \\
\hline 64 & ja & 0 & 14 & high-risk & high & \\
\hline
\end{tabular}

${ }^{*}$ RF-Zeit = rezidivfreie Überlebenszeit 


\subsection{Ergebnisse der CGH - Kollektivübersicht}

Tabelle 6.3/1 Ergebnisse der CGH - Kollektivübersicht

\begin{tabular}{|c|c|c|}
\hline Fall & $\mathrm{Cl}^{*}$ & Chromosomale Imbalanzen (“-“ Verlust, “+” Zugewinn, “++” Amplifikation) \\
\hline 01 & 0 & 0 \\
\hline 02 & 4 & $+5 q,-1 p,-10 q,-14 q$ \\
\hline 03 & 15 & $+4 p,+4 q,+5 p,+5 q,+7 p,+7 q,+10 p,+11 q,+14 q,+15 q,+16 p,+16 q,-1 p,-9 q,-10 q$ \\
\hline 04 & 1 & $-14 q$ \\
\hline 05 & 1 & $-14 q$ \\
\hline 06 & 13 & $+4 p,+5 p,+5 q,+8 p,+8 q,+11 q,+12 p,+12 q,+16 p,+16 q,+17 p,+17 q,-6 q$ \\
\hline 07 & 2 & $-14 q,-22 q$ \\
\hline 08 & 5 & $-1 p,-3 p,-3 q,-14 q,-21 q$ \\
\hline 09 & 5 & $+2 q,+20 p,+20 q,-1 p,-14 q$ \\
\hline 10 & & technisch nicht gelungen \\
\hline 11 & 10 & $+1 q,+2 q,+4 p,+4 q,+17 p,+17 q,+20 q,-2 q,-6 q,-14 q$ \\
\hline 12 & 4 & $+8 p,+8 q,-14 q,-22 q$ \\
\hline 13 & 1 & $-14 q$ \\
\hline 14 & 14 & $+17 q,-3 p,-4 q,-5 q,-8 p,-8 q,-9 p,-13 q,-14 q,-17 p,-21 q,-22 q,++5 p,++8 q$ \\
\hline 15 & 3 & $-1 q,-14 q,-21 q$ \\
\hline 16 & 1 & $-14 q$ \\
\hline 17 & 2 & $-14 q,-22 q$ \\
\hline 18 & 16 & $+17 p,+17 q,+20 p,+20 q,-1 p,-6 p,-6 q,-7 p,-7 q,-9 p,-9 q,-11 p,-11 q,-14 q,-15 q,-22 q$ \\
\hline 19 & 1 & $-14 q$ \\
\hline 20 & 4 & $+4 p,+4 q,+12 p,+12 q$ \\
\hline 21 & 9 & $+5 p,+5 q,+X p,+X q,-1 p,-3 p,-3 q,-14 q,-22 q$ \\
\hline 22 & 2 & $-14 q,-22 q$ \\
\hline 23 & 1 & $-14 q$ \\
\hline 24 & 21 & $\begin{array}{l}+5 p,+6 p,+6 q,+7 p,+7 q,+8 p,+8 q,+11 p,+11 q,+12 p,+12 q,+18 p,+18 q,-1 q,-9 p,-9 q, \\
-10 p,-10 q,-14 q,-15 q,-22 q\end{array}$ \\
\hline 25 & 5 & $-1 p,-3 p,-3 q,-14 q,-21 q$ \\
\hline 26 & 1 & $-14 q$ \\
\hline 27 & 0 & 0 \\
\hline 28 & 0 & z: 0 \\
\hline 29 & 2 & $-14 q,-22 q$ \\
\hline 30 & 2 & $-14 q,-21 q$ \\
\hline 31 & 0 & 0 \\
\hline
\end{tabular}




\begin{tabular}{|c|c|c|}
\hline 32 & 4 & $-1 p,-14 q,-X p,-X q$ \\
\hline 33 & 3 & $+5 p,+5 q,-14 q$ \\
\hline 34 & 2 & $-14 q,-22 q$ \\
\hline 35 & 5 & $-4 p,-14 q,-22 q,++8 p,++8 q$ \\
\hline 36 & 8 & $+4 p,+4 q,+5 p,+5 q,+13 q,+18 p,+18 q,-1 p$ \\
\hline 37 & 10 & $+5 p,+5 q,+8 p,+8 q,+15 q,-1 p,-10 p,-10 q,-14 q,-22 q$ \\
\hline 38 & 7 & $+8 q,-3 q,-6 q,-8 p,-13 q,-14 q,-22 q$ \\
\hline 39 & 5 & $-3 p,-9 p,-13 q,-14 q,-15 q$ \\
\hline 40 & 10 & $-3 p,-3 q,-7 p,-9 p,-10 p,-10 q,-11 q,-13 q,-14 q,-22 q$ \\
\hline 41 & 7 & $+1 q,+17 q,-1 p,-9 p,-9 q,-13 q,-17 p$ \\
\hline 42 & 1 & $-22 q$ \\
\hline 43 & 2 & $-14 q,-22 q$ \\
\hline 44 & 3 & $-1 p,-14 q,-21 q$ \\
\hline 45 & 0 & 0 \\
\hline 46 & 4 & $+5 p,-1 p,-14 q,-22 q$ \\
\hline 47 & 3 & $-1 p,-15 q,-22 q$ \\
\hline 48 & 15 & $+1 p,+5 p,+13 q,-3 p,-3 q,-6 q,-8 p,-10 q,-11 q,-12 p,-13 q,-14 q,-17 q,-18 p,-X p$ \\
\hline 49 & 5 & $+9 p,+9 q,-1 p,-14 q,-15 q$ \\
\hline 50 & 17 & $\begin{array}{l}+3 q,+5 p,+5 q,+6 p,+8 q,+12 q,+20 p,+20 q,-1 p,-3 p,-6 q,-8 p,-9 p,-9 q,-10 p,-14 q,- \\
15 q\end{array}$ \\
\hline 51 & 14 & $+5 p,+8 p,+8 q,+21 q,-1 p,-2 p,-2 q,-3 q,-10 q,-11 q,-13 q,-15 q,-18 q,-22 q$ \\
\hline 52 & 4 & $+8 q,-1 p,-15 q,-22 q$ \\
\hline 53 & 7 & $+4 p,+4 q,+7 q,-1 p,-15 q,-22 q,++5 p$ \\
\hline 54 & 13 & $+5 p,+5 q,-1 p,-5 q,-9 p,-9 q,-14 q,-15 q,-18 p,-18 q,-21 q,-22 q,++5 q$ \\
\hline 55 & 5 & $+2 q,-1 p,-15 q,-18 q,-22 q$ \\
\hline 56 & 4 & $-1 p,-10 q,-14 q,-15 q$ \\
\hline 57 & 0 & 0 \\
\hline 58 & 9 & $+2 q,+5 p,+11 q,+12 q,-9 p,-9 q,-10 q,-13 q,-22 q$ \\
\hline 59 & 15 & $+5 p,+5 q,+8 p,+8 q,+13 q,-1 p,-4 p,-4 q,-6 q,-9 p,-9 q,-10 p,-10 q,-14 q,-22 q$ \\
\hline 60 & 6 & $+11 q,-1 p,-2 p,-4 p,-9 q,-22 q$ \\
\hline 61 & 13 & $-1 p,-1 q,-3 p,-3 q,-4 q,-10 p,-10 q,-11 p,-11 q,-14 q,-15 q,++8 p,++8 q$ \\
\hline 62 & 6 & $+15 q,-6 p,-7 q,-8 p,-10 q,-16 q$ \\
\hline 63 & 11 & $+X p,+X q,-1 p,-2 p,-2 q,-9 q,-11 p,-11 q,-13 q,-15 q,-22 q$ \\
\hline 64 & 5 & $-3 q,-9 p,-9 q,-14 q,-22 q$ \\
\hline
\end{tabular}

* Anzahl chromosomaler Imbalanzen 


\subsection{Ergebnisse der Mutationsanalyse - Kollektivübersicht}

Tabelle 6.4/1 Ergebnisse der Mutationsanalyse - Kollektivübersicht

\begin{tabular}{|c|c|c|}
\hline Fall & Mutationsgruppe & Mutation \\
\hline 01 & 0 & WT \\
\hline 02 & 0 & WT \\
\hline 03 & 1 & PDGFRA Exon 18 D842V \\
\hline 04 & 6 & KIT Exon 11 V559G \\
\hline 05 & 3 & KIT Exon 11 K550L, Del 551-556 \\
\hline 06 & 4 & KIT Exon 11 W557E, Del 558 \\
\hline 07 & 4 & KIT Exon 11 Del 557-558 \\
\hline 08 & 1 & PDGFRA Exon 18 D842A, Del 843-846 \\
\hline 09 & 1 & PDGFRA Exon 18 D842V \\
\hline 10 & 1 & PDGFRA Exon 12 Dup 556-565 \\
\hline 11 & 4 & KIT Exon 11 Del 555-559 \\
\hline 12 & 3 & KIT Exon 11 Del 552-555 \\
\hline 13 & 1 & PDGFRA Exon 18 D842V \\
\hline 14 & 1 & PDGFRA Exon 18 D842H, Del843-846 \\
\hline 15 & 1 & PDGFRA Exon 18 D842V \\
\hline 16 & 1 & PDGFRA Exon 18 D842V \\
\hline 17 & 7 & KIT Exon 11 Dup 577-580 \\
\hline 18 & 4 & KIT Exon 11 Del 550-558, Del 6bp Intron10, AG from 558 \\
\hline 19 & 1 & PDGFRA Exon 18 D842V \\
\hline 20 & 0 & WT \\
\hline 21 & 6 & KIT Exon 11 V559D \\
\hline 22 & 2 & KIT Exon 9 ins AY nach 503 \\
\hline 23 & 7 & KIT Exon 11 Dup 579-580 \\
\hline 24 & 4 & KIT Exon 11 Del 558-562 \\
\hline 25 & 6 & KIT Exon 11 V560D \\
\hline 26 & 7 & KIT Exon 11 Dup 571-579 nach 579 \\
\hline 27 & 3 & KIT Exon 11 Del 557 \\
\hline 28 & 0 & WT \\
\hline 29 & 2 & KIT Exon 9 Ins AY nach 503 \\
\hline 30 & 6 & KIT Exon 11 V560D \\
\hline 31 & 0 & WT \\
\hline
\end{tabular}




\begin{tabular}{|c|c|c|}
\hline 32 & 4 & KIT Exon 11 Del 557-558 \\
\hline 33 & 6 & KIT Exon 11 V560D \\
\hline 34 & 5 & KIT Exon 11 W557R \\
\hline 35 & 7 & KIT Exon 11 Dup IDPTQLPYD 571-579 at Codon 579 \\
\hline 36 & 6 & KIT Exon 11 V560D \\
\hline 37 & 4 & KIT Exon 11 Del 557-558 \\
\hline 38 & 4 & KIT Exon 11 W557C, Del558-559 \\
\hline 39 & 6 & KIT Exon 11 K558R, Del 559-565 \\
\hline 40 & 6 & KIT Exon 11 V559D \\
\hline 41 & 0 & WT \\
\hline 42 & 4 & KIT Exon 11 Del 553-558 \\
\hline 43 & 6 & KIT Exon 11 Del 560 \\
\hline 44 & 1 & PDGFRA Exon 18 D842V \\
\hline 45 & 0 & WT \\
\hline 46 & 6 & KIT Exon 11 V559G \\
\hline 47 & 3 & KIT Exon 11 Del 555-556 \\
\hline 48 & 1 & PDGFRA Exon 12 R554G, D576G \\
\hline 49 & 6 & KIT Exon 11 V559D \\
\hline 50 & 6 & KIT Exon 11 Del 559-561 \\
\hline 51 & 5 & KIT Exon 11 W557G \\
\hline 52 & 6 & KIT Exon 11 V560E \\
\hline 53 & 6 & KIT Exon 11 V559D \\
\hline 54 & 4 & KIT Exon 11 Del 557-558 \\
\hline 55 & 2 & KIT Exon 9 Dup 502-503 \\
\hline 56 & 0 & WT \\
\hline 57 & 4 & KIT Exon 11 Del 557-558 \\
\hline 58 & 5 & KIT Exon 11 K558N, Del 559 \\
\hline 59 & 4 & KIT Exon 11 Del 556-558 \\
\hline 60 & 5 & KIT Exon 11 K558N, Del 559 \\
\hline 61 & 5 & KIT Exon 11 W557G, KIT Exon 9 DelC1461 in Codon 480 \\
\hline 62 & 0 & WT \\
\hline 63 & 6 & KIT Exon 11 V560D \\
\hline 64 & 4 & KIT Exon 11 Del 558-572 \\
\hline
\end{tabular}




\subsection{Tabellenverzeichnis}

Tabelle 1.3/1 Literaturübersicht über die Häufigkeit chromosomaler Imbalanzen bei GIST

Tabelle 1.3/2 Lokalisationsabhängige chromosomale Imbalanzen bei GIST (nach Gunawan et al. 2004)

Tabelle 1.6/1 GIST - Risikoklassifizierung nach Franquemont (1995)

Tabelle 1.6/2 GIST - Risikoklassifizierung nach Fletcher et al. (2002)

Tabelle 1.6/3 GIST - Dignität nach Miettinen et al. (2002)

Tabelle 1.7/1 Prognose in Abhängigkeit vom Progress-Status bei

Präsentation (nach DeMatteo et al. 2000)

Tabelle 1.7/2 Signifikante chromosomale Imbalanzen nach El-Rifai et al. (2000)

Tabelle 2.2.1/1 Materialen - Immunhistochemie

Tabelle 2.2.1/2 Materialen - Immunhistochemie

Tabelle 2.2.2/1 Materialien - DNA-Isolierung

Tabelle 2.2.3/1 Materialien - Nick-Translation

Tabelle 2.2.3/2 Materialien - Hybridisierung

Tabelle 2.2.3/3 Materialien - Hybridisierung

Tabelle 3.1.3/1 Immunhistochemische Ergebnisse von 64 Primär-GIST

Tabelle 3.1.3/2 Immunhistochemische Ergebnisse der Metastasen

Tabelle 3.1.4/1 Risiko- und Dignitätsklassifikation

Tabelle 3.1.6/1 Primärtumorgröße und Progress bei den Primär-GIST

Tabelle 3.2.2/1 Häufigkeit spezifischer chromosomaler Imbalanzen in Abhängigkeit von der Lokalisation

Tabelle 3.2.4/1 Anzahl chromosomaler Imbalanzen nach den Risiko/Dignitäts-klassifikationen (Median)

Tabelle 3.2.4/2 Chromosomale Imbalanzen vs. Lokalisation vs. "highrisk"-GIST (nach Fletcher) vs. Prognose 
Tabelle 3.2.5/1 Chromosomale Imbalanzen bei den Primär-GIST und zugehörigen Metastasen

Tabelle 3.3.1/1 Anzahl GIST in den Mutationsgruppen 0 - 7

Tabelle 3.3.2/1 Mutationsraten in KIT und PDGFRA - Vergleich mit der Literatur

Tabelle 3.3.2/2 Mutationsraten in KIT Exon 11 - Vergleich mit der Literatur

Tabelle 3.3.2/3 Anzahl der Mitosen/10 HPF - gegliedert nach Mutationsgruppen

Tabelle 3.3.3/1 Risiko-/Dignitätsklassifikationen - gegliedert nach Mutationsgruppen

Tabelle 3.3.3/2 Progrediente Primär-GIST - gegliedert nach 62 Mutationsgruppen

Tabelle 3.3.5/1 Verteilung der 17 Imatinib-behandelten Fälle

Tabelle 3.3.5/2 Rezidivfreie Überlebenszeit 63

Tabelle 3.4.6/1 Mutationen im KIT- und PDGFRA-Gen bei ausgewählten chromosomalen Imbalanzen

Tabelle 4.2.1/1 Häufigkeit chromosomaler Imbalanzen im Vergleich mit der Literatur

Tabelle 4.4/1 Rezidivfreie Überlebenszeit bei Primär-GIST >= 5 chromosomale Imbalanzen

Tabelle 4.4.4/1 Rezidivfreie Überlebenszeit bei spezifischen Imbalanzen und Mutationen

Tabelle 4.4.5/1 Anteil mit Imatinib behandelter GIST bei Mutation in KIT bzw. Mutationsgruppe $4+5$

Tabelle 6.1/1 Klinisch-pathologische Parameter - Kollektivübersicht 91

Tabelle 6.2/1 Risikoklassifikation und Follow-Up - Kollektivübersicht 93

Tabelle 6.3/1 Ergebnisse der CGH - Kollektivübersicht 95

Tabelle 6.4/1 Ergebnisse der Mutationsanalyse - Kollektivübersicht $\quad 97$ 


\subsection{Abbildungsverzeichnis}

Abbildung 1.3/1 Darstellung der Tumorgenese und -progression (nach Heinrich et al. 2002)

Abbildung 3.1.4/1 Zusammenhang zwischen Tumorgröße und Mitosenzahl/10 HPF

Abbildung 3.2.1/1 CGH - Häufigkeitsverteilung in \% (Primär-GIST)

Abbildung 3.2.3/1 Anzahl chromosomaler Veränderungen in

Abhängigkeit von der Primärtumorgröße

Abbildung 3.2.3/2 Anzahl chromosomaler Veränderungen in Abhängigkeit von der Anzahl an Mitosen / 10 HPF

Abbildung 3.3.3/1 Rezidivfreie Überlebenszeit der Patienten mit PrimärGIST (Kaplan-Meier)

Abbildung 3.4.1/1 Anzahl der chromosomalen Gesamtveränderungen gegliedert nach Mutationsgruppen (Box-Plot) 


\subsection{Abkürzungsverzeichnis}

AS

bp

$\mathrm{CGH}$

c-kit

$\mathrm{Cl}$

GIST

HPF

ITD

KIT

PCNA

PDGFRA

SMA

WT
Aminosäure

Basenpaar

Komparative genomische Hybridisierung

Protein des KIT-Gens

Chromosomale Imbalanz

Gastrointestinaler Stromatumor

High Power Fields

Internal Tandem Duplication

KIT - Gen

Proliferating cell nuclear antigen

Platelet derived growth factor receptor alpha -Gen

Smooth muscle antigen

Wildtyp 
6.8 Aminosäuren - 1-Buchstaben-/ 3-Buchstaben-Code

$\begin{array}{lll}\text { G } & \text { Gly } & \text { Glycin } \\ \text { A } & \text { Ala } & \text { Alanin } \\ \text { V } & \text { Val } & \text { Valin } \\ \text { I } & \text { Ile } & \text { Isoleucin } \\ \text { F } & \text { Phe } & \text { Phenylalanin } \\ \text { P } & \text { Pro } & \text { Prolin } \\ \text { S } & \text { Ser } & \text { Serin } \\ \text { T } & \text { Thr } & \text { Threonin } \\ \text { C } & \text { Cys } & \text { Cystein } \\ \text { M } & \text { Met } & \text { Methionin } \\ \text { W } & \text { Trp } & \text { Tryptophan } \\ \text { Y } & \text { Tyr } & \text { Tyrosin } \\ \text { N } & \text { Asn } & \text { Asparagin } \\ \text { Q } & \text { Gln } & \text { Glutamin } \\ \text { D } & \text { Asp } & \text { Asparaginsäure } \\ \text { E } & \text { Glu } & \text { Glutaminsäure } \\ \text { H } & \text { Hist } & \text { Histidin } \\ \text { K } & \text { Lys } & \text { Lysin } \\ \text { R } & \text { Arg } & \text { Arginin }\end{array}$




\section{Literaturverzeichnis}

Andersson et al. 2005: Andersson J, Sinto $H$, Meis-Kindblom JM, Joensuu $H$, Nupponen N, Kindblom LG (2005): NF1-associated gastrointestinal stromal tumors have unique clinical, phenotypic, and genotypic characteristics.

Am J Surg Pathol $\underline{9}, 1170$ - 1176

Andersson et al. 2006: Andersson J, Bümming $P$, Meis-Kindblom JM, Sihto $H$, Nupponen N, Joensuu H, Odén A, Gustavsson B, Kindblom LG, Nilsson B. (2006): Gastrointestinal stromal tumors with KIT exon 11 deletions are associated with poor prognosis.

Gastroenterology $\underline{130}, 1573-1581$

Antonescu et al. 2003: Antonescu R, Sommer G, Sarran L, Tschernyavsky SJ, Riedel E, Woodruff JM, Robson M, Maki R, Brennan MF, Ladanyi M (2003): Association of KIT exon 9 mutations with nongastric primary site and aggressive behavior: KIT mutation analysis and clinical correlates of 120 gastrointestinal stromal tumors.

Clin Cancer Res $\underline{9}, 3329$ - 3337

Antonescu et al. 2005: Antonescu R, Besmer P, Guo T, Arkun K, Hom G, Koryotowski B, Leversha MA, Jeffrey PD, Desantis D, Singer S (2005): Acquired resistance to Imatinib in gastrointestinal stromal tumor occurs through secondary gene mutation.

Clin Cancer Res 11, 4182 - 4190

Appelman 1986: Appelman HD (1986): Smooth muscle tumors of the gastrointestinal tract: What we know now that Stout didn't know.

Am J Surg Pathol 10 Suppl 1, 83 - 99

Bergmann et al. 1998: Bergmann F, Gunawan B, Hermanns B, Höer J, Schumpelick V, Füzesi L (1998): Cytogenetic and morphologic characteristics of gastrointestinal stromal tumors. Recurrent rearrangements of chromosome 1 and losses of chromosomes 14 and 22 as common anomalies.

Verh Dtsch Ges Pathol 82, 275 - 278 
Blanke 2003: Blanke CD: Therapeutic options for gastrointestinal stromal tumors. Educational Book ASCO 2003: Gastrointestinal (Colorectal and Noncolorectal) Cancer; hrsg v. American Society of Clinical Oncology; HighWire Press, Stanford 2003, 266 272

Blay et al. 2005: Blay JY, Bonvalot S, Casali P, Choi H, Debiec-Rychter M, Dei Tos AP, Emile JF, Gronchi A, Hogendoorn PCW, Joensuu H (2005): Consensus meeting for the management of gastrointestinal stromal tumors. Report of the GIST consensus conference of 20-21 March 2004, under the auspices of ESMO.

Ann Oncol 16, 566 - 578

Blume-Jensen et al. 1991: Blume-Jensen P, Claesson-Welsh L, Siegbahn A, Zsebo KM, Westermark B, Heldin CH (1991): Activation of the human c-kit product by ligandinduced dimerization mediates circular actin reorganization and chemotaxis.

EMBO J 10, 4121 - 4128

Buchdunger et al. 2000: Buchdunger E, Cioffi CL, Law N, Stover D, Ohno-Jones S, Druker BJ, Lydon NB (2000): Abl protein-tyrosine kinase inhibitor STI571 inhibits in vitro signal transduction mediated by c-kit and platelet-derived growth-factor receptors. J Pharmacol Exp Ther 295, 139 - 145

Bumming et al. 2003: Bumming $P$, Andersson J, Meis-Kindblom JM, Klingenstierna $\mathrm{H}$, Engstrom K, Stierner U, Wangberg B, Jansson S, AhIman H, Kindblom LG, Nilsson B (2003): Neoadjuvant, adjuvant and palliative treatment of gastrointestinal stromal tumours (GIST) with Imatinib: A centre-based study of 17 patients.

Br J Cancer 89, 460 - 464

Carillo et al. 1997: Carillo R, Candia A, Rodriguez-Peralto JL, Caz V (1997): Prognostic significance of DNA ploidy and proliferative index (MIB-1 index) in gastrointestinal stromal tumors.

Hum Pathol $\underline{28}, 160$ - 165

Carney 1999: Carney JA (1999): Gastric stromal sarcoma, pulmonary chondroma, and extra-adrenal paraganglioma (Carney triad): Natural history, adrenocortical component, and possible familial occurrence. 
Casali et al. 2009: Casali PG, Jost L, Reichardt P, Schlemmer M, Blay JY; ESMO Guidelines Working Group (2009): Gastrointestinal stromal tumors: ESMO clinical recommendations for diagnosis, treatment and follow-up.

Ann Oncol 19 Suppl 2, ii35-8

Chen L et al. 2004: Chen LL, Trent JC, Wu EF, Fuller GN, Ramdas L, Zhang W, Raymond AK, Prieto VG, Oyedeji CO, Hunt KK (2004): A missense mutation in KIT kinase domain 1 correlates with Imatinib resistance in gastrointestinal stromal tumors. Cancer Res $\underline{64}, 5913$ - 5919

Chen Y et al. 2004: Chen Y, Tzeng CC, Liou CP, Chang MY, Li CF, Lin CN (2004): Biological significance of chromosomal imbalance aberrations in gastrointestinal stromal tumors.

J Biomed Sci 11, 65 - 71

Chen Y et al. 2009: Chen Y, Liou CP, Tseng HH, Jan YJ, Li CF, Tzeng CC. (2009): Deletions of chromosome $1 p$ and $15 q$ are associated with aggressiveness of gastrointestinal stromal tumors.

J Formos Med Assoc 108, 28 - 37

Chompret et al. 2004: Chompret A, Kannengiesser C, Barrois M, Terrier P, Dahan P, Tursz T, Lenoir GM, Bressac-De Paillerets B (2004): PDGFRA germline mutation in a family with multiple cases of gastrointestinal stromal tumor.

Gastroenterology 126, 318 - 321

Corless et al. 2002: Corless CL, McGreevey L, Haley A, Town A, Heinrich MC (2002): KIT mutations are common in incidental gastrointestinal stromal tumors one centimeter or less in size.

Am J Pathol 160, 1567 - 1572.

Corless et al. 2004: Corless CL, Fletcher JA, Heinrich MC (2004): Biology of gastrointestinal stromal tumors.

J Clin Oncol 22, $3813-3825$ 
Corless et al. 2005: Corless CL, Schroeder A, Griffith D, Town A, McGreevey L, Harrell P, Shiraga S, Bainbridge T, Morich J, Heinrich MC (2005): PDGFRA mutations in gastrointestinal stromal tumors: Frequency, spectrum and in vitro sensitivity to Imatinib.

J Clin Oncol 23, 5357 - 5364

Debiec-Rychter et al. 2001: Debiec-Rychter M, Lasota J, Sarlomo-Rikala M, Kordek $\mathrm{R}$, Miettinen M (2001): Chromosomal aberrations in malignant gastrointestinal stromal tumors: correlation with c-kit gene mutation.

Cancer Genet Cytogenet 128, 24 - 30

Debiec-Rychter et al. 2004 a: Debiec-Rychter M, Wasag B, Stul M, de Wever I, van Oosterom A, Hagemeijer A, Sciot R (2004): Gastrointestinal stromal tumours (GISTs) negative for KIT (CD117 antigen) immunoreactivity.

J Pathol 202, 430 - 438

Debiec-Rychter et al. 2004 b: Debiec-Rychter M, Dumez H, Judson I, Wasag B, Verweij J, Brown M, Dimitrijevic S, Sciot R, Stul M, Vranck H (2004): Use of CKIT/PDGFRA mutational analysis to predict the clinical response to imatinib in patients with advanced gastrointestinal stromal tumours entered on phase I and II studies of the EORTC Soft Tissue and Bone Sarcoma Group.

Eur J Cancer 므, 689 - 695

DeMatteo 2002: DeMatteo RP (2002): The GIST of targeted cancer therapy: A tumor (gastrointestinal stromal tumor), a mutated gene (c-kit), and a molecular inhibitor (STI571).

Ann Surg Oncol $\underline{9}, 831-839$

DeMatteo et al. 2000: DeMatteo RP, Lewis JJ, Leung D, Mudan SS, Woodruff JM, Brennan MF (2000): Two hundred gastrointestinal stromal tumors: Recurrence patterns and prognostic factors for survival.

Ann Surg 231, 51 - 58

DeMatteo et al. 2001: DeMatteo RP, Shah A, Fong Y, Jarnagin WR, Blumgart LH, 
Brennan MF (2001): Results of hepatic resection for sarcoma metastatic to the liver. Ann Surg 234, 540 - 547

DeMatteo et al. 2008: Dematteo RP, Gold JS, Saran L, Gönen M, Liau KH, Maki RG, Singer S, Besmer P, Brennan MF, Antonescu CR. (2008): Tumor mitotic rate, size, and location independently predict recurrence after resection of primary gastrointestinal stromal tumor (GIST).

Cancer $\underline{112}, 608-615$

Demetri et al. 2002: Demetri GD, von Mehren M, Blanke CD, van den Abbeele AD, Eisenberg B, Roberts PJ, Heinrich MC, Tuveson DA, Singer S, Janicek M (2002): Efficacy and safety of Imatinib mesylate in advanced gastrointestinal stromal tumors. N Engl J Med $\underline{347}, 472$ - 480

Derré et al. 2001: Derré J, Lagace R, Terrier P, Sastre X, Aurias A (2001): Consistent DNA losses on the short arm of chromosome 1 in a series of malignant gastrointestinal stromal tumors.

Cancer Genet Cytogenet 127, 30 - 33

Du et al. 2008: Du CY, Shi YQ, Zhou Y, Fu H, Zhao G. (2008): The analysis of status and clinical implication of KIT and PDGFRA mutations in gastrointestinal stromal tumor (GIST).

J Surg Oncol $\underline{98}, 175-178$

El-Rifai et al. 1996: El-Rifai W, Sarlomo-Rikala M, Miettinen M, Knuutila S, Andersson LC (1996): DNA copy number losses in chromosome 14: An early change in gastrointestinal stromal tumors.

Cancer Res 56, 3230 - 3233

El-Rifai et al. 2000: El-Rifai W, Sarlomo-Rikala M, Andersson LC, Knuutila S, Miettinen M (2000): DNA sequence copy number changes in gastrointestinal stromal tumors: Tumor progression and prognostic significance.

Cancer Res $\underline{60}, 3899$ - 3903

Emory et al. 1999: Emory TS, Sobin LH, Lukes L, Lee DH, O'Leary TJ (1999): 
Prognosis of gastrointestinal smooth muscle (stromal) tumors: Dependance on anatomic site.

Am J Surg Pathol $\underline{23}, 82-87$

Erlandson et al. 1996: Erlandson RA, Klimstra DS, Woodruff JM (1996): Subclassification of gastrointestinal stromal tumors based on evaluation by electron microscopy and immunhistochemistry.

Ultrastruct Pathol 20, 373 - 393

Fletcher et al. 2002: Fletcher CDM, Berman JJ, Corless C, Gorstein F, Lasota J, Longley BJ, Miettinen M, O'Leary TJ, Remotti H, Rubin BP (2002): Diagnosis of gastrointestinal stromal tumors: A consensus approach.

Hum Pathol $\underline{33}, 459$ - 465

Franquemont 1995: Franquemont DW (1995): Differentiation and risk assessment of gastrointestinal stromal tumors.

Am J Clin Pathol 103, 41- 47

Füzesi 2003: Füzesi L (2003): Gastrointestinaler Stromatumor: Pathologie.

Viszeralchirurgie $\underline{38}, 358$ - 362

Furitsu et al. 1993: Furitsu T, Tsujimura T, Tono T, Ikeda $\mathrm{H}$, Kitayama $\mathrm{H}$, Koshimizu U, Sugahara H, Butterfield JH, Ashman LK, Kanayama Y (1993): Identification of mutations in the coding sequence of the proto-oncogene c-kit in a human mast cell leukemia cell line causing ligand-independent activation of c-kit product.

J Clin Invest $\underline{92}, 1736$ - 1744

Golden und Stout 1941: Golden T, Stout AP (1941): Smooth muscle tumors of the gastrointestinal tract and retroperitoneal tissues.

Surg Gynecol Obstet 73, 784 - 810

Gomes et al. 2008: Gomes AL, Gouveia A, Capelinha AF, de la Cruz D, Silva P, Reis RM, Pimenta A, Lopes JM. (2008): Molecular alterations of KIT and PDGFRA in GISTs: evaluation of a Portuguese series.

J Clin Pathol $\underline{61}, 203$ - 208 
Gunawan et al. 2004: Gunawan B, Schulten HJ, von Heydebreck A, Schmidt B, Enders C, Höer J, Langer C, Schüler P, Schindler CG, Kuhlgatz J, Füzesi L (2004): Site-independent prognostic value of chromosome 9q loss in primary gastrointestinal stromal tumours.

J Pathol 202, 421 - 429

Gunawan et al. 2007: Gunawan B, von Heydebreck A, Sander B, Schulten HJ, Haller F, Langer C, Armbrust T, Bollmann M, Gasparov S, Kovac D, Füzesi L. (2007): An oncogenetic tree model in gastrointestinal stromal tumours (GISTs) identifies different pathways of cytogenetic evolution with prognostic implications.

J Pathol 211, 463 - 470

Hartmann et al. 2005: Hartmann K, Wardelmann E, Ma Y, Merkelbach-Bruse S, Preussner LM, Woolery C, Baldus SE, Heinicke T, Thiele J, Buettner R (2005): Novel germline mutation of KIT associated with familial gastrointestinal stromal tumors and mastocytosis.

Gastroenterology $\underline{129}, 1042$ - 1046

Heinrich et al. 2002: Heinrich MC, Rubin BP, Longley BJ, Fletcher JA (2002): Biology and genetic aspects of gastrointestinal stromal tumors: KIT activation and cytogenetic alterations.

Hum Pathol $\underline{33}, 484$ - 495

Heinrich et al. 2003 a: Heinrich MC, Corless CL, Duensing A, McGreevey L, Chen CJ, Joseph N, Singer S, Griffith DJ, Haley A, Town A, Demetri GD, Fletcher CDM, Fletcher JA (2003): PDGFRA activating mutations in gastrointestinal stromal tumors.

Science $\underline{299}, 708-710$

Heinrich et al. 2003 b: Heinrich MC, Corless CL, Demetri GD, Blanke CD, von Mehren M, Joensuu H, McGreevey LS, Chen CJ, van den Abbeele, Druker BJ (2003): Kinase mutations and Imatinib response in patients with metastatic gastrointestinal stromal tumor.

J Clin Oncol $\underline{21}, 4342$ - 4349 
Heinrich et al. 2003 c: Heinrich MC, Corless CL, von Mehren M, Joensuu H, Demetri GD, Blanke CD, Dimitrijevic S, Kiese B, Fletcher CDM, Flechter JA (2003): PDGFRA and KIT mutations correlate with the clinical reponses to imatinib mesylate in patients with advanced gastrointestinal stromal tumors (GIST).

Proc Am Soc Clin Oncol 22: S. 815, 2003 (Abstrakt 3274)

Hirota et al. 1998: Hirota S, Isozaki K, Moriyama $Y$, Hashimoto K, Nishida T, Ishiguro S, Kawano K, Hanada M, Kurata A, Takeda M (1998): Gain-of-function mutations of ckit in human gastrointestinal stromal tumors.

Science $\underline{279}, 577$ - 580

Hirota et al. 2001: Hirota S, Nishida T, Isozaki K, Taniguchi M, Nakamura J, Okazaki T, Kitamura $Y$ (2001): Gain-of-function mutation at the extracellular domain of KIT in gastrointestinal stromal tumours.

J Pathol 193, 505 - 510

Hornick und Fletcher 2002: Hornick JL, Fletcher CD (2002): Immunhistochemical staining for KIT (CD117) in soft tissue sarcomas is very limited in distribution. Am J Clin Pathol 117, 188 - 193

Joensuu et al. 2001: Joensuu H, Roberts PJ, Sarlomo-Rikala M, Andersson LC, Tervahartiala P, Tuveson D, Silberman S, Capdeville R, Dimitrijevic S, Druker B (2001): Effect of the tyrosin kinase inhibitor STI571 in a patient with metastatic gastrointestinal stromal tumor.

N Engl J Med $\underline{344}, 1052$ - 1056

Judson et al. 2004: Judson I, Ma P, Peng B, Verweij J, Racine A, Donato di Paola ED, van Glabbeke M, Dimitrijevic S, Scurr M, Dumez H (2004): Imatinib pharmacokinetics in patients with gastrointestinal stromal tumour: A retrospective population pharmacokinetic study over time. EORTC Soft Tissue and Bone Sarcoma Group. Cancer Chemother Pharmacol 토, 379 - 386

Kallioniemi A et al. 1992: Kallioniemi A, Kallioiemi OP, Sudar D, Rutovitz D, Gray JW, Waldman F, Pinkel D (1992): Comparative genomic hybridization for molecular cytogenetic analysis of solid tumors. 
Science $258,818-821$

Kallioniemi O et al. 1994: Kallioniemi OP, Kallioniemi A, Piper J, Isola J, Waldman FM, Gray JW, Pinkel D (1994): Optimizing comparative genomic hybridization for analysis of DNA sequence copy number changes in solid tumors.

Genes Chromosomes Cancer 10, 231 - 243

Keun Park et al. 2008: Keun Park C, Lee EJ, Kim M, Lim HY, Choi DI, Noh JH, Sohn TS, Kim S, Kim MJ, Lee HK, Kim KM. (2008): Prognostic stratification of high-risk gastrointestinal stromal tumors in the era of targeted therapy.

Ann Surg 247, 1011 - 1018

Kim NG et al. 2000: Kim NG, Kim JJ, Ahn JY, Seong CM, Noh SH, Kim CB, Min JS, Kim H (2000): Putative chromosomal deletions on 9p, 9q and 22q occur preferentially in malignant gastrointestinal stromal tumors.

Int J Cancer $\underline{85}, 633$ - 638

Kim TW et al. 2004: Kim TW, Lee H, Kang YK, Choe MS, Ryu MH, Chang HM, Kim JS, Yook JH, Kim BS, Lee JS (2004): Prognostic significance of c-kit mutation in localized gastrointestinal stromal tumors.

Clin Cancer Res 10, 3076 - 3081

Kindblom et al. 1998: Kindblom LG, Remotti HE, Aldenborg F, Meis-Kindblom JM (1998): Gastrointestinal pacemaker cell tumor (GIPACT): Gastrointestinal stromal tumors show phenotypic characteristics of the interstitial cells of Cajal.

Am J Pathol 152, 1259 - 1269

Koay et al. 2005: Koay E, Goh YW, lacopetta B, Grieu F, Segal A, Sterrett GF, Platten M, Spagnolo DV (2005): Gastrointestinal stromal tumours (GISTs): a clinicopathological and molecular study of 66 cases.

Pathology $\underline{37}, 22$ - 31

Kontogianni-Katsarou et al. 2008: Kontogianni-Katsarou K, Dimitriadis E, Lariou C, Kairi-Vassilatou E, Pandis N, Kondi-Paphiti A. (2008): KIT exon 11 codon 557/558 deletion/insertion mutations define a subset of gastrointestinal stromal tumors with 
malignant potential.

World J Gastroenterol 14, 1891 - 1897

Lam et al. 1996: Lam KY, Law SY, Cheung LK, Luk TF, Wong J (1996): Gastrointestinal autonomic nerve tumors of the oesophagus. A clinicopathologic, immunhistochemical, ultrastructural study of a case and review of literature.

Cancer $\underline{78}, 1651$ - 1959

Lasota und Miettinen 2008: Lasota J, Miettinen M. (2008): Clinical significance of oncogenic KIT and PDGFRA mutations in gastrointestinal stromal tumours.

Histopathology $\underline{53}, 245-266$

Lasota et al. 1999: Lasota J, Jasinski M, Sarlomo-Rikala M, Miettinen M. (1999): Mutations in exon 11 of c-Kit occur preferentially in malignant versus benign gastrointestinal stromal tumors and do not occur in leiomyomas or leiomyosarcomas.

Am J Pathol 154, 53 - 60

Lasota et al. 2000: Lasota J, Wozniak A, Sarlomo-Rikala M, Rys J, Kordek R, Nassar A, Sobin LH, Miettinen M (2000): Mutations in exons 9 and 13 of KIT gene are rare events in gastrointestinal stromal tumors. A study of 200 cases.

Am J Pathol 157, 1091 - 1095

Lasota et al. 2004: Lasota J, Dansonka-Mieszkowska A, Sobin LH, Miettinen M (2004): A great majority of GISTs with PDGFRA mutations represent gastric tumors of low or no malignant potential.

Lab Invest 1 84, 874 - 883

Lasota et al. 2007: Lasota J, Wasag B, Steigen SE, Limon J, Miettinen M. (2007): Improved detection of KIT exon 11 duplications in formalin-fixed, paraffin-embedded gastrointestinal stromal tumors.

J Mol Diagn $\underline{9}, 89$ - 94

Liu et al. 2005: Liu XH, Bai CG, Xie Q, Feng F, Xu ZY, Ma DL (2005): Prognostic value of KIT mutation in gastrointestinal stromal tumors.

World J Gastroenterol 11, 3948 - 3952 
Loughrey et al. 2005: Loughrey MB, Mitchell C, Mann GB, Michael M, Waring PM (2005): Gastrointestinal stromal tumour treated with neoadjuvant Imatinib.

J Clin Pathol $\underline{58}, 779$ - 781

Lux et al. 2000: Lux ML, Rubin BP, Biase TL, Chen CJ, Maclure T, Demetri G, Xiao S, Singer S, Fletcher CDM, Fletcher JA (2000): KIT extracellular and kinase domain mutations in gastrointestinal stromal tumors.

Am J Pathol 156, 791 - 795

Ma et al. 2002: Ma Y, Zeng S, Metcalfe DD, Akin C, Dimitrijevic S, Butterfield JH, McMahon G, Longley BJ (2002): The c-kit mutation causing human mastocytosis is resistant to STI-571 and other KIT kinase inhibitors: Kinases with enzymatic site mutations show different inhibitor senstivity profiles than wild-type kinases and those with regulatory-type mutations.

Blood $\underline{99}, 1741$ - 1744

Marci et al. 1998: Marci V, Casorzo L, Sarotto I, Dogliani N, Milazzo MG, Risio M. (1998): Gastrointestinal stromal tumor, uncommitted type, with monosomies 14 and 22 as the only chromosomal abnormalities.

Cancer Genet Cytogenet 102, 135-138

Martin et al. 2005: Martín J, Poveda A, Llombart-Bosch A, Ramos R, López-Guerrero JA, García del Muro J, Maurel J, Calabuig S, Gutierrez A, González de Sande JL, Martínez J, De Juan A, Laínez N, Losa F, Alija V, Escudero P, Casado A, García P, Blanco R, Buesa JM; Spanish Group for Sarcoma Research. (2005): Deletions affecting codons 557-558 of the c-KIT gene indicate a poor prognosis in patients with completely resected gastrointestinal stromal tumors: a study by the Spanish Group for Sarcoma Research (GEIS).

J Clin Oncol $\underline{23}, 6190-6198$

Miettinen und Lasota 2001: Miettinen M, Lasota J (2001): Gastrointestinal stromal tumors - definition, clinical, histological, immunohistochemical, and molecular genetic features and differential diagnosis.

Virchows Arch $\underline{438}, 1$ - 12 
Miettinen und Lasota 2006: Miettinen M, Lasota J. (2006): Gastrointestinal stromal tumors: pathology and prognosis at different sites.

Semin Diagn Pathol $\underline{23}, 70$ - 83

Miettinen et al. 1999 a: Miettinen M, Sarlomo-Rikala M, Lasota J (1999): Gastrointestinal stromal tumors: Recent advances in understanding of their biology. Hum Pathol $\underline{30}, 1213$ - 1220

Miettinen et al. 1999 b: Miettinen M, Monihan JM, Sarlomo-Rikala M, Kovatich AJ, Carr NJ, Emory TS, Sobin LH (1999): Gastrointestinal stromal tumors/smooth muscle tumors (GISTs): Primary in the omentum and mesentery: Clinicopathologic and immunhistochemical study of 26 cases.

Am J Surg Pathol $\underline{23}, 1109-1118$

Miettinen et al. 2000 a: Miettinen M, Sarlomo-Rikala M, Sobin LH, Lasota J (2000): Esophageal Stromal Tumors: A clinicopathologic, immunhistochemical and molecular genetic study of 17 cases and comparison with esophageal leiomyomas and leiomyosarcomas.

Am J Surg Pathol 2ي4, 211 - 222

Miettinen et al. 2000 b: Miettinen M, Sobin LH, Sarlomo-Rikala M (2000): Immunhistochemical spectrum of GISTs at different sites and their differential diagnosis with a refrerence to CD117 (KIT).

Mod Pathol 13, 1134 - 1142

Miettinen et al. 2000 c: Miettinen M, Sarlomo-Rikala M, Lasota J (2000): KIT expression in angiosarcomas and fetal endothelial cells: Lack of mutations of exon 11 and exon 17 of c-kit.

Mod Pathol $\underline{13}, 536$ - 541

Miettinen et al. 2000 d: Miettinen M, Sobin LH, Sarlomo-Rikala M (2000): Immunohistochemical spectrum of GISTs at different sites and their differential diagnosis with a reference to CD117 (KIT).

Mod Pathol $\underline{13}, 1134$ - 1142 
Miettinen et al. 2002: Miettinen M, El-Rifai W, Sobin LH, Lasota J (2002): Evaluation of malignancy and prognosis of gastrointestinal stromal tumours: A review.

Hum Pathol $\underline{33}, 478$ - 483

Miettinen et al. 2005: Miettinen M, Sobin LH, Lasota J (2005): Gastrointestinal stromal tumors of the stomach: A clinicopathologic, immunohistochemical, and molecular genetic study of 1765 cases with long-term follow-up.

Am J Surg Pathol 29, 52 - 68

Miettinen et al. 2006: Miettinen M, Makhlouf H, Sobin LH, Lasota J. (2006): Gastrointestinal stromal tumors of the jejunum and ileum: a clinicopathologic, immunohistochemical, and molecular genetic study of 906 cases before imatinib with long-term follow-up.

Am J Surg Pathol $\underline{30}, 477$ - 489

Mitelmann 1995: Mitelmann F (1995): Chromosomes, genes, and cancer.

CA Cancer J Clin $\underline{44}, 133-135$

Montone et al. 1997: Montone KT, van Belle P, Elenitsas R, Elder DE (1997): Protooncogene c-kit expression in malignant melanoma: Protein loss with tumor progression.

Mod Pathol 10, 939 - 44

Nakai et al. 2008: Nakai N, Ishikawa T, Nishitani A, Liu NN, Shincho M, Hao H, Isozaki K, Kanda T, Nishida T, Fujimoto J, Hirota S. (2008): A mouse model of a human multiple GIST family with KIT-Asp820Tyr mutation generated by a knock-in strategy.

J Pathol 214, 302 - 311

Nilsson et al. 2005: Nilsson B, Bümming $P$, Meis-Kindblom JM, Oden A, Dortok A, Gustavsson B, Sablinska K, Kindblom LG (2005): Gastrointestinal stromal tumors: The incidence, prevalence, clinical course, and prognostication in the preimatinib mesylate era. A population-based study in western Sweden.

Cancer 103, 821 - 829 
Nishida et al. 2008: Nishida T, Kanda T, Nishitani A, Takahashi T, Nakajima K, Ishikawa T, Hirota S. (2008): Secondary mutations in the kinase domain of the KIT gene are predominant in imatinib-resistant gastrointestinal stromal tumor.

Cancer Sci $\underline{99}, 799$ - 804

van Oosterom et al. 2002: van Oosterom AT, Judson IR, Verweij J, Stroobants S, Dumez H, Donato di Paola ED, Sciot R, van Glabbeke M, Dimitrijevic S, Nielson OS (2002): Update of phase I study of Imatinib (STI571) in advanced soft tissue sarcomas and gastrointestinal stromal tumors: A report of the EORTC Soft Tissue and Bone Sarcoma Group.

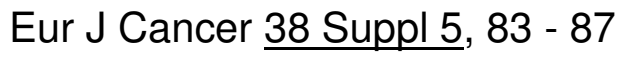

Pauls et al. 2005: Pauls K, Merkelbach-Bruse S, Thal D, Büttner R, Wardelmann E (2005): PDGFRa- and c-kit-mutated gastrointestinal stromal tumours (GISTs) are characterized by distinctive histological and immunohistochemical features.

Histopathology $\underline{46}, 166-175$

Penzel et al. 2005: Penzel R, Aulmann S, Moock M, Schwarzbach M, Rieker RJ, Mechtersheimer G (2005): The location of KIT and PDGFRA gene mutations in gastrointestinal stromal tumours is site and phenotype associated.

J Clin Pathol $\underline{58}, 634$ - 639

Petersen et al. 1996: Petersen I, Schwendel A, Bockmuhl U, Dietel M (1996): Comparative genomic hybridization. A screening method in genetic tumor diagnosis. Pathologe 17, 333 - 341

Presti et al. 1991: Presti JC Jr, Rao PH, Chen Q, Reuter VE, Li FP, Fair WR, Jhanwar SC (1991): Histopathologic, cytogenetic, and molecular characterization of renal cortical tumors.

Cancer Res $\underline{51}, 1544$ - 1552

Qiu et al. 1988: Qiu FH, Ray P, Brown K, Barker PE, Jhanwar S, Ruddle FH, Besmer P (1988): Primary structure of C-kit: Relationship with the CSF-1/PDGF receptor kinase family - oncogenic activation of $\mathrm{v}$-kit involves deletion of extracellular domain and $\mathrm{C}$ terminus. 
EMBO J $\underline{7}, 1003-1011$

Reith et al. 2000: Reith JD, Goldblum JR, Lyles RH, Weiss SW (2000): Extragastrointestinal (soft tissue) stromal tumors: An analysis of 48 cases with emphasis on histologic predictors of outcome.

Mod Pathol $\underline{13}, 577$ - 585

Rossi et al. 2003: Rossi CR, Mocellin S, Mencarelli R, Foletto M, Pilati P, Nitti D, Lise M (2003): Gastrointestinal stromal tumors: From a surgical to a molecular approach. Int J Cancer 107, 171 - 176

Rubin et al. 2001: Rubin BP, Singer S, Tsao C, Duensing A, Lux ML, Ruiz R, Hibbard MK, Chen CJ, Xiao S, Tuveson DA (2001): KIT activation is a ubiquitous feature of gastrointestinal stromal tumors.

Cancer Res $\underline{61}, 8118$ - 8121

Rubin et al. 2005: Rubin BP, Antonescu CR, Scott-Browne JP, Comstock ML, Gu Y, Tanas MR, Ware CB, Woodell J. (2005): A knock-in mouse model of gastrointestinal stromal tumor harboring kit K641E.

Cancer Res $\underline{65}, 6631$ - 6639

Rubin et al. 2007: Brian P Rubin, Michael C Heinrich, Christopher L Corless (2007): Gastrointestinal stromal tumour.

Lancet $\underline{369}, 1731-1741$

Sakurai et al. 2001: Sakurai S, Oguni S, Hironaka M, Fukayama M, Morinaga S, Saito K. (2001): Mutations in c-kit gene exons 9 and 13 in gastrointestinal stromal tumors among Japanese.

Jpn J Cancer Res 92, 494 - 498

Sarlomo-Rikala et al. 1998 a: Sarlomo-Riakala M, Kovatich AJ, Barusevicius A, Miettinen M (1998): CD117: A sensitive marker for gastrointestinal stromal tumors that is more specific than CD34.

Mod Pathol 11, 728 - 734 
Sarlomo-Rikala et al. 1998 b: Sarlomo-Rikala M, El-Rifai W, Lahtinen T, Andersson LC, Miettinen M, Knuutila S (1998): Different patterns of DNA copy number changes in gastrointestinal stromal tumors, leiomyomas, and schwannomas.

Hum Pathol $\underline{29}, 476$ - 481

Shah et al. 2005: Shah JN, Sun W, Seethala RR, Livolsi VA, Fry RD, Ginsberg GG (2005): Neoadjuvant therapy with Imatinib mesylate for locally advanced GI stromal tumor.

Gastrointest Endosc 무, 625 - 627

Sihto et al. 2005: Sihto H, Sarlomo-Rikala M, Tynninen O, Tanner M, Andersson LC, Franssila K, Nupponen NN, Joensuu H (2005): KIT and platelet-derived growth factor receptor alpha tyrosine kinase gene mutations and KIT amplifications in human solid tumors.

J Clin Pathol $\underline{23}, 49-57$

Singer et al. 2002: Singer S, Rubin BP, Lux ML, Chen CJ, Demetri GD, Fletcher CDM, Fletcher JA (2002): Prognostic value of KIT mutation type, mitotic activity, and histologic subtype in gastrointestinal stromal tumors.

J Clin Oncol 20, 3898 - 3905

Sircar et al. 1999: Sircar K, Hewlett BR, Huizinga JD, Chorneyko K, Berezin I, Riddell $\mathrm{RH}$ (1999): Interstitial cells of Cajal as precursors of gastrointestinal stromal tumors. Am J Surg Pathol $\underline{23}, 377$ - 389

Sommer et al. 2003: Sommer G, Agosti V, Ehlers I, Rossi F, Corbacioglu S, Farkas J, Moore M, Manova K, Antonescu CR, Besmer P. (2003): Gastrointestinal stromal tumors in a mouse model by targeted mutation of the Kit receptor tyrosine kinase.

Proc Natl Acad Sci U S A $\underline{100}, 6706$ - 6711

Tamborini et al. 2004: Tamborini E, Bonadiman L, Greco A, Albertini V, Negri T, Gronchi A, Bertulli R, Colecchia M, Casali PG, Pierotti MA (2004): A new mutation in the KIT ATP pocket causes acquired resistance to Imatinib in a gastrointestinal stromal tumor patient.

Gastroenterology 127, 294 - 299 
Taniguchi et al. 1999: Taniguchi M, Nishida T, Hirota S, Isozaki K, Ito T, Nomura T, Matsuda H, Kitamura Y. (1999): Effect of c-kit mutation on prognosis of gastrointestinal stromal tumors.

Cancer Res $\underline{59}, 4297$ - 4300

Tran et al. 2005: Tran T, Davila JA, El-Serag HB (2005): The epidemiology of malignant gastrointestinal stromal tumors: An analysis of 1,458 cases from 1992 to 2000.

Am J Gastroenterol 100, 162 - 168

Tryggvason et al. 2005: Tryggvason G, Gislason HG, Magnusson MK, Jonasson JG (2005): Gastrointestinal stromal tumors in Iceland 1990-2003: the icelandic GIST study, a population-based incidence and pathologic risk stratification study.

Int J Cancer 117, 289-293

Tsuura et al. 1994: Tsuura Y, Hiraki H, Watanabe K, Igarashi S, Shimamura K, Fukuda T, Suzuki T, Seito (1994): Preferential localization of c-kit product in tissue mast cells, basal cells of skin, epithelial cells of breast, small cell lung carcinoma and seminoma/dysgerminoma in human: immunohistochemical study on formalin-fixed, paraffin-embedded tissues.

Virchows Arch 424, 135 - 141

Tzen et al. 2007: Tzen CY, Wang MN, Mau BL. (2007): Spectrum and prognostication of KIT and PDGFRA mutation in gastrointestinal stromal tumors.

Eur J Surg Oncol $\underline{34}, 563$ - 568

Verweij et al. 2003: Verweij J, van Oosterom A, Blay JY, Judson I, Rodenhuis S, van der Graaf W, Radford J, le Cesne A, Hogendoorn PC, Donato di Paola ED (2003): Imatinib mesylate (STI-571 Glivec, Gleevec) is an active agent for gastrointestinal stromal tumours, but does not yield responses in other soft-tissue sarcomas that are unselected for a molecular target. Results from an EORTC Soft Tissue and Bone Sarcoma Group phase II study.

Eur J Cancer 39, 2006 - 2011 
Wakai et al. 2004: Wakai T, Kanda T, Hirota S, Ohashi A, Shirai Y, Hatakeyama K (2004): Late resistance to imatinib therapy in a metastatic gastrointestinal stromal tumour is associated with a second KIT mutation.

Br J Cancer 므, 2059 - 2061

Wardelmann et al. 2002: Wardelmann E, Neidt I, Bierhoff E, Speidel N, Manegold C, Fischer HP, Pfeifer U, Pietsch T (2002): c-kit mutations in gastrointestinal stromal tumors occur preferentially in the spindle rather than in the epitheloid cell variant.

Mod Pathol $\underline{15}, 125$ - 136

Wardelmann et al. 2003: Wardelmann E, Losen I, Hans V, Neidt I, Speidel N, Bierhoff E, Heinicke T, Pietsch T, Büttner R, Merkelbach-Bruse S (2003): Deletion of Trp-557 and Lys-558 in the juxtamembrane domain of the c-kit protooncogene is associated with metastatic behavior of gastrointestinal stromal tumors.

Int J Cancer 106, 887 - 895

Wardelmann et al. 2004: Wardelmann E, Hrychyk A, Merkelbach-Bruse S, Pauls K, Goldstein J, Hohenberger P, Losen I, Manegold C, Büttner R, Pietsch T (2004): Association of platelet-derived growth factor receptor a mutations with gastric primarysite and epitheloid or mixed-cell morphology in gastrointestinal stromal tumors. J Mol Diagn $\underline{6}, 197$ - 204

Wasag et al. 2004: Wasag B, Debiec-Rychter M, Pauwels $P$, Stul M, Vranckx H, van Oosterom A, Hagemeijer A, Sciot R (2004): Differential expression of KIT/PDGFRA mutant isoforms in epithelioid and mixed variants of gastrointestinal stromal tumors depends predominantly on the tumor site.

Mod Pathol 17, 889 - 894

Willmore et al. 2004: Willmore C, Holden JA, Zhou L, Tripp S, Wittwer CT, Layfield LJ (2004): Detection of c-kit-activating mutations in gastrointestinal stromal tumors by high-resolution amplicon melting analysis.

Am J Clin Pathol 122, 206 - 216

Willmore-Payne et al. 2005: Willmore-Payne C, Layfield LJ, Holden JA (2005): c-kit mutation analysis for diagnosis of gastrointestinal stromal tumors in fine needle 
aspiration specimens.

Cancer $\underline{105}, 165-170$

Wong et al. 2003: Wong NA, Young R, Malcomson RD, Nayar AG, Jamieson LA, Save VE, Carey FA, Brewster DH, Han C, Al-Nafussi A (2003): Prognostic indicators for gastrointestinal stromal tumours: A clinicopathological and immunohistochemical study of 108 resected cases of the stomach.

Histopathology $\underline{43}, 118$ - 126

Wozniak et al. 2007: Wozniak A, Sciot R, Guillou L, Pauwels P, Wasag B, Stul M, Vermeesch JR, Vandenberghe P, Limon J, Debiec-Rychter M. (2007): Array CGH analysis in primary gastrointestinal stromal tumors: cytogenetic profile correlates with anatomic site and tumor aggressiveness, irrespective of mutational status.

Genes Chromosomes Cancer 느, 261 - 276

Yamamoto et al. 2004: Yamamoto H, Oda Y, Kawaguchi K, Nakamura N, Takahira T, Tamiya S, Saito T, Oshiro Y, Ohta M, Yao T, Tsuneyoshi M (2004): c-kit and PDGFRA mutations in extragastrointestinal stromal tumor (gastrointestinal stromal tumor of the soft tissue).

Am J Surg Pathol $\underline{28}, 479$ - 488

Yang et al. 2008: Yang J, Du X, Lazar AJ, Pollock R, Hunt K, Chen K, Hao X, Trent J, Zhang W. (2008): Genetic aberrations of gastrointestinal stromal tumors.

Cancer $\underline{113}, 1532$ - 1543

Zsebo et al. 1990: Zsebo KM, Williams DA, Geissler EN, Broudy VC, Martin FH, Atkins HL, Hsu RY, Birkett NC, Okino KH, Murdock DC (1990): Stem cell factor is encoded at the SI locus of the mouse and is the ligand for the c-kit tyrosine kinase receptor.

Cell $\underline{63}, 213-224$ 


\section{Danksagung}

Mein Dank gilt allen, die mich bei dieser Arbeit unterstützt haben. Vor allem danke ich Herrn Prof. Dr. L. Füzesi und seinen Mitarbeitern für die exzellente Betreuung.

Herrn PD Dr. B. Gunawan, Herrn PD Dr. F. Haller sowie Herrn Dr. H.-J. Schulten danke ich für ihre Hilfe bei der Zusammenstellung und Organisation des Patientenkollektivs, sowie ihrer tatkräftigen Mithilfe bei der Auswertung der Ergebnisse.

Nicht zuletzt danke ich natürlich besonders auch den MTA's Frau C. Enders, Frau S. Schwager, Frau J. Wolff-Salgo und Frau I. Dückmann für die experimentelle Anleitung und Unterstützung im Labor, sowie Frau K. Hannemann für die Hilfe bei der Erstellung der Patientendatenbank und der Erhebung der Follow-Up-Daten. 